This document is not to be further disseminated without the express writen consent of the Director, Fuel Cycle Program Office, Savannah Rver Operations

Alternate Fuel Cycle Technologies/Thorium Fuel Cycle Technology Programs Quarterly Report for Period April 1 to June 30, 1978

Jare $\quad 1-11-12$

Any further distribution why holder of this downent of the data

men to thro parties repmsenting foreign intrusts, foreign governm foreign companies antoreign subsidiarles foreign divisions of US companies should be cordunated with the Dire Nuclear Power Devetoment Division, Departmet Energy

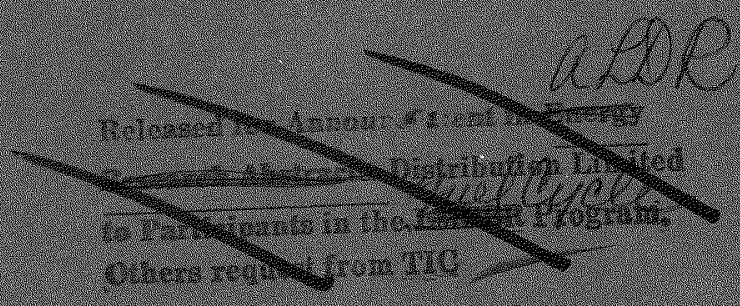

OAK RIDGE NATIONAL LABORATORY OPERATE BY UNION CARBIDE CORPORATION- FOR THE DEPARTMEMT OF ENERGY 


\section{DISCLAIMER}

This report was prepared as an account of work sponsored by an agency of the United States Government. Neither the United States Government nor any agency Thereof, nor any of their employees, makes any warranty, express or implied, or assumes any legal liability or responsibility for the accuracy, completeness, or usefulness of any information, apparatus, product, or process disclosed, or represents that its use would not infringe privately owned rights. Reference herein to any specific commercial product, process, or service by trade name, trademark, manufacturer, or otherwise does not necessarily constitute or imply its endorsement, recommendation, or favoring by the United States Government or any agency thereof. The views and opinions of authors expressed herein do not necessarily state or reflect those of the United States Government or any agency thereof. 


\section{DISCLAIMER}

Portions of this document may be illegible in electronic image products. Images are produced from the best available original document. 
THIS DOCUMENT IS NOT TO BE FURTHER DISSEMINATED WITHOUT THE EXPRESS WRITTEN CONSENT OF THE DIRECTOR, FUEL CYCLE PROGRAM OFFICE

\title{
Alternate Fuel Cycle Technologies/Thorium Fuel Cycle Technology Programs Quarterly Report for Period April 1 to June 30, 1978
}

\author{
B. L. Vondra, Program Manager \\ Compiled by A. D. Kelmers \\ Contributing Authors:
}

(ORNL)
W. D. Bond
D. C. Kocher
D. O. Campbell
J. C. Mailen
J. H. Goode
S. A. Meacham
W. S. Groenier
A. D. Ryon
F. D. Hammerling
V.C.A. Vaughen
L. J. King
M. E. Whatley

(ORGDP)

C. P. McGinnis

M. J. Stephenson

Date Published: August 1978

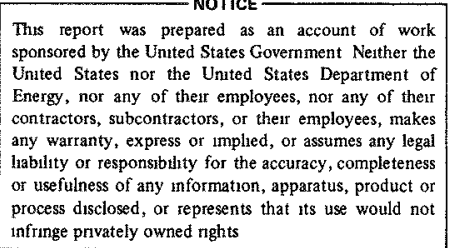

This report was prepared as an account of work This report was prepared as an account of work sponsored by the United States Government Nether the
United States nor the United States Department of United States not the United States Department of
Energy, nor any of therr employees, nor any of ther Energy, nor any of therr employees, nor any of therr
contractors, subcontractors, or therr employees, makes contractors, subcontractors, or their employees, makes any warranty, express or implied, or assumes any legal habilty or responsibulty for the accuracy, completeness or usefulness of any information, apparatus, product or process disclosed, or represents that its use would not infringe privately owned rights
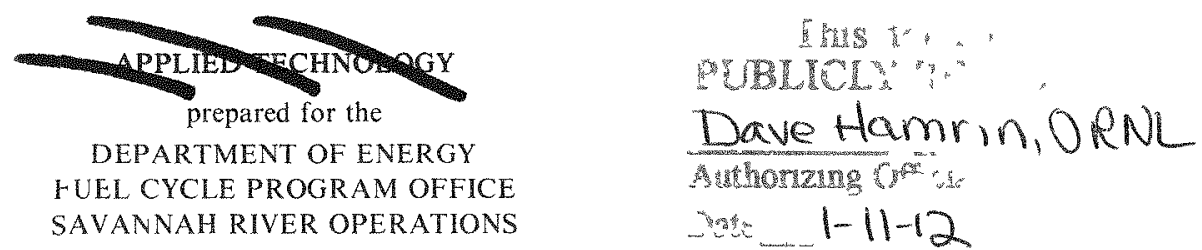

NOTICE: This document contans information of a prelmmary nature. It is subject to revision or correction and therefore does not represent a final report

OAK RIDGE NATIONAL LABORATORY

Oak Rudge, Tennessee 37830 operated by

UNION CARBIDE CORPORATION

for the

DEPARTMENT OF ENERGY

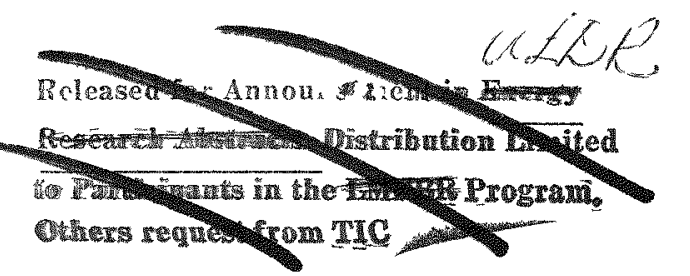


. 
CONTENTS

2. HEAD-END STUDIES - VOLOXIDATION AND DISSOLUTION

2.1 Voloxidation Development

2.I. I Component development

2.1.2 Rotary-kiln heat-transfer studies

2.1.3 Erosion/corrosion test

2.2 Experimental Investigations

2.2. I Hot-cell dissolution

2.2.2 Radioactivity in off-gas

2.2.3 Dissolver residue

2.2. 4 Fuel characterization

2.2.5 Low-decontamination-factor coprocessing

$2-6$

$2-6$

$2-6$

$2-6$

$2-7$

$2-7$
$2-8$

2. 3 Hot-CelI Process Development

2.3.1 Fuel procurement

2.3.2 Shearing studies

2.3.3 Voloxidation studies

2.3.4 Dissolution studies

2.3.5 Residue characterization

2.3.6 Component tests

REFERENCES FOR SECTION 2

$2-10$

$2-10$

$2-10$

$2-10$

$2-14$

$2-16$

$2-17$

$2-18$

3. THORIUM DISSOLUTION STUDIES

3.I Laboratory Experiments

3.1. I Kinetic determinations

3.1.2 Process development tests

3.1.3 Solubility studies

3.2 Hot-Cell Experiments

3.2. I Exploratory tests

REFERENCES FOR SECTION 3

$3-1$

$3-1$

$3-\frac{1}{4}$

$3-6$

4. OFF-GAS CONTAINMENT

$4-1$

4. 1 FIuorocarbon Absorption Studies

4.1. I Fuorocarbon absorption process development

4.1.2 Chemical studies of contaminants in AFCT/IFCT off-gas processing

$4-1$

4.1.3 Noble gas solubility studies

4.2 Tritium Retention from Voloxidizer Process off-Gas

4. 3 Carbon-14 Remova.1 and Fixation

4. 3. I Analytical instrumentation

4.3.2 Gas-sluxry stirred-tank reactor

4.3.3 $\mathrm{CO}$ removal with $\mathrm{Ba}(\mathrm{OH})$ hydrates

4.3.4 Molecular sjeve (13X) for $\mathrm{CO}_{2}$ removal REFERENCES FOR SECPION 4

$4-1$

$4-6$

4-6

$4-8$

$4-9$

4-9

$4-10$

$4-12$

$4-14$

$4-15$

5. SEPARATIONS PROCESSES - THORIUM SYSTEMS

5. I Laboratory Studies

5.1.1 Solvent extraction kinetics

$5-1$

$5-1$

$5-1$ REFERENCE FOR SECTION 5

$5-2$ 
6. SEPARATION PROCESSES - URANIUM AND PIUTONIUM SYSTEMS

6.1 Laboratory studies

6.1. I Ruthenium chemistry

6.1.2 Fast-contactor studies

$6=1$

$6-1$

$6-4$

$6-8$

$6-9$

6.2.1 Development of the mixer-settler system

$6-9$

6.2.2 Application of the SEPHIS program to flowsheet evaluation 6-11

6. 3 Solvent Fxtraction Flowsheet Test Facility

6.3.1 Status

$6-15$

$6-16$

6.4 Analytical Chemistry Development

REFERENCES FOR SECTION 6

$6-17$

7. URANIUM HEXAFLUORIDE CONVERSION

$7-1$

8. RADIOLOGICAI TECHIIQUES FOR ENVIRONMENTAL IMPACT ASSESSMENTS OF AITERNATE FUEI CYCLE TECHNOLOGIES

8.1 Building Shielding Effects

8.2 Resuspension

8.3 Iong-Term Dose Commitments

RETERENCES FOR SECTTON 8

$8-1$

$8-1$

$8-2$

$8-4$

$8-5$

9. ENVIRONMENTAT EFFECTS SUPPORT - STANDARD DATA IMTERCHANGE FORMATS

$9-1$ 
2.I Summary of run conditions and some calculated results for runs HTS-II through HTS -30

2.2 Distribution of ${ }^{3} \mathrm{H},{ }^{14} \mathrm{C}$, and ${ }^{129} \mathrm{I}$ during dissolution in runs 14 and 15

2.3 Isotopic composition of uranium and plutonium in small fuel samples

2. 4 Composition of low DF mixed oxide

2.5 Size distribution of dislodged (U,Th) $\mathrm{O}_{2}$ fuel

$2-10$

2.6 Voloxidation tests of unclad $\mathrm{UO}_{2}$ from $\mathrm{H}$. B. Robinson fuel

$2-11$

2.7 Material balances for voloxidation tests of $\mathrm{UO}_{2}$

$2-11$

2.8 Gaseous radionuclide inventories of $\mathrm{H}$. B. Robinson $\mathrm{UO}_{2}$

$2-14$

2.9 Gaseous release

$2-14$

2.10 Selected fission product inventories of $\mathrm{H}$. B. Robinson $\mathrm{UO}_{2}$

2.II Selected fission product recoveries from the voloxidizer and off-gas system following voloxidation of $\mathrm{H}$. B. Robinson $\mathrm{UO}_{2}$

2. 12 Ratios of ruthenium to selected fission products recovered from the voloxidizer system

2.13 Material balances for dissolution experiments

$2-16$

2. I4 Residue from dissolution

$2-16$

2.15 Solubility of voloxidized $\mathrm{U}_{3} \mathrm{O}_{8}$

$2-17$

3. I Dissolution of Tho, microspheres in $12.0 \mathrm{M}$ HNO 3 with 0.01 to $0.1 \mathrm{M}$ initial HF concentrations both with and without $0.01 \mathrm{M} \mathrm{Al}^{2}\left(\mathrm{NO}_{3}\right)_{3}$

4.1 Noble gas solubilities in Refrigerant-12

6.I Percentage of cationic nitrosylruthenium-nitrato complexes in various nitric acid solutions

$6-2$

6.2 Percentage of trinitrato- and tetranitratonitrosylruthenium in nitric acid solutions

$6-2$

6.3 Calculated vs experimental zirconium distributions $\left(D_{Z r}\right.$ ) from contactor tests 6-6

6.4 Feed stream flow rates and compositions during solvent extraction run PS-2 6-10

6.5 Summary of flow rates of the feed streams during solvent extraction run PS-2 6-1I 
-

$-$ , . 
IIST OF FIGURES

2.I Temperature and heat-flux profile - run HTS-16.

2.2 Tritium concentration profiles in voloxidizer off-gas.

2.3 Gaseous release and oxygen consumption during voloxidation (LWR-6).

3.1 Effect of initial fluoride concentration on thoria dissolution rate in $12 \mathrm{M} \mathrm{HINO}_{3}$ at $100^{\circ} \mathrm{C}$.

3.2 Dissolution rate of Zircaloy-4 in 4.0,8.0, and $12.0 \mathrm{MHNO}_{3}$ as a function of $\mathrm{HF}$ concentration at $100^{\circ} \mathrm{C}$.

3. 3 Zircaloy 4 and Tho dissolution rates as a function of HF concentration in $12.0 \mathrm{MHNO}_{3}$ without $\mathrm{AI}\left(\mathrm{NO}_{3}\right)_{3}$

3.4 Dissolution rate of Tho, pellets in $13 \mathrm{M}$ HNO $3-0.04 \mathrm{M} \mathrm{NaF}$ containing zirconium added as zirconium oxynitrate; curve $B$, as received pellets $0.75 \mathrm{in}$. in length and diameter; curve $A$, after firing in air at $1400^{\circ} \mathrm{C}$ for $5 \mathrm{~h}$.

3.5 Corrosion of type 304I stainless steel tubing in boiling $13 \mathrm{M} \mathrm{HNO}_{3}-0.04 \mathrm{M}$ $\mathrm{NaF}$ (curve A) pIus $0.1 M$ thorium (curve B), plus $0.1 M$ aluminum (curve $C$ ), and $0.015,0.04$, or $0.1 M$ zirconium (curves $D$, E, and $F$ ).

4. I OveraII view of the combination absorber/fractionator/stripper column during installation.

$4-2$

4.2 Typical distribution of ${ }^{85} \mathrm{Kr}$ in the combination column.

$4-3$

4. 3 Comparison of fractionator model results with pilot plant data.

$4-6$

4.4 Schematic of the gas sampling and analysis operation.

4.5 Carbon dioxide removal from aix in the gas-slurry stirred-tank reactor with $\mathrm{Ca}(\mathrm{OH})_{2}$ and $\mathrm{Ba}(\mathrm{OH})_{2}$ slurries.

4. 6 Comparison of DFs and final product conversions for $\mathrm{CO}_{2}$ removal with $\mathrm{Ba}(\mathrm{OH})_{2} \cdot \mathrm{H}_{2} \mathrm{O}, \mathrm{Ba}(\mathrm{OH})_{2} \cdot 5 \mathrm{H}_{2} \mathrm{O}$, and $\mathrm{Ba}(\mathrm{OH})_{2} \cdot 8 \mathrm{H}_{2} \mathrm{O}$ (vendor $\mathrm{B}$ ).

4.7 Carbon dioxide from an $88.35 \%$ Con-water-saturated feed gas with a $\mathrm{Ba}(\mathrm{OH}) \mathrm{P} \mathrm{H}_{2} \mathrm{O}$-sand-packed bed in a $1: I$ volume ratio.

4. 8 Carbon dioxide removal from $0.033 \% \mathrm{CO}_{2}$-water-saturated feed gas with a $\mathrm{Ba}(\mathrm{OH})_{2} \cdot \mathrm{H}_{2} \mathrm{O}$-sand-packed bed in a $1: 1$ volume ratio.

6. I Mixer and centrifugal separator.

6.2 Calculated uranium distribution and the uranium-zirconium separation. for a Kenics mixer. 
6.4 Experimental area-to-volume ratio vs that calculated by the Kenics Corporation correlations.

6.5 Comparison of the product stream nitric acid concentration response data ( $r u n$ PS-1) with the SEPHIS prediction using the measured flow rates.

6.6 Profile of the uranium in the aqueous phase at $10 \mathrm{~h}$ compared with modified SEPHIS prediction (PS-I).

6.7 Profile of the uranium in the organic phase at $10 \mathrm{~h}$ compared with modified SEPHIS prediction (PS-I).

6.8 Profile of uranium in the aqueous phase at $10.5 \mathrm{~h}$ (PS-2).

6.9 Profile of uranium in the organic phase at $10.5 \mathrm{~h}$ (PS-2). 
FOREWORD

Ten tasks under the Alternate Fuel Cycle Technologies/Thorium Fuel Cycle Technology Programs (AFCT/TFCT) have been assigned to Union Carbide Coxporation, Nuclear Division. The major efforts are centered at the Oak Ridge National Laboratory (ORNI), and the off-gas fluorocarbon process pilot plant is at the oak Ridge Gaseous Diffusion Plant. Because of the close relationship of the reprocessing activities with the ongoing Advanced Fuel Recycle (AFR) Program at ORNL, these tasks are managed within a combined AFR/AFCT/TFCT Program under the direction of W. D. Burch. The AFCT/TFCT programs are managed by B. I. Vondra who coordinates all activities reported here. The responsibility for the coordination and collation of reports of all work at oak Ridge was assigned to ORNI by the Savannah River Laboratory (SRI), the office designated as the lead organization for the Alternate Fuel Cycle Technologies Program and the Thorium Fuel Cycle Technology Program.

Tasks for the AFCT/WTCT Programs are as follows:

310.3 Assistance in shear Development and Related Activities

320.2 Voloxidation System - Voloxidation and Dissolution studies

330.2 Thorium Dissolution Studies

340.2 Carbon-14 Removal from off-Gas and Fixation

340.4 off-Gas Fluorocarbon Absorption Studies

350. 3 Separations Processes - Thorium

350. 4 Separations Processes

410.1 Uranium Hexafluoride Conversion

810.2 Radiological Techniques for Environmental Impact Assessments of AFCT/TFCT Fuel Cycles

810.3 Environmental Effects Support - Standard Data Interchange Formats 
-

$\star$

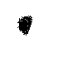

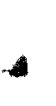

- 
SUMMARY

This is the tenth quarterly technical progress report initiated under the IWR Fuel Reprocessing and Recycle Program, which was later changed to the Alternate Fuel Cycle Technologies Program (FY 1977), and now, beginning in FY 1978, is designated as the Alternate Fuel Cycle Technologies/Thorium Fuel Cycle Technology Programs, administered by the Fuel Cycle Program office, Department of Energy, Savannah River. The preceding report in this series, Alternate Fuel Cycle Technologies/Thorium Fuel Cycle Technology Programs Quarterly Report for Period January I to March 31, 1978, ORNI/TM-6307, was pubIished in May 1978.

\subsection{Assistance in Shear Development and Related Activities}

Engineering design of the Phase I, II, and III shear tooling, compactors, and feed systems for the 250-ton Birdsboro shear has been completed. Fabrication of the Phase I tooling has been initiated. Fabrication of two $17 \times 17$ dummy fuel subassemblies has been completed. A source of prototypic reject grids has been established. A formal response to SRI's request for information regarding the nature of the environment of an in-cell shear has been transmitted.

\subsection{Voloxidation System - Voloxidation and Dissolution Studies}

Installation of the $0.5-t / a$ rotary-kiln voloxidizer system is essentially complete. Procedures for system checkout and shakedown are being reviewed.

Rotary-kiln heat-transfer tests are under way using a small rotary kiln along with the development of a mathematical model to determine kiln-heat-flux profiles necessary to maintain a desired temperature gradient. The erosion/corrosion test for evaluating materials of construction is operational.

Fuel from a BWR (Big Rock Point) yielded more fine solid residue on dissolution than was seen in previous tests with PWR fuel. This residue was due to a coating of reactor system corrosion products on the outside of the Zircaloy cladding which spalled during shearing and dissolution.

Two additional parametric voloxidation tests with $\mathrm{H}$. B. Robinson fuel compared air vs pure oxygen atmospheres at $550^{\circ} \mathrm{C}$; overall tritium release and subsequent fuel dissolution were equivalent.

\subsection{Thorium Dissolution Studies}

The dissolution rate of thoria in fluoride-catalyzed 8 to $14 \mathrm{M} \mathrm{HNO}_{3}\left(100^{\circ} \mathrm{C}\right)$ was maximal between 0.04 to $0.06 \mathrm{MHF}$; at higher fluoride concentrations, $\mathrm{ThF}_{4} \cdot 5 \mathrm{H}_{2} \mathrm{O}$ precipitated. The rate of Zircaloy dissolution continued to increase with increasing fluoride concentration. OptimaI conditions (rapid thorium solubilization and minimal zirconium solubilization) for the dissolution of Zircaloy-clad thoria will be attained with low HF concentrations. 
Stainless-steel-clad ( $T$, U $)_{2}$ fuel rods irradiated in the NRX reactor were sheared, voloxidized, and dissolved. Ten percent or less of the tritium was released during voloxidation in aix at $600^{\circ} \mathrm{C}$.

\subsection{Carbon-14 Removal from off-Gas and Fixation}

Analytical capability for carbon dioxide was extended to $100 \mathrm{ppb}$. Carbon dioxide removal. with Iinde $13 x$ molecular sieves to less than 100 ppb was experimentally verified from a feed gas containing $300 \mathrm{ppm} \mathrm{CO}_{2}$ in air. Decontamination factors from 3000 to 7500 were obtained for $\mathrm{CO}_{2}$ removal in the gas-slurry stirred-tank reactor with $\mathrm{Ca}(\mathrm{OH})_{2}$ or $\mathrm{Ba}(\mathrm{OH})_{2} \cdot 8 \mathrm{H}_{2} \mathrm{O}$. With $\mathrm{Ba}(\mathrm{OH})_{2} \cdot \mathrm{H}_{2} \mathrm{O}$ in a fixed-bed column, decontamination factors of about 30,000 were obtained.

\subsection{Off-Gas Fluorocarbon Absorption Studies}

Tests and evaluations of the combination absorber/fractionator/stripper column in the selective absorption pilot plant are continuing. Concentration profiles for ${ }^{85} \mathrm{Kr}$ and $133 \mathrm{Xe}$ isotopes have demonstrated the feasibility of this column concept. Concentrated product, collected at an intermediate section takeoff point located at a peak in the concentration profile, has been as high as $42.9 \%$ krypton when feeding the system with a stream containing 15 ppm krypton. A mathematical model to describe the fractionator has been developed and is being tested by using data from previous pilot plant campaigns.

\subsection{Separation processes - Thorium}

Kinetic studies of the extraction of thorium into $30 \%$ TBP-dodecane from fluoride-containing nitric acid solutions showed that fluoride decreased the extraction rate to about half that for uranium.

\section{4 Separation Processes}

In fast-contactor studies, the kinetic constant for uranium was the same in drop tests and. in a motionless mixer; transfer was not diffusion controlled. Kinetic constants developed in

drop tests may therefore be used in the design of fast contactors.

Fabrication and installation of the equipment in the Solvent Extraction lest Facility (SETF) continues on schedule for a projected July 1978 completion.

\subsection{Uranium Hexafluoride Conversion}

Equipment is being installed to study the flow characteristics of product powders. 


\section{ASSISTANCE IN SHEAR DEVEIOPMENT AND RELATED ACTIVITIES}

S. A. Meacham (Westinghouse Advanced Reactors Division, on Ioan to ORNL) and B. S. Weil (Chemical Technology Division, ORNL)

\section{Systems Integration}

The program plan for this activity has been approved and implementation has begun. Current projections indicate that the activity schedules and budgets are in line with the expected results.

\section{Tooling Design and Fabrication}

All design effort has been completed for Phase I, II, and III shear tooling, compactors, and feed systems. Natexial verification (alloy composition) by spectrochemical analysis has been obtained for the A-6 tool steel purchased for this activity. In addition, heat treatment procedures that yield the required hardness have been established and verified on A-6 specimens. Following material verification, the fabrication of phase I tooling was initiated and completed during the quarter. Design changes and modifications have been made to the existing shear feed system to accommodate IWR dummy fuel assemblies.

Dummy Fuel Procurement

Three types of dummy fuel (ceramic-filled) will be used in the experimental program:

1. ORNL-type dummies: $17 \times 17$ pin, 3 ft long, with grids made in-house.

2. Short prototype dummies: $17 \times 17$ pin, 3 ft long, with two reject prototype reactor grids and 25 Inconel thimble tubes.

3. Prototype dummies: $17 \times 17 \mathrm{pin}$, $16 \mathrm{ft}$ long, with eight reject prototype reactor grids, 25 Inconel thimble tubes, and top and bottom toe plates.

All materials needed to fabricate ORNL-type dummies have been received. Tubing for ten units has been filled and cut into 3-ft lengths; two units have been completely assemblea. Six prototype dummies, purchased in FY 1977, are on hand. Negotiations for acquiring reject prototype reactor grids have been successful, and delivexy is expected from JuIy through september. Cost estimates and firm delivery schedules are being developed by the vendor.

Experimentation

Al1. materials and procedures required to conduct experiment I have been acquired and prepared. However, calculations made for predetemining the deflection and the resulting stress that a prototype LWR (ceramic-filled) dummy subassembly might experience when rotated without a "strong back" from a vertical to a horizontal position indicate that such deflections and corresponding stresses will be insignificant and therefore of questionable value in determining the need for a "strong back" when handling irradiated LWR fuel. Since the assumptions used in 
the stress calculations for ceramic-filled assemblies cannot be proven and may not be applicable to actual IWR assemblies, and since the interaction of the eight grids with the thimble tubes is unclear, it has been decided to defer experiment 1 and to observe the actual handling behavior of the dummy IWR subassembly during experiment 2. Recommendations will then be made regarding the potential value of data obtained from experiment 1 .

The subassembly holding fixture for the abrasive-disc cutting test (experiment 2) has been redesigned and modified. Modifications to the saw housing have also been completed. The system will be checked out using an ORNL-type dummy subassembly prior to the actual test with an IWR dummy subassembly.

Modular Shear Concepts

The near-term objective of this activity is to provide a conceptual design to SRI which would include system design requirements and recommendations. Gulf + Westem 's conceptual design of a modular shear has been reviewed, and a system design requirement document has been prepared. A statement of work for the advanced conceptual design phase has been prepared for internal review.

\section{Thoria State-of-the-Art Report}

A report assessing current technology for shearing thoria-based fuels is being prepared.

\section{Consultation}

A formal response to SRL's request for confirmation regarding the nature of the environment of an in-cell shear has been prepared, issued, and transmitted. The information will be used to assist SRT in a forthcoming Iubrication study. 


\section{HEAD-END STUDIES - VOLOXIDATION AND DISSOLUTION \\ 2. I Voloxidation Development \\ W. S. Groenier (Chemical Technology Division, ORNL)}

The voloxidation process is being developed as a head-end method for removing tritium from spent uranium reactor fuel prior to aqueous processing. Based on experimental work, it appears that this objective can be met by reacting the oxide fuel with oxygen or air in a temperature range of 450 to $650^{\circ} \mathrm{C}$. The release of tritium and, to a lesser extent, some of

the other fission products occurs when $\mathrm{UO}_{2}$ is restructured to $\mathrm{U}_{3} \mathrm{O}_{8}$ during oxidation. The early removal of tritium from the fuel into a relatively small volume is desirable to avoid mixing the tritium as water with aqueous streams in subsequent process steps.

An investigation of the applicability of rotary kilns to the voloxidation process has been continued by (1) performing heat-transfer tests using a small rotary kiln, (2) developing a mathematical model for estimating rotary-kiln heat-flux requirements, and (3) placing an erosion/corrosion test into operation to evaluate candidate materials of construction. The status of the installation of a $0.5-t / d$ voloxidizer system for study and testing is also described.

\subsection{Component development ${ }^{*}$}

M. E. Whatley and T. D. Welch (Chemical Technology Division, ORNI)

An experimental voloxidation system scaled to $0.5 \mathrm{t} / \mathrm{d}$ is being provided to study (in nonradioactive experiments) certain important process parameters, to study the applicability of some full-scale standard commercial equipment components, to extend and verify basic data on heat and mass transport in the voloxidation system, and to address the problems of process control. This system, described in some detail in the previous quarterly report, ${ }^{I}$ is being installed in the open bay area of Building 7603.

The rotary kiln was obtained from C. E. Raymond/Bartlett-Snow Company in January, and installation of the kiln and auxiliaries is in progress. The participation of the cost-plusfixed-fee contractor is complete.

The system will now undergo checkout and shakedown; each subsystem will be tested to ascertain its suitability, and adjustments or modifications will be made where necessary. Procedures for this phase are being reviewed.

Some special problems have been encountexed and are being addressed. The feeder system, as installed, provides for screening material into three fractions: fines to represent the

* Jointly funded by the Alternate Fuel Cycle Technologies Program and the Advanced Fuel Recycle Program. 
powder released during shearing, a 0.125 to 1 -in. cut to represent the sheared tube segments, and a greater than 1 -in. cut to represent the pieces of shroud. Each cut is independently fed from a vibrating tray into a weighing tip bucket which controls and records the amount fed. In checking the performance of the vibrating tray which handles shroud pieces, it was found that the material prepared for use as simulated shroud pieces tended to interlock under the vibrating action and fall from the tray in groups rather than singly, as required. Several modifications to the vibrating tray were tested in an attempt to provide a simple answer; however, the characteristic discharge curves of the best modification showed that performance was not improved enough to allow its use. An 18-in.-diam rotary cylinder, similar to those used in residence-time-distribution studies was, however, found to do a good job of disentangling the pieces, with only about a $10 \%$ probability that more than one piece will be discharged in a shot, and a negligible probability that more than six or seven pieces will emerge as a group. System modifications associated with replacing the existing vibrating tray with the rotary feeder do not seem difficult, and plans to implement this are under way.

Because of difficulties in the fabrication of the insertable flight cartridge for the kiln, the vendor has postponed his delivery data. However, the experimental program will not be delayed since the checking of subsystems will be in progress. Under the terms of the purchase agreement, the vendor, C. E. Raymond/Bartlett-Snow, will provide technical assistance in the alignment of trunnion rollers, preoperational checkout, and start-up of the kiln.

The Bristol UCS-3000 unit process controller to control the system and perform some data manipulation has been installed, and the first version of the software is available. Hookup and debugging of this system wiIl proceed. The CRT display to be used with this unit will not be available during initial tests and may not be delivered until fall. This will cause some inconvenience, but wili not prevent the necessary tests.

A telemetry system wich allows thermocouples mounted on the rotating drum to transmit signals to the control system has been planned. A system of high reliability and precision is "pushing" the state of the art. We have been negotiating with several vendors and are in the process of completing a purchase agreement; however, the telemetry system will probably not be available before this fall.

A quality assurance project plan is also being prepared, which will include a preoperational checklist establishing limits on process parameters, the preparation of operating procedures, and a safety program. A safety summary for the project has been completed and a preoperational checklist is near completion.

2.1.2 Rotary-kiln heat-transfer studies

B. B. Spencer and M. E. Whatley (Chemical Technology Division, ORNL)

Twenty-one additional heat transfer experiments have been made using the experimental rotary kiln. Temperature measurements of the outside and inside kiln walls and of the solids bed were obtained using instruments described previously. ${ }^{2}$ operating parameters were varied as follows: kiln slope, 0.0 to $0.0157 \mathrm{ft} / \mathrm{ft}$; solids feed rate, 0 to $300 \mathrm{~g} / \mathrm{min}$; kiln rotational rate, 1 to $5 \mathrm{rpm}$; maximum temperature, 400 to $600^{\circ} \mathrm{C}$. Sheared prototype fuel and sand have been used as feed materials.

The measured temperature profiles show large variations in the axial direction and small variations in the radial direction. Effective heat transfer coefficients were calculated using 
the measured temperature dafferences through the cross section, but the values were scattered because the temperature differences were not signiflcantly larger than the error in the measuring instruments.

A mathematical model is under development, wh which the axial proflle of the wall temperature is used to describe the heat flux in a rotarymaln voloxidzzer. It is a simple, onedimensional model based on first principles which should allow inferenc of heat transfer parameters that can be used to desugn subseouent test and production uncts. The model wIII Indicate the local heat flux at each point along the length of the kin. In the model, the solids bed temperature was assumed to be the same as the tube wall. Fhis assumption Is reasonable for a furst approach un view of the observed cata. Iemperature profiles measured with the thermocouple telemetry device were accopted as characterıstic, since thi Instrument seems to be more reliable than the infrared pyrometer at the present state of the art. In order to facilItate manipulations, the tempexature data were fit to a seventh-degree polynomial, except for the cooling zone which had, within the accuracy of measurement, a flat temperature profile. OutIIned below Is the method of calculating the local heat fluxes

1. Thermal radiation - Geometric view factors were developed for one thin ring radiating to another thin rug on the Internal surface of a kin tubc. The presence of muxing flights and the sollds bed were Ignored. Radzation heat flux was calculated for all such rings by the classical method.

2. Tube wall conductavity - The second derivative of the temperature profilt, togethex wath the measured wall chlckness and the thermal conductivity of steel, ylelds the flux.

3. Solzds translation - Fhe rust derivative of the temperature profile, along with the heat capacity, flow rate, and density of the solids, ylclds the heat flux.

4. Solids dispersion - Dispersion numbers from the residence-time-distribution studies, along with the second derivatıve of the temperature profulc ard appropriate physical constants, yzeld the heat Ilux.

The gas phase also contributed a signiflcant heat flux. To ouantify its contribution, the one-dimensional differential equation describins a jocal gas phase heat balance was used. This, however, required the heat transfer cocffclent between the gas and the tube wall (which in this model includes the charge soluds) and the gas dispersion coeffuctent as parameters. It is hoped that eventually good values for these parameters wil be determned from an analysis of experimental data; however, the values used in the calculations presented here are only estumates. It was assumed that the heat transfer coeffuclent between tho sas and the tube wall was

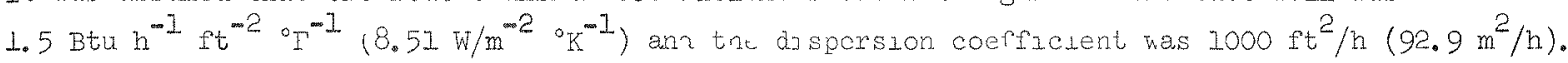
The gas temperature profile was calculated by integrating tho dufferential equation (In finite difference form) over the length of the kin. This invegration was perfoxmed repeatediy, Iterating the assumed gas temperature at the klin fecd eld (Iongtt 0 ) urtil the overall gas heat balance was satisfied. The local gas hcat flux was generated as par of this solution.

Results for a typlcal run are shown In FIg. 2.1. A positive value means that the heat flux. Is toward that point. An examination of FIg. 2.I reveals tnat the ges temperature proflle follows the wall temporature proflle, whych is expected when aealino wh dispersive heat transfer. The Integral of the net heat flux along the length of the $\mathrm{kJ}$ In (curve 9) Is usefuI because the dafference between values at two different polnts is the heat losi (or gain) through the $k I I n$ wall between chose polnts. More hoat is calculated to be lost to the surroundngs from the Inter Im area between the furnace and the cooler rather than to the cooler Itself. The splke that occurs 
CRNL DWG 78-1043

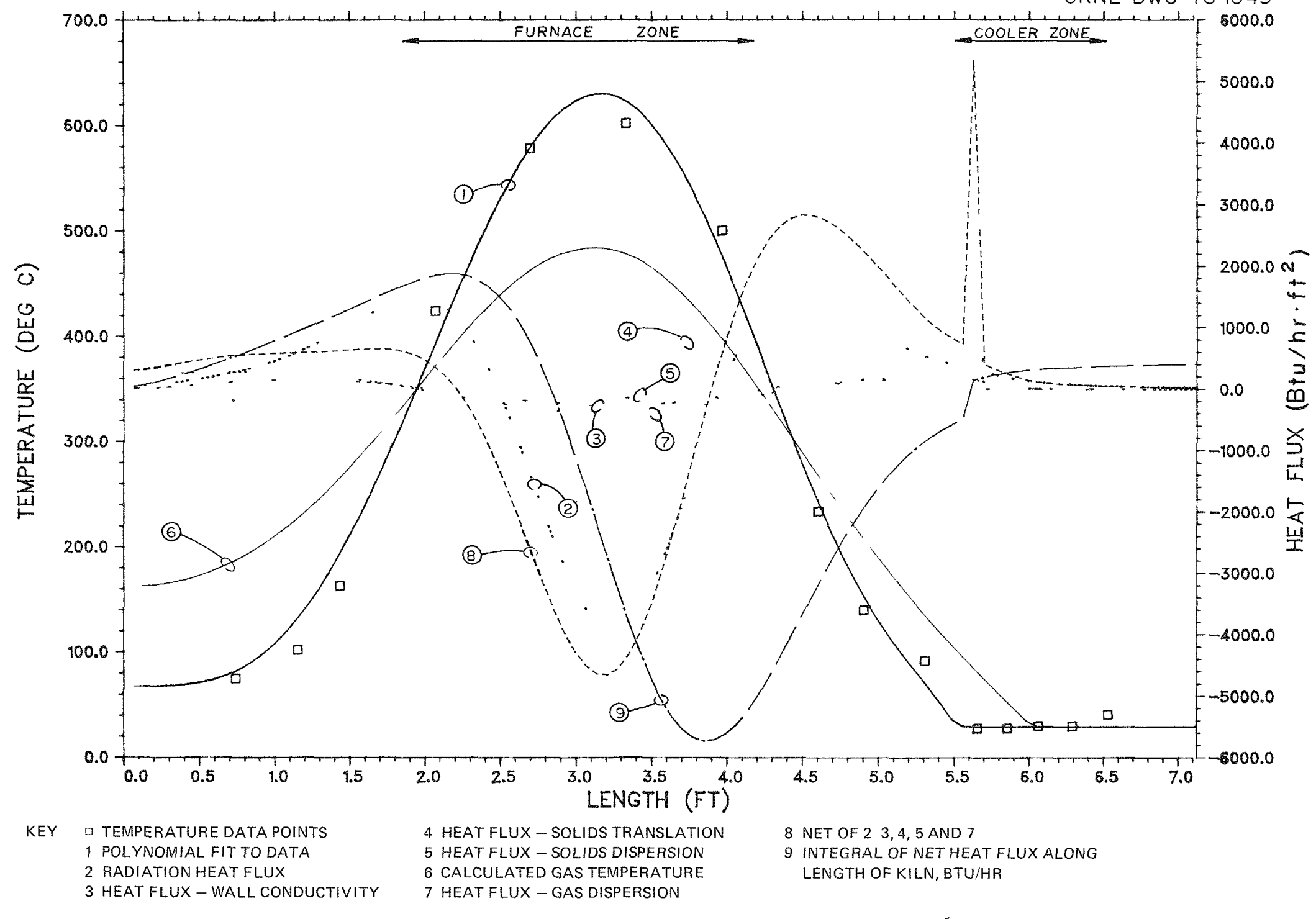

Fig. 2.I. Temperature and heat-flux profile - run HTS-16. 
at the beginning of the cooler zone is an artifact of the discontinuity in the derivative of the temperature curve at that location. Most of the heat absorbed in the cooler, however, is actually absorbed over only a short length.

A summary of the operating conditions for 21 runs is given in Table 2.1. Runs performed with no solids feed but with a specified holdup wexe accomplished by charging the kiln with solids and then installing a dam to contain the solids. The purpose of this procedure was to determine the effect of dispersion alone by comparing such data with data obtained when the kiln contained no solids. The remaining runs were performed in the normal operating mode. Furnace efficlencies (Table 2.1) were calculated by dividing the calculated heat load on the kiIn (using the Integral curve) by the power expended in the electrical resistance heaters. The efficiencies are generally of the magnitude expected. Tests are planned to quantify the furnace losses.

Table 21 Summary of run conditıns and some calculated results for runs HTS 11 through HTS-30

\begin{tabular}{|c|c|c|c|c|c|c|c|c|c|c|}
\hline \multirow[t]{2}{*}{ Run } & \multirow[t]{2}{*}{$\begin{array}{l}\text { Feed rate } \\
(\mathrm{g} / \mathrm{mm})\end{array}$} & \multirow[t]{2}{*}{$\begin{array}{c}\text { Feed } \\
\text { material }\end{array}$} & \multirow[t]{2}{*}{ RPM } & \multirow[t]{2}{*}{$\begin{array}{l}\text { Slope } \\
(\mathrm{ft} / \mathrm{ft})\end{array}$} & \multirow[t]{2}{*}{$\begin{array}{l}\text { Holdup } \\
\text { (g) }\end{array}$} & \multicolumn{2}{|c|}{$\begin{array}{c}\text { Maximum } \\
\text { wall } \\
\text { temperature } \\
\left({ }^{\circ} \mathrm{C}\right)\end{array}$} & \multirow{2}{*}{$\begin{array}{c}\text { Calculated } \\
\text { maximum } \\
\text { heat flux } \\
\text { in furnace } \\
\text { (Btu h }{ }^{1} \mathrm{ft}^{-2} \text { ) }\end{array}$} & \multirow[t]{2}{*}{$\begin{array}{l}\text { Calculated } \\
\text { furnace } \\
\text { efficiency } \\
(\%)\end{array}$} & \multirow[t]{2}{*}{$\begin{array}{l}\text { Calculated } \\
\text { cooler } \\
\text { efficiency } \\
(\%)\end{array}$} \\
\hline & & & & & & Measured & Calculated & & & \\
\hline HTS 11 & 0 & & 5 & 00157 & 0 & 422 & 441 & -1893 & 334 & 1012 \\
\hline HTS 12 & 100 & Sand & 5 & 00157 & 3823 & 402 & 403 & -2515 & 350 & 466 \\
\hline HTS 13 & 100 & Hulls & 2 & 00157 & 9,007 & 406 & 416 & -2835 & 185 & 938 \\
\hline HTS 14 & 300 & Sand & 5 & 00157 & 7,897 & 407 & 409 & 1647 & 233 & 445 \\
\hline HTS 15 & 100 & Sand & 2 & 00157 & 7,870 & 403 & 402 & 1398 & 326 & 463 \\
\hline HTS 16 & 100 & Hulls & 2 & 00157 & 8,405 & 602 & 626 & -4555 & 507 & 1114 \\
\hline HTS 17 & 300 & Hulls & 5 & 00157 & 10,145 & 602 & 603 & .4261 & 886 & 655 \\
\hline HTS 18 & 200 & Ilulls & 5 & 00157 & 7,538 & 601 & 614 & 4335 & 1214 & 980 \\
\hline HTS 19 & 100 & Sand & 2 & 00157 & 8,309 & 602 & 612 & -3773 & 467 & 552 \\
\hline HTS 20 & 100 & Hulls & 2 & 00157 & 9,234 & 603 & 621 & -4428 & 490 & 765 \\
\hline Ha S 21 & 50 & Hulls & 1 & 00157 & 8721 & 603 & 631 & -4646 & 486 & 1181 \\
\hline HTS 22 & 100 & Hulls & 5 & 00157 & 3,791 & 604 & 632 & -4657 & 485 & 1176 \\
\hline HTS 23 & 100 & Hulls & 5 & 00157 & 3,538 & 404 & 416 & -1698 & 353 & 1204 \\
\hline HTS 24 & 0 & & 2 & 00 & 0 & 408 & 432 & 1846 & 334 & 647 \\
\hline HTS 25 & 0 & & 5 & 00 & 0 & 406 & 425 & -1801 & 339 & 619 \\
\hline $\operatorname{HTS} 26$ & 0 & & 2 & 00 & 0 & 613 & 653 & -3970 & 499 & 1136 \\
\hline HIS 26A & 0 & & 2 & 00 & 0 & 610 & 651 & -3953 & 484 & 1131 \\
\hline $\mathrm{HTS} 27$ & 0 & & 5 & 00 & 0 & 612 & 650 & 3940 & 516 & 1200 \\
\hline HTS 28 & 0 & Hulls & 2 & 00 & 7,000 & 406 & 429 & 1874 & 368 & 1416 \\
\hline HTS 29 & 0 & Hulls & 5 & 00 & 7,000 & 406 & 427 & 1937 & 407 & 1812 \\
\hline HTS 30 & 0 & Hulls & 2 & 00 & 7,000 & 606 & 645 & 5014 & 473 & 1364 \\
\hline
\end{tabular}

The cooler efficiencies (Table 2.1) were calculated in the same manner, where the experimental load was calculated from the water rate through the cooler and the change in temperature. These cooler efficiencies are a measure of how well the model predicts the heat load in this region. An efficiency of $100 \%$ indicates exact agreement. As shown, the model seems to predict the heat flux within a factor of 2 , wich is considered to be adequate considering the assumptions that were incorporated into its development.

Additional expeximents are being planned to measure the gas dispersion coefficient and the heat transfer coefficient between the rotating drum wall and the gas. These values will then be included in the model to replace previously assumed values. 
2.1.3 Erosion/corrosion test

W. D. Folland and M. E. Whatley (Chemical Technology Division, ORNI)

Assembly of the test stand has been completed and a test program has begun. Two identical arums (18-in.-diam x 20-in.-long) containing specimens of type 316 stainless steel and Incoloy $800 \mathrm{H}$ have each been loaked. with a charge of $10 \mathrm{~kg}$ of cermic-filled stajniess steel hulls and are being rotated at $1 \mathrm{rpm}$ in an oven maintained at $650^{\circ} \mathrm{C}$. Initial thickness measurements of the specimens were made at 42 specified locations using an ultrasonic technique.

A second series of measurements, made after 22 days of operation, indicates no significant change in the thickness of any specimens. Testing will continue and measurements will be made at monthiy intervals.

\subsection{Experimental Investigations}

D. O. Campbell, S. R. Buxton, and W. I. Pattison (Chemical Technology Division, ORNL)

An experimental program based on hot-cell tests of fuel reprocessing operations was initiated in January 1976. Most of the work to date has been done with irradiated pressurized-water reactor (PWR) fuels cooled from two to four years. One fuel dissolution ( $r$ un 15) was completed during the reported period using clad fuel from the second irradiation cycle of the oconee-1 reactor (Duke Power Company). Additional data have been obtained from previous runs, and data analysis is being emphasized.

\subsubsection{Hot-cell dissolution}

The second dissolution of fuel from the oconee-1 reactor was carried out ( $x$ un 15 ) using 20.25-in. of fuel from rod 32028 sheared into 2 -in. lengths. The rod had been irradiated in assembly 1C46 for two cycles to a calculated burnup of 18, 711 MWd/MTU and was discharged after shutdown in Februaxy 1976. The total weight of fuel charged to the dissolver was 421 g. The dissolution proceeded smoothly and resulted in the recovery of $73 \mathrm{~g}$ of cladding. The calculated amount of uranium dissolved was $297 \mathrm{~g}$; analytical determinations by two different methods indicate recoveries of 103 to $107 \%$.

\subsubsection{Radioactivity in off-gas}

Analyses for ${ }^{3} \mathrm{H},{ }^{14} \mathrm{C}$, and ${ }^{129}$ I for runs 14 (Big Rock Point fuel) and 15 (Oconee-1 fuel) are summarized in Table 2.2. Because there are minor inconsistencies in the data, each solution has been resubmitted for analysis. Analytical methods have been modified during the last few months, and current results are expected to be more accurate than some of the earlier ones.

Table 2.2. Distribution of ${ }^{3} \mathrm{H},{ }^{14} \mathrm{C}$, and ${ }^{129} \mathrm{I}$ during dissolution in runs 14 and 15

\begin{tabular}{llllllll}
\hline \multirow{2}{*}{ Isotope } & \multirow{2}{*}{ Run } & $\begin{array}{c}\text { Amound found } \\
\text { per MTU }\end{array}$ & \multicolumn{5}{c}{ Percent of total found in - } \\
\cline { 6 - 8 } & & Dissolver & Condensate & Scrub 1 & Scrub 2 & Scrub 3 \\
\hline${ }^{3} \mathrm{H}$ & $14^{a}$ & $189 \mathrm{Ci}$ & 98.2 & 1.1 & 0.08 & 0.0003 & 0.61 \\
& $15^{b}$ & $179 \mathrm{Ci}$ & 96.9 & 2.1 & 0.16 & 0.0003 & 0.79 \\
${ }^{14} \mathrm{C}$ & $14^{a}$ & $0.131 \mathrm{Ci}$ & 9.9 & 0.02 & 89.5 & 0.40 & 0.24 \\
& $15^{b}$ & $0.20 \mathrm{Ci}$ & 9.4 & 0.007 & 89.6 & 0.68 & 0.31 \\
${ }^{129} \mathrm{I}$ & $14^{a}$ & $64 \mathrm{~g}$ & 8.8 & 0.54 & 90.2 & 0.06 & 0.44 \\
& $15^{b}$ & $98 \mathrm{~g}$ & 0.7 & 0.8 & 98.4 & 0.06 & 0.06 \\
\hline
\end{tabular}

\footnotetext{
${ }^{a}$ Big Rock Point reactor fuel, 20,000 MWd/MTU.

${ }^{b}$ Oconee-1 second cycle fuel, $18,700 \mathrm{MWd} / \mathrm{MTU}$
} 


\subsection{Dissolver residue}

Solids collected from Big Rock Point fuel (run 14) dissolver solution, by both filtration and centrifugation, totaled about $340 \mathrm{mg}$, equivalent to $0.17 \%$ of the weight of $\mathrm{UO}_{2}$. Nearly half the solids were recovered on the $20-\mu$ screen, and most of the remainder was collected on an 8- $\mu$ Miliipore filter. These two fractions were similar in composition, containing 12 to $16 \%$ iron plus nickel and 12 to $25 \%$ of the noble metals typical of dissolver residue. Solids collected by subsequent filtration with smaller-porosity Miliipore filters contalned only trace quantities of these metals. The solids from this BWR fuel differ from solids recovered from FWR dissolver solutions, primarily because of the presence of iron and nickel corrosion products which presumably result from the brown oxide film on the fuel cladding. Some of the oxide film was loosened from the cladding during fuel shearing and handing. 3 Approximately $3.7 \pm 0.2 \%$ of the total ${ }^{106} \mathrm{Ru}$ was associated with the insoluble residue, and $96.3 \%$ was dissolved with the fuel; thus, with this fuel, the solublity of xuthenium and noble metals Is much greater than for fully irradiated PWR fuels. This result was expected because of the lower burnup of the Big Rock Point fuel (about 20,000 MWa/MTU).

The dissolver solution from run 15 (oconee-1, second cycle) was passed through a 20- $\mu$ screen. In agreement with previous observations for other PWR fuels, essentially no solids were collected. Part of the dissolver solution was centrifuged, and the solids collected correspond to $0.17 \%$ of the weight of $\mathrm{UO}_{2}$ dissolved.

\subsection{Fuel characterization}

Local variations in burnup can occur within a single fuel rod because of a number of factors, such as the position of the control rods, the flux depression in the vicinity of the grid spacers in the fuel assembly, and the large drop in flux at the ends. Tests of the effects of heat treatment on tritium release have produced several different samples of fuel from short sections of the same rod, ${ }^{4}$ which have been used to measure the reproducibility of analyses.

Data for uranium and plutonium isotopic analyses and the plutonium-to-uranium (Pu:U) ratio determined by isotopic dilution and mass analysis (IDMA) are presented in Table 2.3 for four samples from two different Robinson reactor fuel rods. The Isotopic composition is purported to be the most accurate analysis that will be encountered in this sort of work. The element determinations by IDMA are believed to be the most reliable concentration measurements. Samples

Table 23 Isotopic composition of uranium and plutonum in small fuel samples

\begin{tabular}{lrrrrr}
\hline \multirow{2}{*}{$\begin{array}{c}\text { Isotope } \\
\text { (atom \%) }\end{array}$} & \multicolumn{5}{c}{ Sample identification } \\
\cline { 2 - 6 } & Std A & JS 2 & JV 2 & D 2 & ORIGLN \\
\hline Uranum 234 & 0019 & 0018 & 0016 & 0016 & 0015 \\
Uranium 235 & 0661 & 0657 & 0748 & 0653 & 0646 \\
Uranium 236 & 0352 & 0353 & 0343 & 0355 & 0360 \\
Uranum 238 & 98967 & 98966 & 98891 & 98975 & 9898 \\
Plutonium 238 & 1629 & 1626 & 1496 & 1578 & 132 \\
Plutonum 239 & 55465 & 55279 & 57698 & 55296 & 573 \\
Plutonum-240 & 26007 & 26017 & 24634 & 25960 & 241 \\
Plutonium-241 & 11234 & 11341 & 11216 & 11397 & 120 \\
Plutonium 242 & 5664 & 5744 & 4956 & 5770 & 529 \\
Element & & & & & \\
Pu/U (g/g) & 000868 & 000927 & 000911 & 000912 & 000992 \\
\end{tabular}


JV-2 and JS-2 represent 2-in.-Iong sections from one fuel rod, and Std $A$ is loose fuel from several locations along the same fuel rod section. Sample D-2 is representative of fuel from an 18 -in. solution of a different fuel rod.

The uranium isotopic analysis indicated that JV-2 received a lower burnup, as shown by higher ${ }^{235} \mathrm{U}$ and Iower ${ }^{236} \mathrm{U}$ values. The data for plutonium are generally in agreement, with ${ }^{239} \mathrm{Pu}$ higher and other plutonium isotopes lower compared to other samples. It is reasonable that sample JV-2 may have been from the region of a gria spacer, since there was a spacer somewhere within the section of fuel rod from which these pieces were cut.

The other three samples are closer together in isotopic composition; however, some variations are not consistent with expectations for a simple burnup situation. For example, the uranium isotopics for std A and JS-2 are quite similar, as are ${ }^{238} \mathrm{Pu}$ and ${ }^{240} \mathrm{Pu}$, but the lower

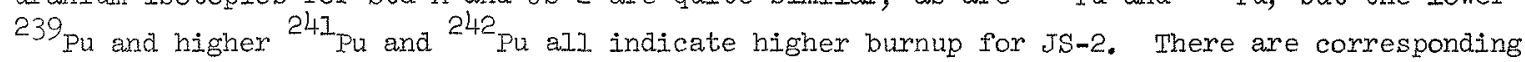
discrepancies in the PU:U ratio, which should increase with burnup; JV-2 is not significantIy lower, as might be expected. These element deteminations, however, are not as accurate as the isotopic distributions.

Calculations by the ORIGEN code of the variation of isotopic composition with burnup indicate that ${ }^{234} \mathrm{~J}, 235 \mathrm{~J}$, and $239 \mathrm{~J}$ decrease with increasing burnup, whereas $236_{\mathrm{U}}$ and alI plutonium isotopes except ${ }^{239} \mathrm{Pu}$ increase. of more significance, the relative change with burnup is on the order of ${ }^{242} \mathrm{Pu}>{ }^{241} \mathrm{Pu} \sim{ }^{238} \mathrm{Pu}>{ }^{239} \mathrm{Pu}$, while ${ }^{240} \mathrm{Pu}$ changes very slightly. In contrast, the data show the least variation for ${ }^{241} \mathrm{Pu}$.

Such observed variations in isotopic composition among similar samples, along with deviations from calculated trends for samples with lower-than-reference burnup, may result from changes in the neutron energy spectrum as well as neutron exposure. The lower burnup regions result primarily from absorption of thermal neutrons, with perhaps little change in the resonance neutron flux, and the resonance neutrons are particularly important in the chains of successive neutron captures. In any case, the localized fuel burnup and the buildup of actinide isotopes may not be related in the simple way usually assumed for computational purposes, which does not take into account the variations in neutron energy distribution.

The significance of these observations is that considerable care must be taken in interpreting analytical results for single small samples of fuel. The variations among such samples exceed any reasonable analytical error, and they are almost certainly real when they exceed a few tenths of $1 \%$. Thus, measurements of burnup, composition, and total inventory should be based on either rather large samples or a large number of small samples so that localized variations in the irradiation parameters can be properly averaged.

\subsubsection{Iow decontamination-factor coprocessing}

Small quantities of highly radioactive mixed oxide were prepared from LWR fuel by means of a low-decontamination-factor (DF) coprocessing, batch extraction/stripping procedure followed by (1) precipitation with ammonia or (2) evaporation with formic acid to reduce volatilization of $\mathrm{RuO}_{4^{\circ}}$. The coprocessed plutonium was prepared by extracting run 13 dissolver solution ( $310 \mathrm{~g}$ of uranium per liter) with 7 volumes of $30 \%$ TBP to give an organic loading of about $44 \mathrm{~g}$ of uranium per liter. The organic was scrubbed with $1 / 45$ volume of $2 \mathrm{M} \mathrm{HNO}$ and stripped twice with $I / 9$ volume of $1 \mathrm{M} \mathrm{HNO}_{3}-0.2 \mathrm{M}$ HAN-O.I $M$ hydrazine nitrate, each with 30 -min contact time. The two strips were combined, sampled, and split into two fractions for preparation of the solids; the products were dried at $450^{\circ} \mathrm{C}$. 
Analyses are repoxted in Table 2.4 for the feed and strip solutions and the two mixed oxides - each is normalized to the total in the feed. only about one-third of the plutonium stripped into the organic because of a high $\mathrm{HNO}_{3}$ concentration resulting from acid that extracted from the feed and stripped into the product. High acidity interferes with plutonium reduction by HAN. Although the Pu:U ratio was lower than desired because of the incomplete stripping of plutonium, the fraction of uranium that stripped was the desired value.

The mixed oxide prepared by ammonia precipitation had a high Pu:U ratio because part of the uranium did not precipitate; the incomplete precipitation was probably due to the presence of carbonate in the $\mathrm{NH}_{4} \mathrm{OH}$. This product contained about $11 \%$ of the ruthenium and $6 \%$ of the cesium in the feed. Part of the mixed oxide obtained by evaporation was not recovered from the flask, but the product had the same Pu:U ratio as the strip product and contained relatively less ruthenium ( $\sim 5 \%)$, which suggests that about half the ruthenium may have volatilized during evaporation. The measured cesium and ruthenium contents of the two products were used to calculate radiation fields from large quantities of these oxides. Values are in the vicinity of 400 to $500 \mathrm{R} / \mathrm{h}$ per $\mathrm{kg}$ of plutonium.

Although certain problems were encountered in this first experiment, specifically the low recoveries of plutonium and ruthenium and the incomplete precipitation of uranium, the experiment did demonstrate two essential features of a low DF coprocessing flowsheet (such as CIVEX), namely (1) an increase in the plutonium content of the mixed oxide from the value in IWR fuel to that suitable for plutonium recycle or fast breeder fuel, and (2) coprocessing of gammaemitting fission products from $5 \mathrm{~kg}$ of plutonium to the extent required to yield a radiation field $>1000 \mathrm{R} / \mathrm{h}$ at $1 \mathrm{ft}$. The experiment also suggests that solvent stripping is the critical problem in achieving such a large increase in the Pu:U ratio.

Table 2.4. Composition of low DF mixed oxide ${ }^{a}$

\begin{tabular}{|c|c|c|c|c|}
\hline & Feed & $\begin{array}{l}\text { Strip } \\
\text { product }\end{array}$ & $\begin{array}{l}\mathrm{NH}_{4} \mathrm{OH} \\
\text { product }\end{array}$ & $\begin{array}{l}\text { Evaporation } \\
\text { product }\end{array}$ \\
\hline $\mathrm{U}, \mathrm{mg}$ & 19,400 & 490 & 115 & 404 \\
\hline $\mathrm{Pu}, \mathrm{mg}$ & 170 & 52 & 57 & 42 \\
\hline $\mathrm{Ru}, \mathrm{d}_{\mathrm{s} \mathrm{s}} \mathrm{s}^{-1} \mathrm{~g}^{-1}$ & $3.9 \leftarrow 10$ & $4.3 \mathrm{E} 9$ & $3.9 \mathrm{E} 9$ & $1.6 \mathrm{E} 9$ \\
\hline $\mathrm{Cs}, \mathrm{d} 1 \mathrm{~s} \mathrm{~s}^{-1} \mathrm{~g}^{-1}$ & $7.0 \mathrm{E} 10$ & $2.7 \mathrm{E} 8$ & $2.5 \mathrm{E} 6$ & $2.5 \mathrm{E} 8$ \\
\hline Ce, dis s ${ }^{-1} \mathrm{~g}^{-1}$ & $1.4 \mathrm{E} 11$ & $8.3 \mathrm{E} 9$ & $9.0 \mathrm{E} 9$ & $7.2 \mathrm{E} 9$ \\
\hline $\mathrm{Pu} /(\mathrm{U}+\mathrm{Pu})$ & 0.0087 & 0.096 & 0.33 & 0.10 \\
\hline \multicolumn{5}{|c|}{$\mathrm{R} / \mathrm{h}$ pet $\mathrm{kg}$ of plutonum at $\mathrm{Itt}$} \\
\hline Flom cerium & & & 218 & 236 \\
\hline From xuthenum & & & 327 & 177 \\
\hline Total & & & 545 & 413 \\
\hline
\end{tabular}

${ }^{a}$ For 21 months cooling time. 


\subsection{Hot-CelI Process Development}

V. C. A. Vaughen, J. H. Goode, H. C. Savage, R. G. Stacy, E. C. Hendren, J. R. Travis C. S. Webster (Chemical Technology Division, ORNL) and G. K. Ford (Engineering Coordination and Analysis, ORNL)

\subsubsection{Fuel procurement}

Four representative rods from the Peach Bottom-2 reactor were shipped to ORNL from the Idaho NationaI Engineering Laboratory (INEI). The shipping cask was returned to INEI to pick up $50 \mathrm{~kg}$ of segments of $\mathrm{H}$. B. Robinson-2 fuel rods from Assembly B-O5 for use in the ORNL Solvent Extraction Test Facility (SETF). The Nuclear Assurance Corporation's NAC-I shipping cask/trailer set was leased by ORVI to move two Dresden-I reactor assemblies from the Morris, Illinois, site to INEL for disassembIy and segmenting. This fuel is also to be used in SETF studies. Fuel shipments to Savannah River Laboratory from ORNL may be temporarily suspendea on JuIy 1, 1978, until ORO-DOE approves the Safety Analyses for Radioactive Packages (SARP) for the casks. All of the Interim Certificates of Compliance expire on that date.

\subsubsection{Shearing studies}

Six 4.5-in.-Iong stainless steel clad (4\% U, Th) O $\mathrm{O}_{2}$ rods (0.31-in. -OD, 0.025-in. -waIl) from the NNX reactor were sheared into short lengths to dislodge fuel for tritium removal tests. The shearing behavior of the rods was variable in that some fractures from a single rod appeared brittle while others appeared ductile. Shear forces were $700 \pm 200 \mathrm{~kg}$ per blade pass. The dislodged fuel was sieved to separate the fines and cladding from the test material; size distribution is listed in Table 2.5. Voloxidation and dissolution tests with the (U, Th) $\mathrm{O}_{2}$ rods are described in sect. 3.2.1.

Table 2.5. Size distribution of dislodged $(\mathrm{U}, \mathrm{Th}) \mathrm{O}_{2}$ fuel

\begin{tabular}{rrrr}
\hline \multicolumn{2}{c}{ Size fraction } & & Weight \\
Mesh & $\begin{array}{c}\text { Opening } \\
(\mu \mathrm{m})\end{array}$ & $(\mathrm{g})$ & Percent \\
\hline & & & 8.1 \\
+18 & 1000 & 11.7 & 23.2 \\
+35 & 500 & 33.4 & 34.5 \\
+100 & 149 & 49.5 & 11.8 \\
+200 & 74 & 16.9 & 6.0 \\
+325 & 44 & 8.6 & 16.4 \\
-325 & $<44$ & 23.6 & 100.0 \\
Total & & 143.7 & \\
\hline
\end{tabular}

\subsubsection{Voloxidation studies}

Parametric voloxidation tests with H. B. Robinson fuel were continued. Three additional experiments (IWR-6, 7, and 8) were made at different temperatures and oxygen feed rates to study the possible effects on the rate of evolution and the yield of tritium. A compilation of the runs made to date in this series appears in Table 2.6. Results from runs LWR-3, 4, and 5 
T thl 26 Voloxkdition tests of uncl td $\mathrm{UO}_{2}$ trom $\mathrm{H}$ B Robinson fuel

\begin{tabular}{|c|c|c|c|c|c|c|}
\hline \multirow[b]{2}{*}{ Run } & \multirow{2}{*}{$\begin{array}{l}\text { I ucl wel,ht } \\
\text { chat od } \\
(\mathrm{g})\end{array}$} & \multirow[b]{2}{*}{$\begin{array}{l}\operatorname{lm} \\
(\mathrm{b})\end{array}$} & \multicolumn{3}{|c|}{ Floxid thone nditions } & \multirow[b]{2}{*}{$\begin{array}{l}\text { Rotation } \\
\text { (rpmin) }\end{array}$} \\
\hline & & & $\begin{array}{c}\text { Iempetature } \\
{ }^{\circ} \mathrm{O}\end{array}$ & Atmosphere & $\begin{array}{l}\text { Flow inte } \\
\left(\mathrm{cm}^{3} \text { Inin }\right)\end{array}$ & \\
\hline$I W R$ & 727 & 30 & 480 & All & 300 & 17 \\
\hline [WR 4 & 199 & 74 & 180 & $\mathrm{O}_{2}$ & 300 & 17 \\
\hline LWR 5 & 1000 & 7 & 480 & $\mathrm{O}_{2}$ & 100 & 17 \\
\hline LWR 6 & 1003 & $? 0$ & 480 & $\mathrm{O}_{2}$ & 500 & 12 \\
\hline LWR 7 & $100 \%$ & 35 & $5>0$ & $\mathrm{O}_{2}$ & 00 & $1 ?$ \\
\hline LWR 8 & 1004 & 28 & 550 & Air & 300 & 17 \\
\hline
\end{tabular}

were presented in part in earlicy reporls. 5, 4 Evaluation of the data from runs IWR 6 and 7 is Imost complete with some of the esuls tepotad here. Dissolution analyces on the voloxidzed product fron IwR 8 aro not yeu a raslable.

Qugen consumption. Naterzal balances for the tests are presented in Table 2.7. Based on the welght gain of the vntoradized produrts, the $\mathrm{r}_{2}$ conversion was essextially complote under the conditions given in the tablo. In most cases, the nearly complete conversion was verified

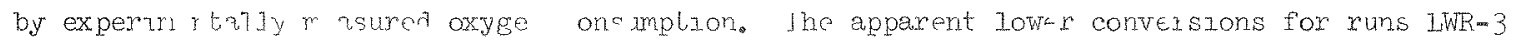

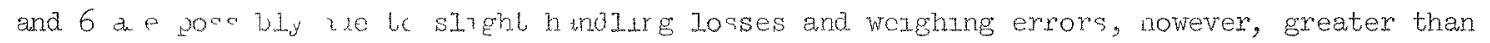
$99 \%$ of che $U_{3} O_{8}$ product from each experment was found beneatr the $44-\mu m$ sieve, which also Inducates comploteness of conversi $n_{\text {. }}$

The cate of oxyeen consunption was xopraclably fistex when pure oxygen was the oxidant.

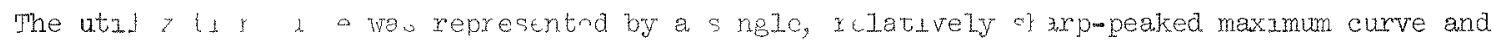
took absut 1 , caen completzon. Verzations in temperature from 480 to $550^{\circ} \mathrm{C}$ and In feed Iow rate from $\omega 0$ to $500 \mathrm{~cm}^{3} / \mathrm{m}$ dad not appear to alter the ratc at which ruel was oxldzzed or the ratc au tnicn trutzun was released. Wher aly was tho ox ldant, the oxygen depletion curre exhıbled a double-peared conumption pattern at took tisce as long to complete. 5 In these cases, measureme $1^{+}$s on pas llow inzinzld that, w port of maximum consumption, nearly all whe of wa buts uscd in rume with pur oryges as th oxidant, the maymum consumption catc genezally rang, from 50 to $90 \%$, affending on the parge flow rate.

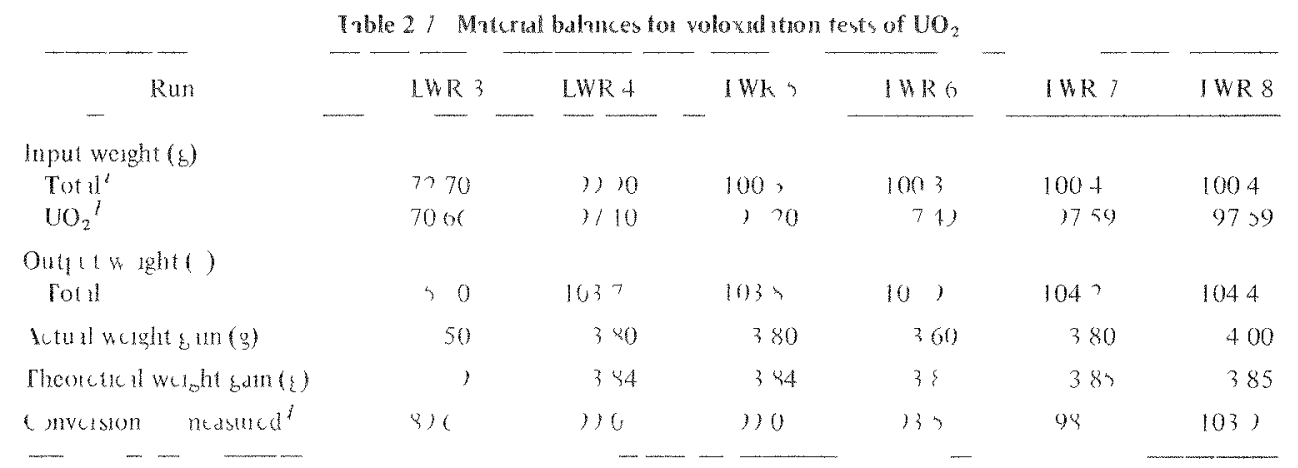

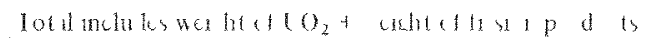

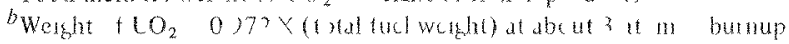

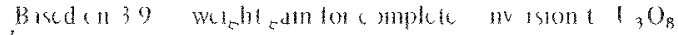

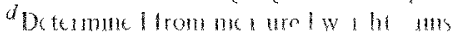


Fission gas release. Tritium evolution rate curves (presented as average concentrations found in the off-gas with time) for voloxidations in oxygen at two temperatures are shown in Fig. 2.2. The rate of release of tritium from the $\mathrm{UO}_{2}$ was quite similar for each experiment, with off-gas concentrations rapidly increasing and reaching a maximum within the first hour at voloxidation temperature. A difference in feed gas flow rates for the two runs $\left(500 \mathrm{~cm}^{3} / \mathrm{min}\right.$ for LWR-6 vs $300 \mathrm{~cm}^{3} /$ min for LWR-7) had little noticeable effect on release rates and total amounts of tritiun evolved. Profiles for oxygen consumption likewise showed little variation between the two sets of rum conditions. This would indicate that the fuel was oxidized (and tritium was released) at approximately the same rate in both cases. The lower purge flow in LWR-7 apparentIy slowed the rate at which tritium was swept through the off-gas system to adsorption traps, particularly during the later half of the run. However, the amount of tritium remaining in the fuel after $1.5 \mathrm{~h}$ at the experimental temperature is estimated as being $\operatorname{smal1}(<1 \%)$.

Profiles for the release of $3_{H}$ and ${ }^{85}$ Hr and the cumulative consumption of oxygen during the IWR-6 experiment are presented in Fig. 2.3. The utilization of oxygen commenced as the

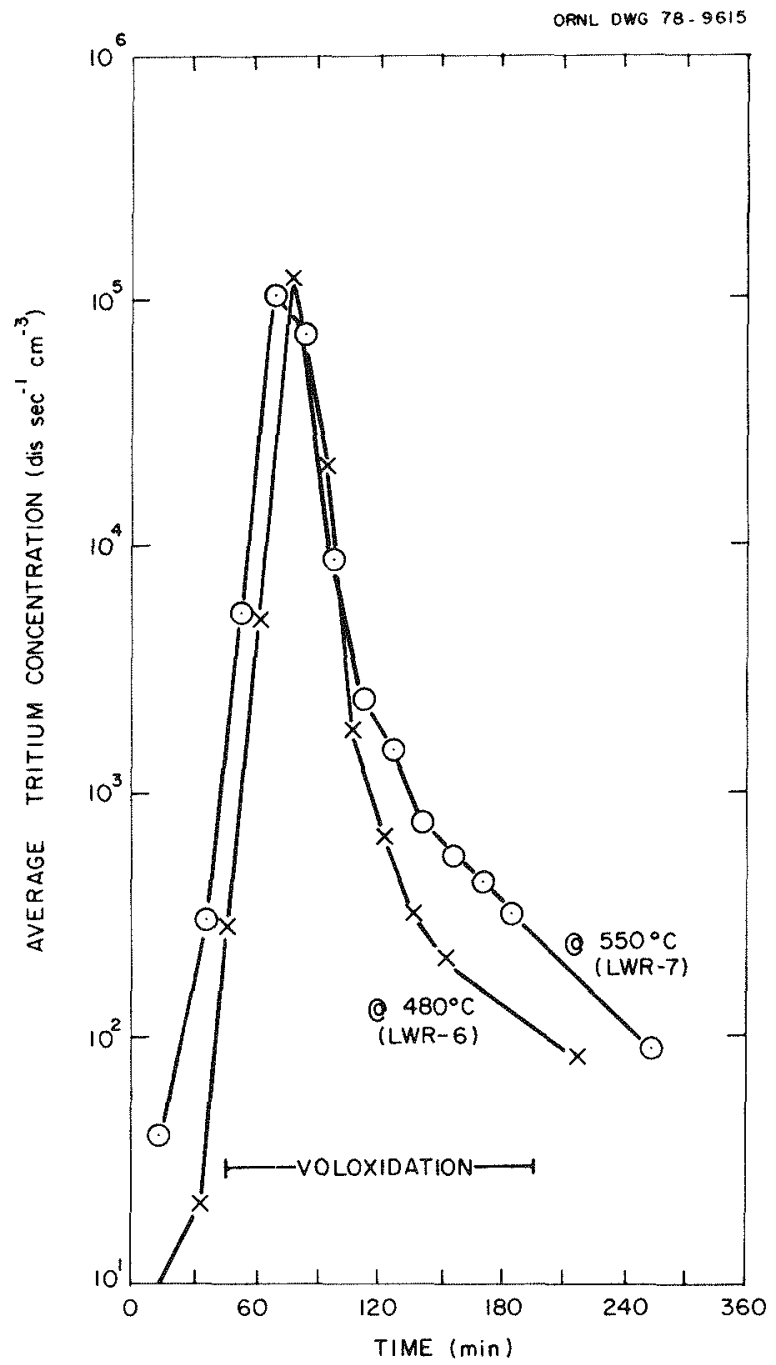

Fig. 2.2. Tritium concentration profiles in voloxidizer off-gas. 


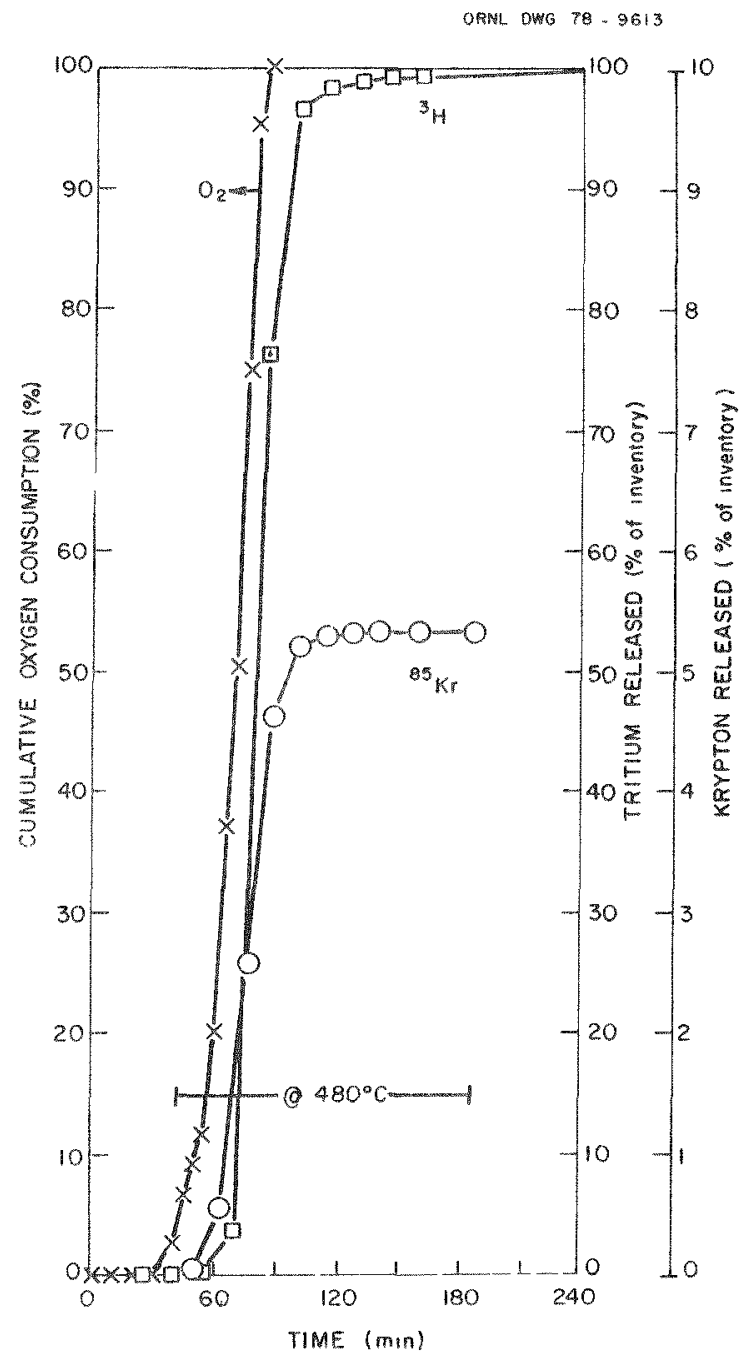

Fig. 2. 3. Gaseous relcase and oxygen consumption durang voloxidation (IWR-6).

Uo reached $400^{\circ} \mathrm{C}$ and was completed in about $1 \mathrm{~h}$. Tritium and krypton evolution were delayed intil the charge reached the experimontal temperature, but thereafter, the gaseous releases trere quite rapid. After $1.5 \mathrm{~h}$ at $480^{\circ} \mathrm{C}$, only about $1 \%$ of the iritium remained in the fuel, whereas as much as $95 \%$ of the krypton remained. Small anounts of tritium continued to be collected until the end of the roloxidation and during a $2-b$ purge in air.

The geseous radionuclidc inventories of $H_{*}$ B. Robinson fuel exporimentally determined in a series of baseline experiments aro listed in Tablc 2,8. Gaweous releasc material balances for runs IWR-6 and IWP-7 were determjned from the dissolution of the voloxidized oxide and from cumulative samples of collected voloxidizex offmgas. Release totals for the hwo experiments are shown in Table 2.9. For each case, the release of tritium from the unclad vo by voloxidation was essentially quantitative ( $299.98 \%$ of the fuel irventory). Recoveries of ${ }^{-} \mathrm{H}$, retained on silica gel as $3_{\mathrm{ji}} \mathrm{O}$, from the off-gas amounted to 95 and $85 \%$ of these totals, respectively, for runs TWR 6 and IWR 7 . Apparently, the difference in voloxidation temperature for the two cxperiments had no affect on the total amounts of ${ }^{14} \mathrm{C}$ and ${ }^{85} \mathrm{Kr}$ evolved. 
Table 2.8. Gaseous radionuclide inventories of H. B. Robinson $\mathrm{UO}_{2}$

\begin{tabular}{ccc}
\hline \multicolumn{3}{c}{ Contents dis s ${ }^{-1} \mathrm{~g}^{-1}(\mathrm{U}+\mathrm{Pu})$} \\
\hline${ }^{3} \mathrm{H}$ & ${ }^{14} \mathrm{C}$ & ${ }^{85} \mathrm{Kr}$ \\
\hline $1.05 \times 10^{7}$ & $2.05 \times 10^{4}$ & $3.56 \times 10^{8}$ \\
\hline
\end{tabular}

Table 2.9. Gaseous release

\begin{tabular}{|c|c|c|c|c|}
\hline \multirow[t]{2}{*}{ Run } & \multirow{2}{*}{$\begin{array}{c}\text { Voloxidation } \\
\text { temperature } \\
\left({ }^{\circ} \mathrm{C}\right)\end{array}$} & \multicolumn{3}{|c|}{$\begin{array}{l}\text { Released to voloxidizer off-gas } \\
\text { ( } \% \text { of } \mathrm{UO}_{2} \text { fuel inventory) }\end{array}$} \\
\hline & & ${ }^{3} \mathrm{H}^{a}$ & ${ }^{14} \mathrm{C}^{a}$ & ${ }^{85} \mathrm{Kr}^{a, b}$ \\
\hline LWR-6 & 480 & 99.99 & 15.5 & 5.3 \\
\hline LWR-7 & 550 & 99.98 & 19.1 & 5.2 \\
\hline
\end{tabular}

${ }^{a}$ Based on residual levels determined from dissolution of voloxidized oxide.
${ }^{b}$ Determined from cumulative samples of voloxidizer off-gas.

Fission product distribution. Experimentally determined inventories of fission products In H. B. Robinson fuel are listed in Table 2.10. Fission product amounts remaining on voloxidizer walls and on samples located in the off-gas system were determined following voloxidation at several conditions. Selected recoveries are shown in Table 2.11 as the percentages of inventories listed in Table 2.10. Results for run IWR-3 were reported previous Iy. ${ }^{6}$ Gamma spectrometric analyses of off-gas samples from IWR -5 have not been completed; these results will be reported later.

Genera.11y, less than $0.1 \%$ of the total ${ }^{106} \mathrm{Ru},{ }^{125} \mathrm{Sb}, 134-137 \mathrm{Cs}$, and ${ }^{144} \mathrm{Ce}$ left the fuel and was found in the system after voloxidation in oxygen at either 480 or $550^{\circ} \mathrm{C}$. Higher temperatures and purge flow rates tended to increase volatilization. With the exception of ${ }^{129}$ I and to some extent ${ }^{106} \mathrm{Ru}$, most of the recovered fission products were deposited on sample surfaces within the voloxidizer. Recoveries of volatilized iodine usually ranged from $I$ to $2 \%$ of the total fuel inventories, nearly all of which was located on downstream charcoal beds heated to $125^{\circ} \mathrm{C}$.

Under the conditions studied, the ruthenium released from the fuel apparently acted somewhat differently from other fission products. Approximately the same amount of ${ }^{106}$ Ru was found. on off-gas system samples as was recovered from inside the voloxidizer. Most of the released ruthenium was retained on tubing specimens, where surface temperatures ranged from above $400^{\circ} \mathrm{C}$ down to about $100^{\circ} \mathrm{C}$. A comparison of fission product ratios shown in Table 2.12 indicates that ${ }^{106} \mathrm{Ru}$ is volatilized (as presumably $\mathrm{RuO}_{2}$ ) to a greater extent than the other semivolatile fission product oxides. One possibility, oxidation to volatile $\mathrm{RuO}_{4}$, would be promoted by increases in temperature and in the oxygen feed rate. We are continuing to investigate this phenomenon as an extension of the current parametric series.

\subsubsection{Dissolution studies}

Dissolution studies were continued using the $\mathrm{U}_{3} \mathrm{O}_{8}$ products from the voloxidation tests to determine the residual $3_{\mathrm{H}},{ }^{14} \mathrm{C}$, and other fission product contents. Material balances (Table 2.13) indicate that recoveries were generally within limits of weighing $( \pm 1 \%)$ and analysis $( \pm 3 \%)$. 
Fable 210 Selcated tisson product minentorics of $\mathrm{H}$ is Robmson $\mathrm{UO}_{2}$

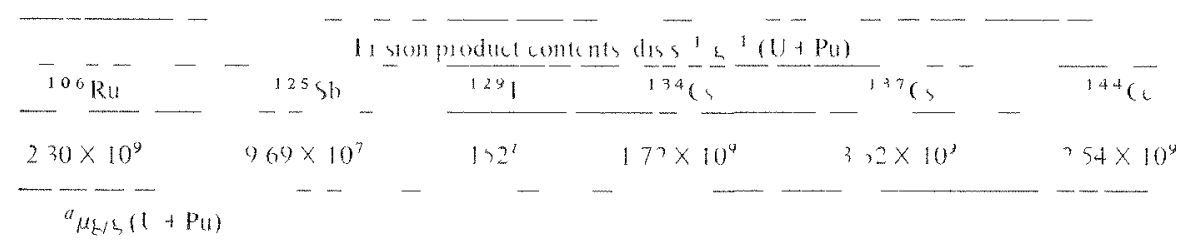

Table 211 Selacted tission product recovcres trom the volosidict and off gads sy stem followng voloxidation of $\mathrm{H} B$ Robuson $\mathrm{UO}_{2}$

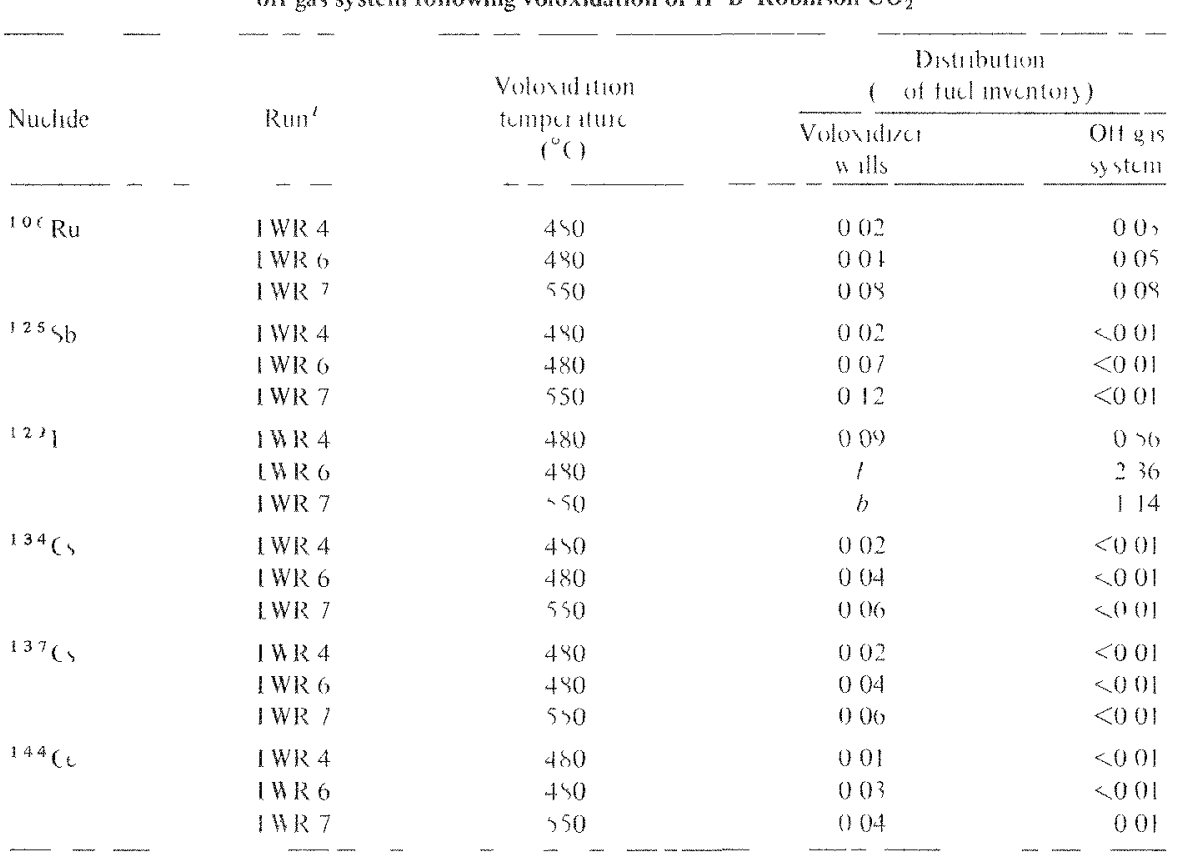

"All suns nuth in pur $\mathrm{O}_{2}$ IWR 4 it $200 \mathrm{~cm}^{3}$ mul lWR 6 it $500 \mathrm{~cm}^{4} / \mathrm{mm}$ and IWR 7 it 300 $(m)^{3} / m n$

Not deterted

\begin{tabular}{|c|c|c|c|c|c|c|}
\hline \multirow{2}{*}{ Nuchics } & \multirow[b]{2}{*}{ Rum } & \multicolumn{2}{|c|}{ Voloxiduteon comditioms } & \multirow[b]{2}{*}{$|n|$} & \multicolumn{2}{|c|}{ Rutiog (lowdton) } \\
\hline & & $\begin{array}{c}1004)^{\circ} \\
-\end{array}$ & $\begin{array}{l}11 \mathrm{~g} \times \mathrm{ath} \\
\left(6 \mathrm{~m}^{3} / \mathrm{mm}\right)\end{array}$ & & $\operatorname{Vol} 3 \mathrm{~d} d \mathrm{~h} \mathrm{e}^{a}$ & $\begin{array}{l}\text { Otl gis } \\
\text { s) } 5 t 2 m^{2}\end{array}$ \\
\hline \multirow[t]{3}{*}{$\left.{ }^{10} \mathrm{Ru}\right)^{1 \neq}(\mathrm{s}$} & $1 M R+$ & 480 & 200 & 0692 & $046 ?$ & 315 \\
\hline & LWR :" & 180 & 500 & 0692 & 0709 & 168 \\
\hline & IWR 7 & 30 & 300 & 0692 & 0995 & 160 \\
\hline \multirow[t]{3}{*}{${ }^{105} \mathrm{Ru} /{ }^{144} \mathrm{Ce}$} & LWR 4 & 180 & 200 & 0906 & 114 & 230 \\
\hline & IWR 6 & 490 & 400 & 0406 & 108 & 484 \\
\hline & $(H R)$ & $\{0$ & 300 & 0906 & 160 & 297 \\
\hline
\end{tabular}

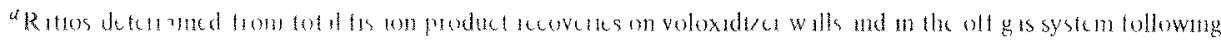
voloxutition 
Table 2.13. Material balances for dissolution experiments

\begin{tabular}{|c|c|c|c|c|}
\hline & \multicolumn{4}{|c|}{ Run } \\
\hline & LWR-4 & LWR-5 & LWR-6 & LWR-7 \\
\hline \multicolumn{5}{|c|}{ Input } \\
\hline $\mathrm{U}_{3} \mathrm{O}_{8}(\mathrm{~g})$ & 102.0 & $25.2^{a}$ & $25.0^{b}$ & $24.7^{c}$ \\
\hline Equivalent $\mathrm{UO}_{2}(\mathrm{~g})$ & 98.2 & 24.3 & 24.1 & 23.7 \\
\hline \multicolumn{5}{|c|}{ Output } \\
\hline $\mathrm{UO}_{2}(\mathrm{~g})$ & 92.49 & 22.82 & 22.57 & 21.15 \\
\hline $\mathrm{PuO}_{2}(\mathrm{~g})$ & 0.80 & 0.18 & 0.17 & 0.20 \\
\hline Residue (g) & 0.28 & 0.03 & 0.10 & 0.13 \\
\hline Soluble fission products $(\mathrm{g})$ & 2.57 & 0.43 & 0.41 & 0.40 \\
\hline Total $(\mathrm{g})$ & 96.14 & 23.46 & 23.25 & 21.88 \\
\hline Recovery (\%) & 97.9 & 96.7 & 96.6 & 93.3 \\
\hline
\end{tabular}

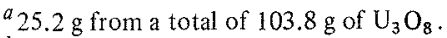

${ }_{2} 25.0 \mathrm{~g}$ from a total of $103.9 \mathrm{~g}$ of $\mathrm{U}_{3} \mathrm{O}_{8}$.

${ }^{c} 24.7 \mathrm{~g}$ from a total of $104.2 \mathrm{~g}$ of $\mathrm{U}_{3} \mathrm{O}_{8}$.

The dissolution of the voloxidizer products in nitric acid was conducted in the standard manner, that is, successive $2-\mathrm{h}$ leaches in 92 to $95^{\circ} \mathrm{C} 7 \mathrm{M} \mathrm{HNO}_{3}, 3 \mathrm{MHNO}_{3}$, and $7 \mathrm{M} \mathrm{HNO} 3^{\circ}$ Table 2.14 indicates that the changes from air to pure oxygen and from $480^{\circ}$ to $550^{\circ} \mathrm{C}$ apparently had little effect on the solubility of uranium and plutonium.

\subsubsection{Residue characterization}

The undissolved residue at the end of each dissolution was centrifuged from solution, washed, dried, and weighed before analysis. Table 2.15 indicates that the change from air to oxygen did not increase the amount of residue, compared with that produced by voloxidation in runs I to $3(0.45-0.72 \%)$.

The residues contained an average of $14 \mathrm{mg}$ of uranium and $0.5 \mathrm{mg}$ of plutonium per gram (of residue), along with the noble metal fission products. This represents a loss of about $0.01 \%$ uranium and about $0.04 \%$ plutonium. The ruthenium content of the residues produced by oxidation in oxygen was about the same as that from air oxidation, that is, about 27 wt $\%$

Table 2.14. Residue from dissolution

\begin{tabular}{lcccc}
\hline & \multicolumn{4}{c}{ Run } \\
\cline { 2 - 5 } & LWR-4 & LWR-5 & LWR-6 & LWR-7 \\
\hline Voloxidation temperature $\left({ }^{\circ} \mathrm{C}\right)$ & 480 & 480 & 480 & 550 \\
Atmosphere & $\mathrm{O}_{2}$ & $\mathrm{O}_{2}$ & $\mathrm{O}_{2}$ & $\mathrm{O}_{2}$ \\
Residue $(\mathrm{g})$ & 0.279 & $0.030^{a}$ & 0.104 & 0.129 \\
$\mathrm{UO}_{2}-\mathrm{PuO}_{2}(\mathrm{~g})$ & 93.29 & 23.00 & 22.74 & 21.35 \\
Residue, \% of $(\mathrm{U}, \mathrm{Pu}) \mathrm{O}_{2}$ weight & 0.30 & $0.13^{a}$ & 0.46 & 0.61 \\
\hline
\end{tabular}

${ }^{a}$ Apparently low. 
Table 2.15. Solubility of voloxidized $\mathrm{U}_{3} \mathrm{O}_{8}$

\begin{tabular}{|c|c|c|c|c|c|c|c|c|c|c|}
\hline & \multicolumn{10}{|c|}{ Run } \\
\hline & LWR-1 & 3 & \multicolumn{2}{|c|}{ LWR-4 } & \multicolumn{2}{|c|}{ LWR-5 } & \multicolumn{2}{|c|}{ LWR-6 } & \multicolumn{2}{|c|}{ LWR-7 } \\
\hline Voloxidation tcmperature $\left({ }^{\circ} \mathrm{C}\right)$ & \multicolumn{2}{|c|}{480} & \multicolumn{2}{|c|}{480} & \multicolumn{2}{|c|}{480} & \multicolumn{2}{|c|}{480} & \multicolumn{2}{|c|}{550} \\
\hline \multirow[t]{3}{*}{ Voloxidation atmosphere } & A11 & & & & & & & & & \\
\hline & \multicolumn{10}{|c|}{ Quantity dissolved, $\%$ of total } \\
\hline & U & Pu & U & $\mathrm{Pu}_{\mathrm{u}}$ & $\mathrm{U}$ & $\mathrm{Pu}$ & $\mathrm{U}$ & Pu & U & $\mathrm{Pu}$ \\
\hline Leach 1 & 99.98 & 9997 & 99.96 & 99.95 & 99.99 & 99.96 & 99.81 & 99.74 & 99.69 & 99.69 \\
\hline Leach 2 & 0.01 & 0.01 & 0.04 & 0.01 & & & 0.18 & 0.21 & 0.28 & 0.37 \\
\hline Leach 3 & 0.01 & 0.01 & 0.01 & 0.02 & & & 0.01 & 0.03 & 0.02 & 0.13 \\
\hline Residue & 0.01 & 0.02 & 0.01 & 0.02 & 0.01 & 0.04 & 0.01 & 0.01 & 0.01 & 0.04 \\
\hline
\end{tabular}

2.3.6 Component tests

Solution clarification. Previously reported results 7 of filtration tests of unvoloxidized H. B. Robinson fuel dissolver solutions indicated that a 1-um pore size etched-disk filter (Vacco Industries, South EI Monte, CaIifornia) may be sujtable for clarification of the dissolver feed solutions in the Solvent Extraction Test Facility (SETF). A diatomaceous filter precoat is required to prevent plugging. The filter aid precoat also improves the efficiency of the filter in removing solids from the dissolver solutions.

Additional tests were carried out during this report period. All tests except one used about $90 \mathrm{~cm}^{3}$ of dissolver solutions from the dissolution of unvoloxidized H. B. Robinson fuel. In one test, about $700 \mathrm{~cm}^{3}$ of dissolver solution was used. All solutions contained about $300 \mathrm{~g}$ of uranium per liter. The etched-disk filter (surface area: $28.3 \mathrm{~cm}^{2}$ ) was the same as that used in all previous tests. In most tests the differential pressure ( $\Delta \mathrm{P}$ ) across the filter was held constant at $2 \mathrm{in.} \mathrm{Hg.} \mathrm{One} \mathrm{test} \mathrm{was} \mathrm{made} \mathrm{at} \mathrm{a} \mathrm{constant} \Delta \mathrm{p}$ of 23 in. Hg; during the filtration of about $700 \mathrm{ml}$ of dissolver solution, the pressure was increased.

Tests to measure the filtration rates and efficiency of the clean filter and the effects of a filter air precoat were repeated. Plugging of the filter occurred, as in the previous test, ${ }^{7}$ and a small quantity of solids was removed from the filtrate by centrifugation. The solids collected on the filter were removed by backflushing, and the filter was precoated with $10.6 \mathrm{mg} / \mathrm{cm}^{2}$ of Celite 535, with an additional coating of $0.1 \mathrm{~g}$ of Celite standard Supercel ${ }^{*}$ over the 535. The filtration rate with the precoated filter was similar to that previously reported $\left(9 \mathrm{~cm}^{3} / \mathrm{min}\right)$, and no significant decrease in the filtration rate was observed. No solids were removed from the filtrate on centrifugation immediately after completion of the test.

A floceulating agent, Primafloe C-3 (Rohm and Haas), was added to the dissolver solution (2 $\mathrm{ml}$ of diluted Primafloc added to $90 \mathrm{ml}$ of dissolver solution) at a concentration of 200 ppm (wt) for compaxison with the previous test in which primafloc $\mathrm{C}-3$ at a concentration of 980 ppm (wt) was used. No solids appeared to have settled from the solution after standing overnight.

\footnotetext{
* Trademark, Johnsmanvilie.
} 
The filtration rate for the dissolver solution with $200 \mathrm{ppm}$ (wt) of flocculating agent was much faster than that with $980 \mathrm{ppm}$ (24 vs $\left.1.8 \mathrm{~cm}^{3} / \mathrm{min}\right)$. However, filtering efficiency appeared to be poor based on the relatively large quantity of solids removed from the filtrate by centrifugation.

A wood-cellulose type of filter aid precoat (Solka-Floc BW-40*) was also tested. The etched-disk filter was precoated with $0.3 \mathrm{~g}$ of Solka-Floc BW-40. The filtration rate of the dissolver solution was about the same as that obtained with the Celite filter aid $\left(9 \mathrm{~cm}^{3} / \mathrm{min}\right)$ and the rate remained constant. Some solids, however, were observed in the centrifuged filtrate, whereas none were seen in the test with the celite filter aid.

A test was performed to determine the effect of rapidly increasing the $\triangle \mathrm{P}$ across the filter. The dissolver solution, using the etched-disk filter precoated with Celite 535 and standard Supercel as before, was filtered with a constant $\Delta \mathrm{P}$ of $23 \mathrm{in}$. Hg. The filtration rate was very fast $\left(124 \mathrm{~cm}^{3} / \mathrm{min}\right)$ and there was no evidence of plugging. However, solids were found in the filtrate, indicating there was a loss of efficiency at the higher initial pressure drop.

In all of the tests using H. B. Robinson fuel dissolver solutions (a total of ten), backflushing after each test with air at about 15 psig pressure has been effective in removing solids from the filter and in restoring the filtration rate to that of the "as-received" filter.

The final test (scaled to about one-half the volume-to-filter surface area ratio to be used in the SETF) was made using a dissolver solution obtained by dissolving $275 \mathrm{~g}$ of H. B. Robinson fuel in $740 \mathrm{ml}$ of nitric acid. A batch dissolution procedure developed at the Savannah River Laboratory was used. The etched-disk filter with a Celite precoat was used. The initial filtration rate was about $4.8 \mathrm{~cm}^{3} / \mathrm{min}$ at a $\Delta P$ of $2 \mathrm{in.} \mathrm{Hg}$. This rate was lower than in previous tests $\left(9 \mathrm{~cm}^{3} / \mathrm{min}\right)$; therefore, the pressure was increased to obtain a rate of $7.8 \mathrm{~cm}^{3} / \mathrm{min} \mathrm{A}$ very slow decrease in the rate $\left(6 \mathrm{~cm}^{3} / \mathrm{min}\right.$ after filtering $170 \mathrm{ml}$ of solution) was observed. This slow decrease in rate continued throughout the test; however, the pressure was increased as required (about every $100 \mathrm{~cm}^{3}$ of volume filtered) to maintain the desired rate. The pressure was thus increased to $16 \mathrm{in.} \mathrm{Hg}$ in filtering the final $150 \mathrm{ml}$ of solution. The average filtration rate for the test was $6.6 \mathrm{~cm}^{3} / \mathrm{min}$. This rate will be increased by a factor of about 6 for the larger-surface-area filter to be used in the SETr.

REFERENCES FOR SECTION 2

1. B. I. Vondra et al., Altemate Fuel Cycle Technologies/Thorium Fuel Cycle Technology Programs Quarterly Report for Period January 1 to March 31, 1978, ORNL/TM-6307 (May 1978), p. 2-1.

2. Ref. 1, p. 2-4.

3. Ref. I, p. 2-6.

4. B. I. Vondra et al., Alternate Fuel Cycle Technologies/Thorium Fuel Cycle Technology Programs Quarterly Report for Period October I to December 31, 1977, ORNI/TM-6206

(February 1978), pp. 2-19-2-23.

5. Ref. 4, p. 2-43.

6. Ref. I, p. 2-10.

7. Ref. I, pp. 2-16-2-22.

8. W. J. Jenkins, Technical Data Summary for Dissolving LWR Fuel, DPSTD-77-3 (Jan. 3, 1977 ).

\footnotetext{
* Trademark, Brown Company, Boston, Mass.
} 


\section{THORIUM DISSOLUTION STUDIES}

3.1 Laboratory Experiments

J. C. Mailen (Chemical Technology Division, ORNL)

\subsubsection{Kinetic determinations}

O. K. Tallent and I. M. Gray (Chemical Technology Division, ORNL)

The kinetics of the dissolution of both $\mathrm{ThO}_{2}$ and Zircaloy are being studied to allow optimization of the conditions for Zircaloy-clad thoria fuel dissolution. Studies are in progress to define the effects of $\mathrm{HNO}_{3}$ and $\mathrm{HF}$ concentration on $\mathrm{ThO}_{2}$ and Zircaloy-4 dissolution rates at $100^{\circ} \mathrm{C}$ in $\mathrm{HNO}_{3}-\mathrm{HF}$ solutions with and without $\mathrm{Al}\left(\mathrm{NO}_{3}\right)_{3}$ present. While there is a large body of information ${ }^{2}$ on $\mathrm{ThO}_{2}$ dissolution in $\mathrm{HNO}_{3}-\mathrm{HF}-\mathrm{Al}\left(\mathrm{NO}_{3}\right)_{3}$ systems, there is less information on dissolution without $\mathrm{Al}_{2}\left(\mathrm{NO}_{3}\right)_{3}$ present ${ }^{2-8}$ and very little information on Zircaloy-4 dissolution. 9

The $\mathrm{ThO}_{2}$ dissolution tests were conducted by digesting $0.5 \mathrm{~g}$ of $99 \%$ theoretically dense $\mathrm{ThO}_{2}$ microspheres in $10 \mathrm{ml}$ of 8.0 to $14.0 \mathrm{M} \mathrm{HNO}{ }_{3}-0.01$ to $0.1 \mathrm{MHF}$ solutions for $1 \mathrm{~h}$. In certain tests, the dissolver solutions also contained $\left.0.1 \mathrm{M} \mathrm{AI}_{3} \mathrm{NNO}_{3}\right)_{3}$. The ThO microspheres, which had been sintered at $1150^{\circ} \mathrm{C}$, had a bulk density of $9.94 \mathrm{~g} / \mathrm{cm}^{3}$ and a surface area of $120 \mathrm{~cm}^{2} / \mathrm{g}$. The digestions were made in $30 \mathrm{ml}$ polyethylene sample bottles (with attached polyethylene air condensers) immersed directly in boiling $\left(100^{\circ} \mathrm{C}\right)$ water. After $1-h$ digestions, samples of the supernates were analyzed, as required, for thorium, total fluoride, and aluminum. The dissolution tests for Zircaloy-4 were conducted similarly, except that pieces of 1/4-in. Zircaloy-4 tubing ( $1.0 \mathrm{in}$. in length and weighing $\sim 3.5 \mathrm{~g}$ ) were used instead of the microspheres. The amounts of zirconium dissolved were determined from weight losses of the Zircaloy tubing and. from analyses of the dissolution supernates.

The results from $\mathrm{ThO}_{2}$ dissolution tests at given $\mathrm{HNO}_{3}$ concentrations show that the amounts of thorium dissolved in $1 \mathrm{~h}$ first increase to a maximum and then decrease as the initial Hr concentrations are increased. The maximum occurs at $\mathrm{HF}$ concentrations between 0.04 and $0.06 \mathrm{M}$, and the amounts of thorium dissolved at these maximums are almost constant at about 1.0 millimole. Figure 3.1 shows this effect in $12.0 \mathrm{M} \mathrm{HNO}_{3}$. The apparent decrease in ThO dissolved in I h at $\mathrm{HF}$ concentrations $>0.06 \mathrm{M}$ is due to precipitation of $\mathrm{ThF}_{4}$ (see Sect. 3. . 3). Evidence for this precipitation can be seen (Table 3.1) in tests made with $12.0 \mathrm{M} \mathrm{HNO}_{3}$. Without $\mathrm{Al}\left(\mathrm{NO}_{3}\right) 3^{\prime}$ the final HF concentrations were significantIy less than the initial FF concentrations in tests where initial concentrations were $20.04 \mathrm{M}$. The decreases in HF concentration are accompanied by decreases in dissolved thorium concentrations. In tests with $\mathrm{Al}\left(\mathrm{NO}_{3}\right)_{3}$, the amounts of thorium in solution increase to the same maximum of about 1.0 millimole; however, there is no decrease in the amounts of thorium or fluoride in solution at initial HF concentrations $>0.06 \mathrm{M}$. Tests at other $\mathrm{HNO}_{3}$ concentrations gave results similar to the results obtained for $12.0 \mathrm{M} \mathrm{HNO}_{3}$. The 


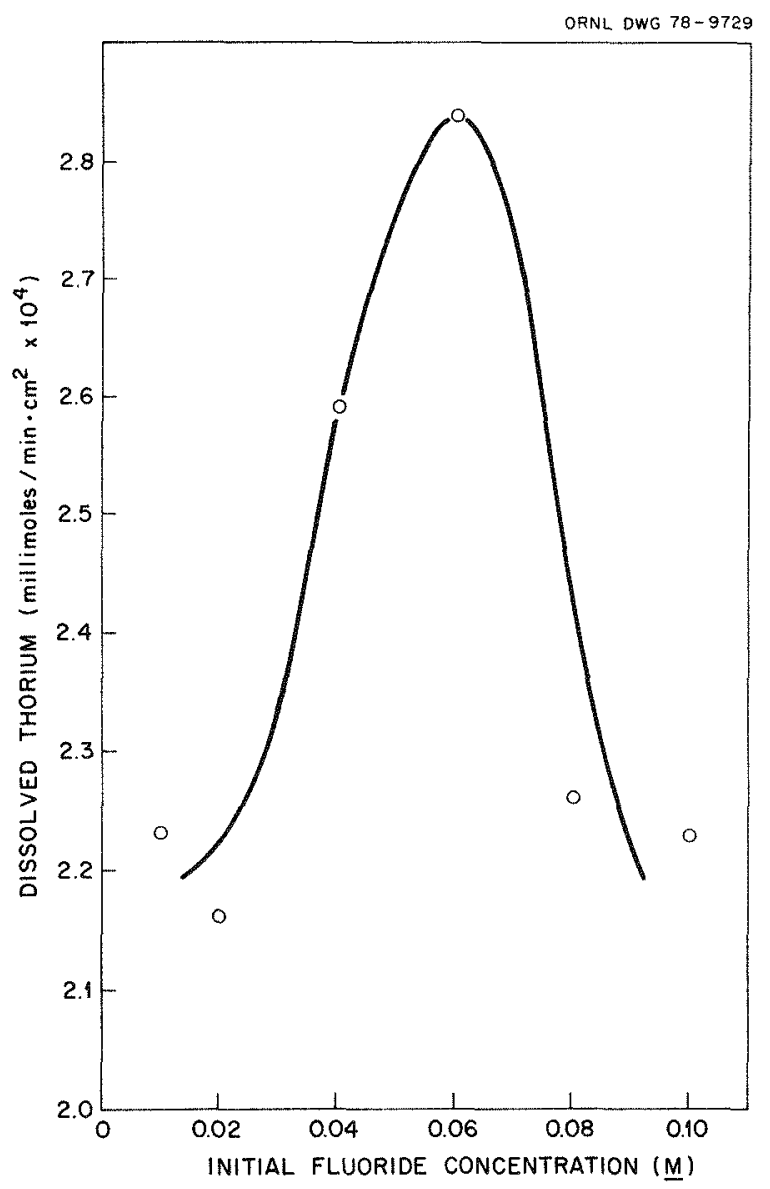

Fig. 3.1. Effect of initial fluoride concentration on thoria dissolution rate in $12 M \mathrm{HNO}_{3}$ at $100^{\circ} \mathrm{C}$

Table 3.1. Dissolution ${ }^{a}$ of $\mathrm{ThO}_{2}$ microspheres in $12.0 \mathrm{M} \mathrm{HNO}_{3}$ with 0.01 to $0.1 M$ initial $\mathrm{HF}$ concentrations both with and without $0.01 \mathrm{MAl}\left(\mathrm{NO}_{3}\right)_{3}$

\begin{tabular}{cccccc}
\hline \multirow{2}{*}{$\begin{array}{c}\text { Initial } \\
\mathrm{HF}\end{array}$} & \multicolumn{2}{c}{ Without $\mathrm{Al}\left(\mathrm{NO}_{3}\right)_{3}$} & & \multicolumn{2}{c}{ With $\mathrm{Al}\left(\mathrm{NO}_{3}\right)_{3}$} \\
\cline { 2 - 3 } \cline { 5 - 6 } $\begin{array}{c}\text { concentration } \\
(M)\end{array}$ & $\begin{array}{c}\text { Final } \\
\mathrm{HF} \\
\text { concentration } \\
(M)\end{array}$ & $\begin{array}{c}\text { Dissolved } \\
\text { thorium } \\
\text { (millimoles) }\end{array}$ & & $\begin{array}{c}\text { Final } \\
\mathrm{HF} \\
\text { concentration } \\
(M)\end{array}$ & $\begin{array}{c}\text { Dissolved } \\
\text { thorium } \\
\text { (millimoles) }\end{array}$ \\
\hline 0.01 & 0.011 & 0.806 & & 0.010 & 0.715 \\
0.02 & 0.019 & 0.780 & & 0.020 & 1.017 \\
0.04 & 0.024 & 0.935 & & 0.039 & 1.168 \\
0.06 & 0.010 & 1.025 & & 0.062 & 1.030 \\
0.08 & 0.025 & 0.814 & & 0.077 & 1.056 \\
0.10 & 0.022 & 0.806 & & 0.102 & 1.008 \\
\hline
\end{tabular}

${ }^{a}$ Dissolutions at $100^{\circ} \mathrm{C}$ for $1 \mathrm{~h}$ with $0.5 \mathrm{~g}$ of $\mathrm{ThO}_{2}$ microspheres in $10 \mathrm{ml}$ of dissolvent.

absence of precipitation in tests with $\mathrm{AI}\left(\mathrm{NO}_{3}\right)_{3}$ present results from the stability constant for $\mathrm{AlF}^{2+}$ being six orders of magnitude ${ }^{10}$ greater than that for ThF $4^{\circ}$ Similar dissolution rate maxima have been reported previous 1 . 5

The dissolution results for Zircaloy-4 were different from those for tho in that the rate continuously increased with initial HF concentration and no zirconium precipitation occurred. Log $-\log$ plots of zirconium dissolution rates at $100^{\circ} \mathrm{C}$ vs initial $\mathrm{HF}$ concentrations in 4.0 , 8.0 , 
and $12.0 \mathrm{M} \mathrm{HNO}_{3}$ are show in Fig. 3.2. The lines in the figure can be defined by equations of the form

$$
\log \text { rate }=n \log [H F]_{\text {init }}+\log \mathrm{k}
$$

or

$$
\text { rate }=k[H F]_{\text {init }}^{\mathrm{n}},
$$

where $n,\left[\mathrm{HF}^{\prime}\right]_{\text {init, }}$ and $\mathrm{k}$, respectively, denote order of reaction with respect to HF concentration, initial HF concentration, and dissolution rate constant. The order of reaction with respect to $\mathrm{HF}$ concentration is determined from the slope of the lines in Fig. 3.2 to be 1.0 , and the individual equations for the lines are:

$$
\begin{aligned}
& \text { rate }=7.3 \times 10^{-3}[\mathrm{HF}]_{\text {init }}\left(4.0 \mathrm{M} \mathrm{HNO}_{3}\right), \\
& \text { rate }=1.0 \times 10^{-2}[\mathrm{HF}]_{\text {init }}\left(8.0 \mathrm{M} \mathrm{HNO}_{3}\right), \\
& \text { rate }=1.3 \times 10^{-2}[\mathrm{HF}]_{\text {init }}\left(12.0 \mathrm{M} \mathrm{HNO}_{3}\right) .
\end{aligned}
$$

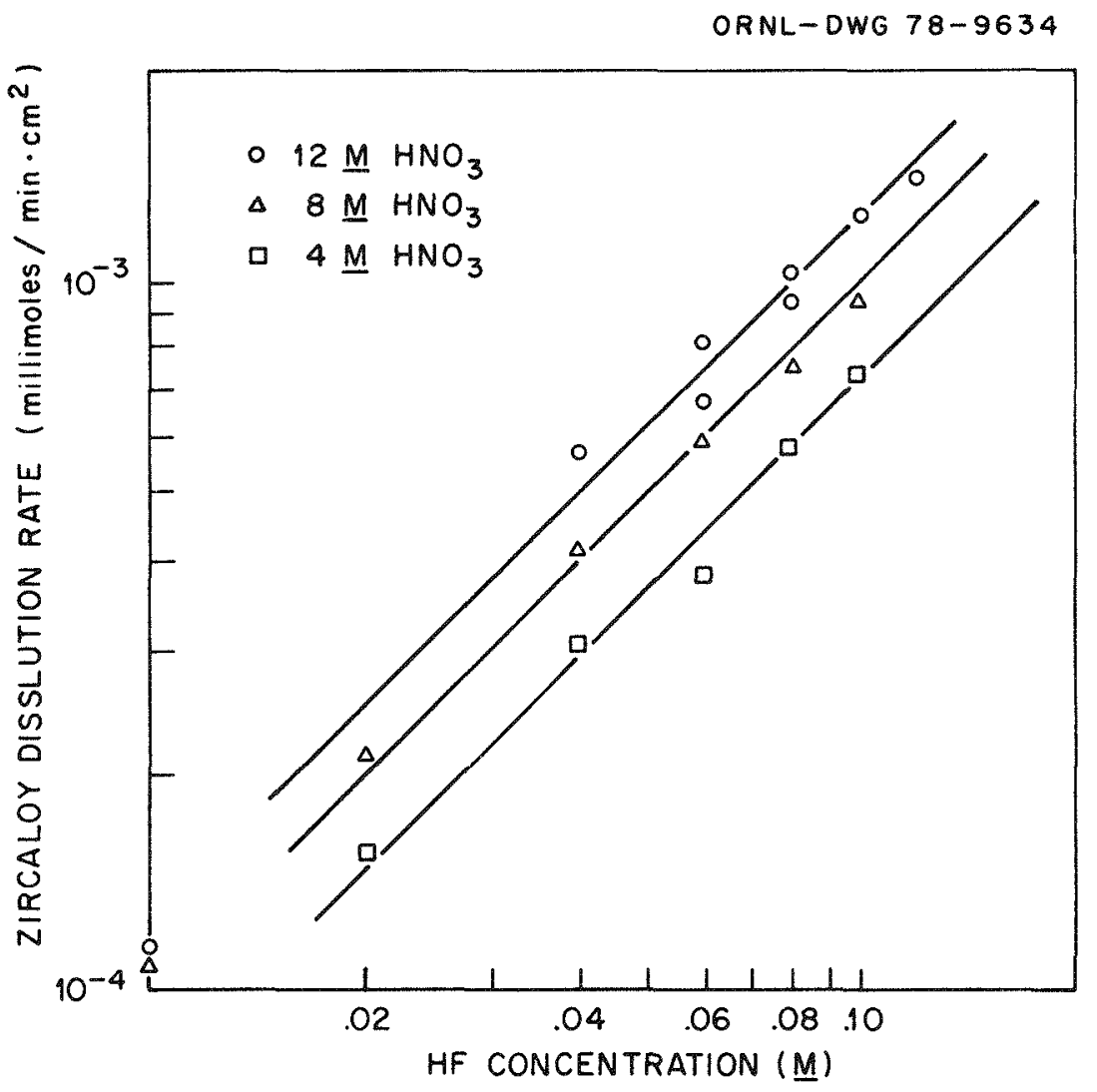

Fig. 3.2. Dissolution rate of Zircaloy-4 in 4.0, 8.0 , and $12.0 \mathrm{MHNO}_{3}$ as a function of HF concentration at $100^{\circ} \mathrm{C}$.

The dissolution rates (millimoles $/ \mathrm{min} \cdot \mathrm{cm}^{2}$ ) can additionally be defined in terms of [HF] init and hydrogen ion activity, $a_{H^{+}}$, by the single equation

$$
R=4.8 \times 10^{-3}[\mathrm{HF}]_{\text {init }} \mathrm{a}_{\mathrm{H}^{+}} \mathrm{O}^{2} \text {. }
$$

This equation represents the data plotted in Fig. 3.2 with a coefficient of correlation greater than 0.98. The dissolution rate dependence on $\mathrm{HF}$ concentration indicated above does not necessarily mean that associated HF molecular species are involved in the dissolution mechanism. It 
is more likely that free $\mathrm{F}^{-}$ions are involved and that the concentrations of $\mathrm{F}^{-}$ions are determined by the amounts of HF added and the stable metal-fluoride complexes formed. These results help predict acid concentrations to optimize $\mathrm{ThO}_{2}$ and to minimize Zircaloy dissolution, for example (Fig. 3.3), the dissolution rate of zircaloy-4 in $12.0 \mathrm{M} \mathrm{HNO}_{3}$ increases much faster with increasing $\mathrm{HF}$ concentration than does the dissolution rate of $\mathrm{ThO}_{2}$.

ORNL-DWG 78-9632

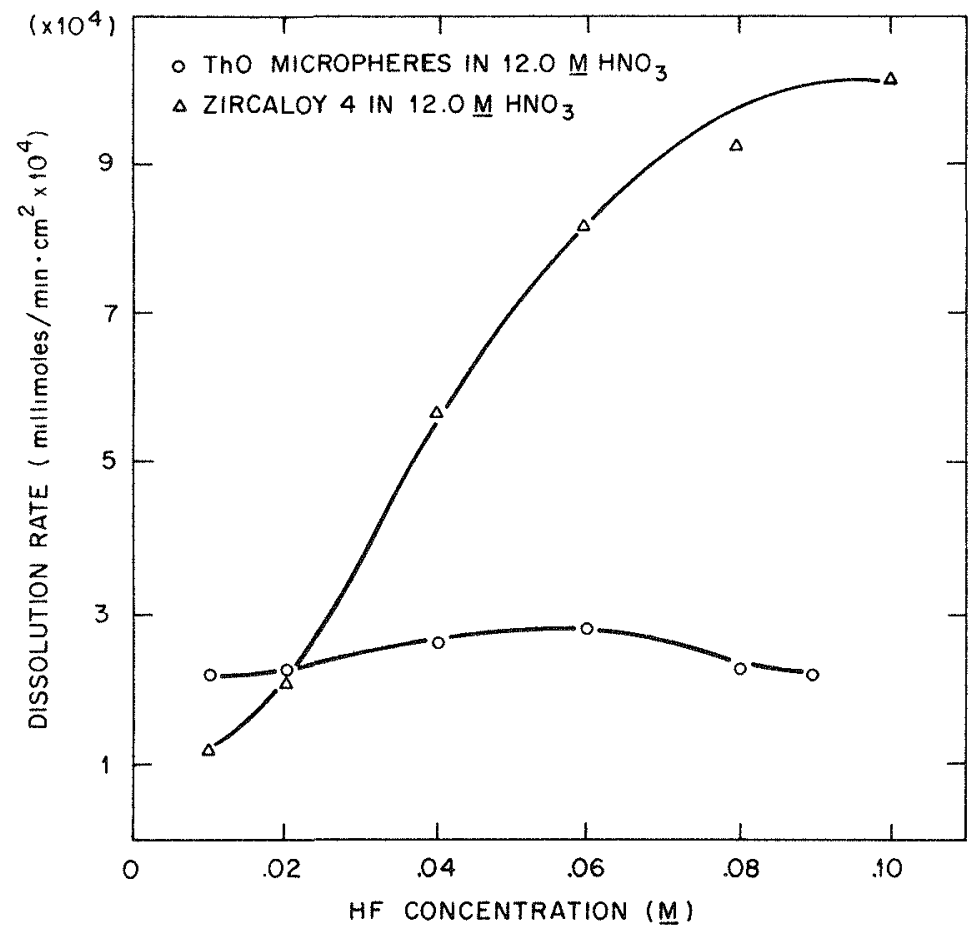

Fig. 3. 3. Zircaloy-4 and $\mathrm{ThO}_{2}$ dissolution rates as a function of $\mathrm{HF}$ concentration in 12. $\mathrm{M} \mathrm{M} \mathrm{HNO}_{3}$ without $\mathrm{AI}\left(\mathrm{NO}_{3}\right)_{3}$.

To obtain the greatest dissolution of $\mathrm{ThO}_{2}$ with a minimum dissolution of Zircaloy, the dissolution step should operate with a low HF activity. This low activity could be attained either by using a low HF concentration or by using complexing reagents such as aluminum, zirconium, or thorium at higher total HF concentration. Additional studies in this area are in progress.

\subsubsection{Process development tests}

D. O. Campiell and S. R. Buxton (Chemical Technology Division, ORNL)

Effect of dissolved zirconium on dissolution rate of thoria. The effect of dissolved zirconium on the dissolution rate of thoria pellets has been studied further, and results are summarized in Fig. 3.4. Data were reported previously for pellets as received; ${ }^{11}$ these results have been extended and recalculated to account for the decrease in the geometric surface area of the pellet as it is progressively dissolved. The thoria (curve B, Fig. 3.4) is of somewhat uncertain history; however, it is believed to be derived from the oxalate precipitation of a purified nitrate solution, with peliets pressed with a binder and fired at $1600^{\circ} \mathrm{C}$ in an atompshere containing hydrogen. The surface area has been determined to be $0.003 \mathrm{~m}^{2} / \mathrm{g}$; porosity is nonuniformly distributed, with one end being relatively pore-free.

These pellets dissolve more readily after they are fired at $1400^{\circ} \mathrm{C}$ in air for $5 \mathrm{~h}$; dissolution rate data for such air-fired pellets are shown in curve $A$ of Fig. 3.4. 


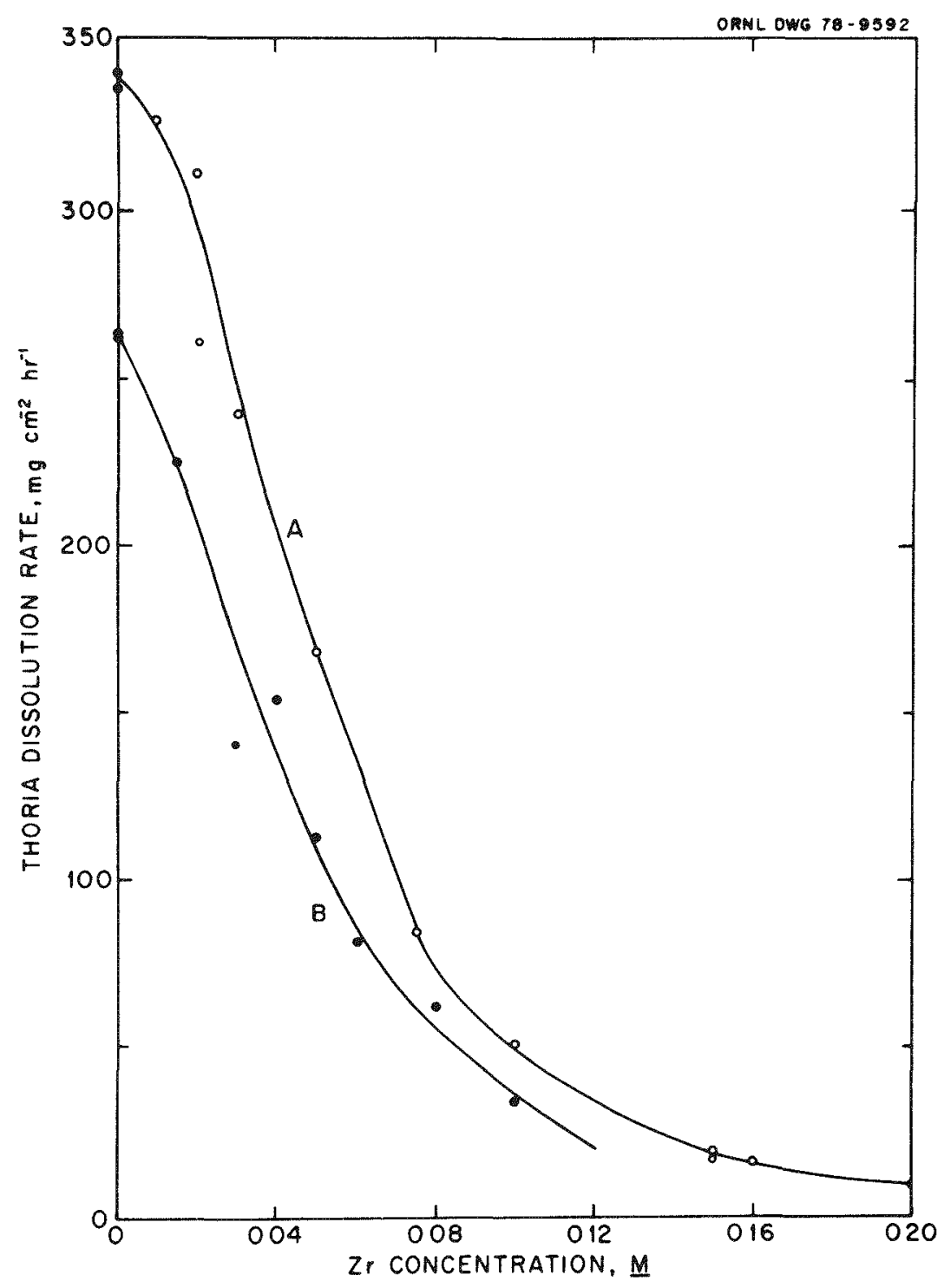

Fig. 3. 4. Dissolution rate of $\mathrm{ThO}_{2}$ pellets in $13 \mathrm{M} \mathrm{HNO}_{3}-0.04 \mathrm{M} \mathrm{NaF}$ containing zirconium added as zirconium oxynitrate; curve $B$, as received pellets 0.75 in. in length and diameter; curve A, after firing in air at $1400^{\circ} \mathrm{C}$ for $5 \mathrm{~h}$.

Effect of complexing of fluoride on stainless steel corrosion. The standard procedure (Thorex process) for dissolving thoria has been to add aluminum to a nitric acid solution containing fluoride; the purpose of the aluminum was to complex the fluoride and reduce the corrosive effect on the stainless steel process equipment. Since both thorium and zirconium also complex fluoride, their effect has been studied briefly.

Figure 3.5 shows the results of short-term corrosion tests with type 304L stainless steel tubing in $13 \mathrm{M} \mathrm{HNO}{ }_{3}-0.04 \mathrm{MNaF}$ containing various metal ion complexants. The zirconium was added as zirconium oxynitrate solution. At equal concentrations, thorium is much less effective than aluminum and zirconium is much more effective, in agreement with the known stability constants of the fluoride complexes. For equal protection against corrosion, $0.03 \mathrm{M}$ zirconium is comparable to the $0.1 \mathrm{M}$ aluminum previously used. Thus, zirconium appears to be a better corrosion inhibitor than aluminum. High thorium concentrations can be maintained during fuel dissolution to minimize attack on the zircaloy cladding; and this, along with the small amount of 
zirconium that dissolves from the cladding, would be expected to provide adequate protection to the stainless steel equipment. Thus, the addition of aluminum would not be required when dissolving zircaloy-clad thoria fuels if a heel of dissolver solution is present.

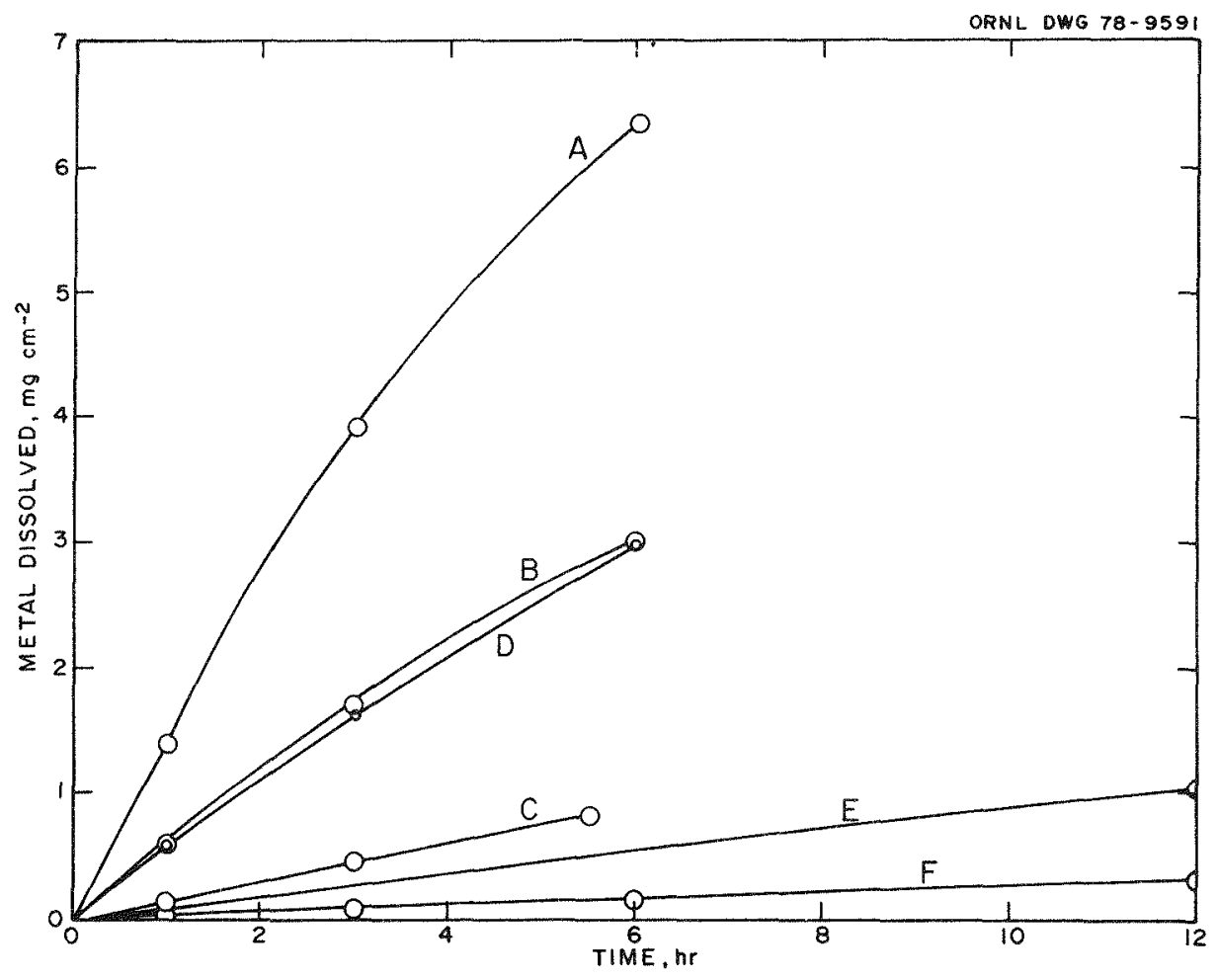

Fig. 3.5. Corrosion of type 304L stainless steel tubing in boiling $13 \mathrm{MHNO}-0.04 \mathrm{MNaF}$ (curve A) plus $0.1 M$ thorium (curve $B$ ), plus $0.1 M$ aluminum (curve $C$ ), and $0.015,0.04$, or O. I $M$ zirconium (curves $D$, E, and $F$ ).

\subsubsection{Solubility studies}

F. J. Smith (Chemistry Division, ORNL) and D. R. McTaggart (Chemical Technology Division, ORNL)

The equilibrium solubilities of thorium, uranium, and zirconium in nitric acid-hydrofluoric acid solutions are being studied (I) to provide information on solubility limits so that precipitates can be avoided during thoria dissolution and (2) to provide fundamental information on solution interactions and complexes in order to obtain a greater understanding of the driving forces governing dissolution. In the initial studies, thorium fluoride solubility is being measured as a function of the Th:F ratio in nitric acid solutions at $25^{\circ} \mathrm{C}$. A series of experiments has been conducted in which thorium nitrate was added to either 4, 8, or $13 \mathrm{M}$ HiNo 3 solutions containing a fluoride concentration between 0.001 and $0.5 \mathrm{M}$. Small additions of thorium nitrate produced a precipitate that has been tentatively identified as $\mathrm{ThF}_{4} \cdot 5 \mathrm{H}_{2} \mathrm{O}$. Larger additions of thorium nitrate caused dissolution of part or all of the precipitate. Log-Iog plots of the total fluoride in solution vs the total thorium in solution gives a U-shaped solubility curve, which is indicative of the presence of complexes of the type $\mathrm{ThF}_{\mathrm{X}}^{+}{ }^{+(4-x)}$. The curves are being interpreted in terms of the equilibria involving these complexes and the solubility product for the solid $\mathrm{ThF}_{4}$. The effect of the varying total nitrate concentration inherent in these experiments is also being evaluated. Further studies will extend to higher temperatures. 


\subsection{Hot-CelI Experiments}

V. C. A. Vaughen, J. F. Goode, R. G. Stacy, E. C. Hendren, J. R. Travis, and C. S. Webster (Chemical Technology Division, ORNL)

\subsubsection{Exploratory tests}

A single $114 \mathrm{~mm}(4.5 \mathrm{-in}$ ) - Iong Zircaloy-clad fuel rod that had been irradiated in the Chalk River, ontario, NRX reactor to about 20,000 MWd/t in 1960-1961 was sheared into pieces about

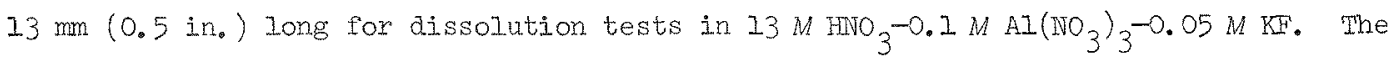
$\left(\mathrm{Th}_{0.96} \mathrm{U}_{0.04}\right)_{2}$ pellet fragments and the cladding were leached three times for $2 \mathrm{~h}$ at about $95^{\circ} \mathrm{C}$; the solutions were centrifuged at the conclusion of each leach and then decanted, and fresh acid was added to the solids.

The results of the analyses indicated that the three leaches dissolved most of the mixed oxide; data further indicated that the cladding (when subsequently dissolved in $6 \mathrm{MNH} \mathrm{NF}_{4} \mathrm{M} \mathrm{MH}_{4} \mathrm{NO}_{3}$ ) contained about $1.40 \%$ of the uranium and $0.04 \%$ of the thorium in the rod. The dissolution was peculiar but typical of thorium in that one segment containing about $1.3 \mathrm{~g}$ of fuel survived the first two leaches without dissolving all of the (Th, U) $\mathrm{O}_{2}$; then a third leach dissolved that oxide. The insoluble residue from the dissolution contained less than $0.01 \%$ of the thorium or uranium. From 1 to $3 \%$ of the airconium from the cladding was dissolved by each pass of dissolvent; sparksource spectrometric analysis of the first two leach solutions indicated concentrations of about $250 \mathrm{\mu g} / \mathrm{ml}$ of "normal" zirconium plus about 30 to $70 \mathrm{\mu g} / \mathrm{mI}$ of fission product zirconium.

The Zircaloy cladding of the $(\mathrm{Th}, \mathrm{U}) \mathrm{O}_{2}$ contained about $9 \%$ of the tritium in the rod; this quantity is similar to other water-coolec Zircaloy-clad fuels.

Voloxidation and dissolution of $(T h, U) O_{2}$. Six 1I4-mm (4.5-in.)-Iong, stainless-steel-clad $\left(\mathrm{Th}, \mathrm{U} \mathrm{O}_{2}\right.$ rods, also irradiated in the $\mathbb{N W X}$ reactor to a nominal peak burnup of 20 , 000 MWd/t, were sheared into 3 mm ( $\left.1 / 8-i n_{0}\right)$ lengths to break up and dislodge the (Th, U) $\mathrm{O}_{2}$ fuel. After removing the clading, (Th, $U)_{2}$ was divided into two portions: one portion was heated in air at $600^{\circ} \mathrm{C}$ for about $2 \mathrm{~h}$ while being rotated at about $12 \mathrm{rpm}$; the other portion was dissolved without oxidation. Voloxidation released about $3 \%$ of the ${ }^{85} \mathrm{Kr}$ and about Io\% of the tritium in the fuel.

The oxidation apparently had little effect on the dissolution of the (Th, U) $\mathrm{O}_{2}$; three $2-\mathrm{h}$ leaches left less than $0.01 \%$ of the thorium and about $0.03 \%$ of the uranium undissolved.

\section{RFERENCES FOR SECTION 3}

1. A. E. Hutton, Dissolution of HTGR Fuel, GAmA-13278 (September 1975), pp. 7-130.

2. M. E. Shying, T. M. Florence, and D. J. Carswell, "Oxide Dissolution Mechanisms I: The Role of Fluoride in the Thoria/Nitric/Hyarofluoric Acia System," J. Inorg. Nucl. Chem. 32: $3493(1970)$.

3. M. E. Shying, T. M. Florence, and D. J. Carswe11, "Oxide Dissolution Mechanisms II: A Mechaniss for the Thoria/Nitric/Hydrofluoric Acid. System, " J. Inorg. Nucl. Chem. 34: 213 (1972).

4. R. I. Moore et al., "Nitric Acid Dissolution of Thorium," Ind. Eng. Chem. 49: 885 (1957).

5. W. D. Bond, Dissolution of Sintered Thorium-Uranium Oxide Fuel in Nitric Acid-Fluoride Solutions, ORNI-2519 (october 1958).

6. K. Kawamura, J. Isono, and T. Takeuchi, "A Kinetic Study on the Dissolution of Thorium Oxide in Nitric Acid," Trans. Nat. Res. Inst. Metals 3: 41 (1961).

7. M. S. Farrell and S. R. Isaacs, Laboratory Development of the Grind-Leach Process for the FICCR Fuel Cycle. Part 1. Dissolution of Urania-Thoria Fuel Particles in Nitric Acid Solutions, AAEC/E-143 (September 1965). 
8. T. Takeuchi, C. K. Hansen, and M. E. Wadsworth, "Kinetics and Mechanisms of the Dissolution of Thorium Oxide in Hydrofluoric Acid and Nitric Acid Mixtures," I. Inorg. Nucl. Chem. 33: 1089 (1971).

9. I. M. Ferris, J. W. Ullman, and C. T. Thompson, Dissolution of Sol-Gel-Derived and Arc-Fused Tho - UO $_{2}$ Fuel Particles in HNO 3 HF Solutions: Laboratory Studies, ORNI/TM-857 (May 1964).

10. I. G. Sillin and A. E. Martell, Stability Constants of Metal-Ion Complexes, The Chemical Society, London (1964).

11. B. I. Vondra et aI., Alternate Fuel Cycle Technologies/Thorium Fuel Cycle Technology Programs Quarterly Report for Period January 1 to March 31, 1978, ORNL/TM-6307 (May 1978), p. 3-7. 


\section{OFE-GAS CONTAINMENT}

This activity is concerned with the development of the noble gas and carbon-14 selective absorption process on an accelerated basis. Funding is provided for the expansion of pilot plant development, the formulation of plant engineering design criteria, a system reliability analysis, a study of the chemical effects of impurities in the fluorocarbon solvent, and an extended investigation of the distribution coefficients of the noble gases in the fluorocarbon solvent. Tests of a solid sorbent system for the retention of tritium from the voloxidizer off-gas in the presence of other constituents, such as iodine, are also reported.

\section{I Fluorocarbon Absorption Studies \\ W. S. Groenier (Chemical Technology Division, ORNL)}

The major emphasis during the past quarter has been on an evaluation of the combination absorber/fractionator/stripper column of the selective absorption pilot plant. Modeling studies of the fractionator and chemical studies to measure impurity effects and distribution coefficients are also reported.

\subsection{Fluorocarbon absorption process development ${ }^{*}$}

M. J. Stephenson and B. E. Kanak (ORGDP)

Pilot plant operation. The combination absorber/fractionator/stripper column has been in operation for nearly three months. Figure 4.1 is a photograph of the column taken during installation. The theory of this unusual piece of equipment has been described previously. 1,2 An external gamma scanner was added to the column as an essential piece of analytical equipment to allow direct measurement of the concentration profiles within the different sections of the column. Tests have been conqucted using both ${ }^{85} \mathrm{Kr}$ and $133_{\mathrm{Xe}}$ isotopes. Figure 4.2 is a typical ${ }^{85} \mathrm{Kr}$ gamma profile of the operating column demonstrating the individual column functions. All gamma counts are relative to the process feed point (count ratio of 1.0 at 15 ft from the bottom of the column). The count ratio is therefore equal to the total amount of krypton at each column position relative to the amount at the feed position. The gamma activity drops sharply in the absorber section (column positions 15 through 24) as krypton is removed from the upflowing feed gas by the downflowing solvent. On the other end of the column, the stripper section (column positions 0 through 4 ) is also characterized by a sharp drop in activity as the krypton is desorbed from the downflowing solvent by the upflowing solvent vapor. The regenerated solvent leaves the reboiler and is recycled to the absorber section. Very little variation in krypton

\footnotetext{
* Jointly funded by the Alternate Fuel Cycle Technologies Program and the Advanced Fuel Recycle Program.
} 


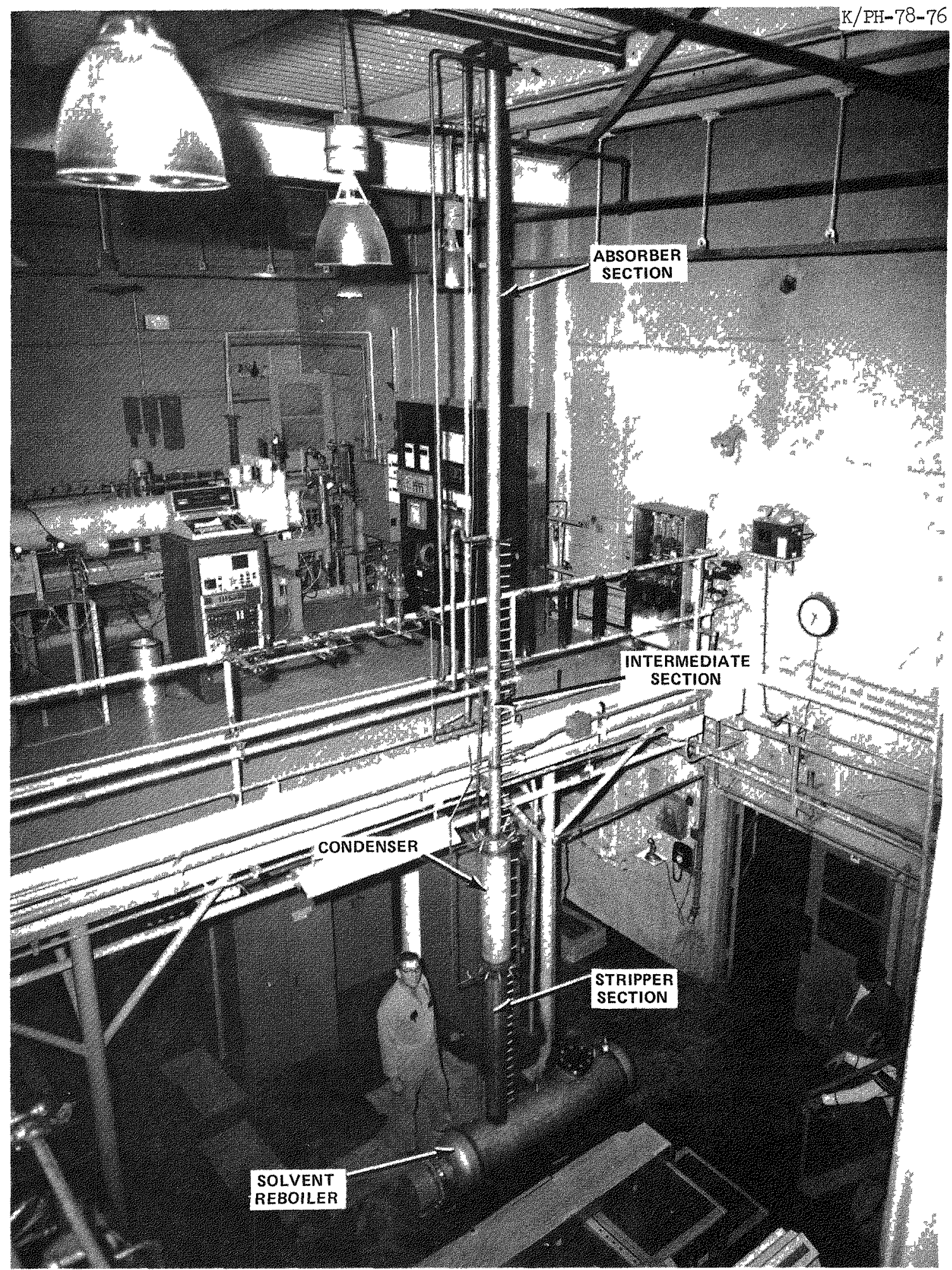

Fig. 4.1. Overall view of the combination absorber/fractionator/ stripper column during installation. 


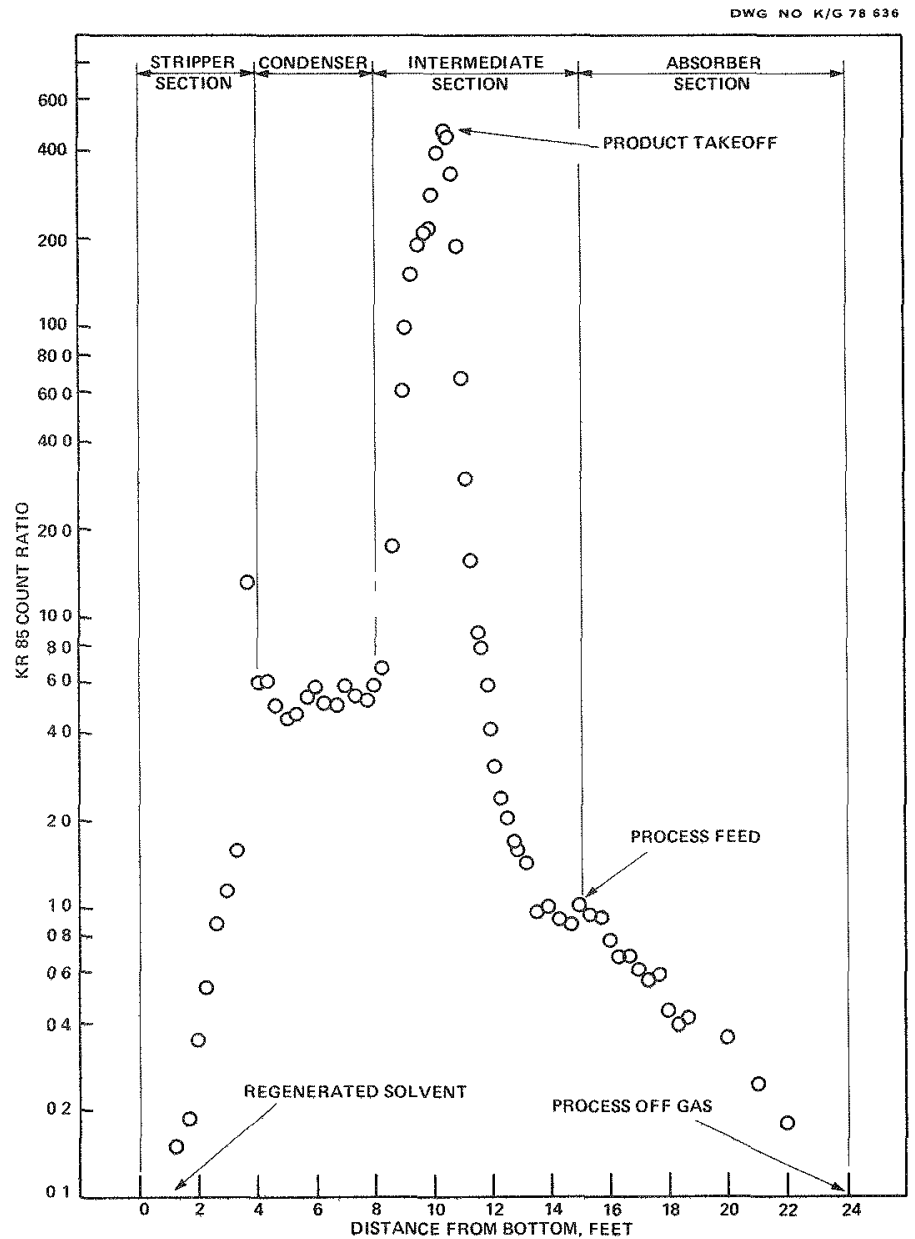

Fig. 4.2. Typical distribution of ${ }^{85} \mathrm{Kr}$ in the combination column.

inventory is found in the condenser section (column positions 4 through 8), although some activity buildup caused by cold condensate reflux can be observed in Fig. 4.2 just below the condenser. The concentrated product is collected at an intermediate section takeoff point located approximately as show where the peak krypton concentration occurs. During tests with a feed gas containing 15 ppm krypton, a product stream containing up to $42.9 \% \mathrm{krypton}$ was obtained. The average product contained approximately $10 \%$ krypton. When combined with the final product purification equipment, products in excess of $90 \%$ krypton are attainable.

The flow rate and temperature of the solvent dictate the location of the concentration peak in the intermediate section of the combination column. Operating conditions must be adjusted to position this peak at an internal gas witharawal point. Also, the total column pressure must be accurately controlled. If not, the concentration peak will tend to smear across the intermediate zone and prevent the collection of a highly concentrated product. The rate of product withorawal also affects the product concentration. If the withrrawal rate is too large, the product will be dilute.

operation of the combination column will continue until enough quantitative information has been obtained to allow comparison with the standard three-column version of the absorption 
process. Other work is currently under way to further evaluate type 13x molecular sieves for removing solvent vapor from the process off-gas and product streams, particularly with regard to methods for regeneration.

Process application. The fractionation step is conducted under conditions that result in a rather sharp temperature gradient within the intermediate packed column. An analysis of the fractionator, therefore, is inherentIy complex because simultaneous mass and heat transfer must be accounted for, and these two transport mechanisms exhibit a high degree of interaction. A dispersed plug-flow packed-column modeI has been derived that adequately describes the pilot plant fractionator. A formal presentation of the model will soon be available. ${ }^{3}$ Ignoring radial gradients and changes with time, the axial and interfacial gas phase mass fluxes for a particular component, $j$, are related by

$$
\frac{\partial N N_{z}}{d z}=-N_{j i^{2}}
$$

where

$N_{j z}=$ axia.I mass flux of component $j$, Ib. mole $h^{-1} \mathrm{ft}^{-2}$;

$\mathbb{N}_{j i}=$ interfacial mass flux of component $j$, Ib. mole $\mathrm{h}^{-1} \mathrm{ft}^{-2}$;

$a=$ effective interfacial mass transfer area, $\mathrm{ft}^{-1}$;

$z=$ axial position in column, ft.

The total mass transport of component $j$ from the bulk gas to the gas-liquid interface in the column increment $d z$ is given as

where

$$
\mathbb{N}_{j i} a=R_{j} F_{G j} a \ln \left[\frac{R_{j}-y_{j i}}{R_{j}-y_{j}}\right] \text {, }
$$

$R_{j}=$ ratio of component $j$ mass flux to the total mass flux;

$F_{G j}=$ gas phase mass transfer coefficient, $1 \mathrm{~b} \cdot$ mole $\mathrm{h}^{-1} \mathrm{ft}^{-2}$;

$\mathrm{y}_{j i}=$ interfacial gas phase composition, mole fraction;

$\mathrm{y}_{\mathrm{j}}=$ bulk gas composition, mole fraction.

The axial mass flux is given by

$$
\mathbb{N}_{j z}=-E_{z} \frac{d M_{j}}{d z}+y_{j} G
$$

where

$E_{z}=$ axial mass dispersion coefficient, $\mathrm{ft}^{2} / \mathrm{h}$

$M_{j}=$ molar concentration of component $j, I b \cdot$ mole $/ \mathrm{ft}^{3}$;

$G=$ total gas flow rate, lo. mole $\mathrm{h}^{-1} \mathrm{ft}^{-2}$.

The total sensible heat flux from the bulk gas to the interface is

$$
q_{G S}=\frac{\xi}{1-e^{-\xi}} h_{G}\left(t_{G}-t_{i}\right)
$$

In this equation, the term $\xi$ is defined as

$$
\xi=\sum_{k}\left(\mathbb{N}_{k i} C_{k K} / h_{G}\right) \text {, }
$$

where

$q_{G s}=$ sensible heat flux, Btu $h^{-1} \mathrm{ft}^{-2}$

$\mathrm{N}_{\mathrm{ki}}$ = interfacial mass flux of each component $\mathrm{k}, 1 \mathrm{~b} \cdot$ mole $\mathrm{h}^{-1} \mathrm{ft}^{-2}$;

$\mathrm{C}_{\mathrm{k}}=$ heat capacity of each component $\mathrm{k}$, Btu $\mathrm{Ib} \cdot \operatorname{mole} \mathrm{e}^{-1}{ }^{\circ} \mathrm{F}^{-1}$; 
$h_{G}=$ gas phase heat transfer coefficient in the absence of simultaneous mass transfer, Btu $\mathrm{h}^{-1} \mathrm{ft}^{-2}{ }^{\circ} \mathrm{F}^{-1}$;

$\mathrm{t}_{\mathrm{G}}=$ bulk gas temperature, ${ }^{\circ} \mathrm{F}$;

$\mathrm{t}_{i}=$ interfacial temperature, ${ }^{\circ} \mathrm{F}$.

In addition to a convective heat transfer term, the sensible heat flux includes the sensible heat transferred by the dispersive movement of mass through the bulk gas-interface temperature difference. The term $\xi /\left(1-e^{-\xi}\right)$ is the Ackermann correction to the heat transfer coefficient to account for simultaneous mass transfer.

Similar mass and heat transfex equations exist for the liquid phase. Evaluation of the interfacial conditions depends on the postulate that static equilibrium conditions exist at the gas-liquid interface. The interfacial temperature is calculated from

$$
t_{i}=t_{L}+\frac{1}{h_{L}{ }^{a}} \sum_{k}\left(\bar{H}_{k i}-H_{G}\right) \frac{d\left(G y_{k}\right)}{d z}-\frac{G}{h_{L}{ }^{a}} \sum_{k} y_{k} C_{k} \frac{d t_{G}}{d z},
$$

where

$\mathrm{t}_{\mathrm{I}}=$ bulk liquid temperature, ${ }^{\circ} \mathrm{F}$;

$\mathrm{h}_{\mathrm{I}_{1}}=$ liquid heat transfer coefficient, Btu h $\mathrm{h}^{-1} \mathrm{ft}^{-2}{ }^{\circ} \mathrm{F}^{-1}$;

$\overline{\mathrm{H}}_{\mathrm{ki}}=$ partial enthalpy of each component $\mathrm{k}$ in solution at concentration $\mathrm{x}_{\mathrm{ki}}$ and temperature $t_{i}, \mathrm{Btu} / \mathrm{lb} \cdot \mathrm{mole}$;

$\mathrm{H}_{\mathrm{G}}=$ enthalpy of each component $\mathrm{k}$ in gas phase at temperature $t_{G}$, Btu/Ib.mole.

The rate of solvent vapor condensation in the fractionator column is determined by the rate of sensible heat and mass transfer to the interfacial surface. Removal of heat may be so rapid that mass diffusion cannot keep up, and fog droplets may form in the gas phase. The model of a direct-contact condenser/absorber that allows for a saturated gas is somewhat more complicated than for the case where the gas phase remains superheated, since condensation takes place both at the cold interface and in the main body of the gas-vapor mixture. The fractionator model incorporates a fog mechanism, and the gas phase temperature gradient is given in this case by

where

$$
\frac{d t_{G}}{d . z_{I}}=\frac{I}{G_{m}}\left\{\frac{\lambda_{S} \alpha R_{S} F_{G S}{ }^{2}}{1-\alpha} \text { In }\left[\frac{R_{S}-y_{S i}}{R_{S}-y_{S}}\right]-\frac{\xi}{1-e^{-\xi}} h_{G} a_{G}\left(t_{G}-t_{i}\right)\right\}
$$

$\alpha=$ fraction of condensate as a mist;

$\lambda_{S}=$ heat of vaporization of solvent, Btu/Ib. mole;

$\mathrm{R}_{\mathrm{s}}=$ ratio of solvent mass flux to the total mass flux;

$\mathrm{F}_{\mathrm{Gs}}=$ solvent gas phase mass transfer coefficient, Ib. mole $\mathrm{h}^{-1} \mathrm{ft}^{-2}$;

$\mathrm{y}_{\mathrm{s}}=$ solvent mole fraction in bulk gas;

$\mathrm{y}_{\mathrm{si}}=$ solvent mole fraction at interface;

$\mathrm{C}_{\mathrm{m}}=$ mean heat capacity of gas phase, Btu $\mathrm{Ib} \cdot \operatorname{mole} \mathrm{e}^{-1}{ }^{\circ} \mathrm{F}^{-1}$.

The model seems to accurately represent the pilot plant fractionator column operation. A fit of the model to a typical set of pilot plant experimental data is given in Fig. 4.3. Both the krypton concentration and bulk temperature profiles are shown. For this particular run, the fractionator was operated at a total pressure of 100 psig, a feed flow rate of $9.261 \mathrm{~b} \cdot \mathrm{mole} / \mathrm{h}$, and a temperature of $-18.9^{\circ} \mathrm{F}$. The reboiler heat input was $26,000 \mathrm{Btu} / \mathrm{h}$ at a temperature of $87.9^{\circ} \mathrm{F}$. The model is being tested with about 40 sets of data collected over the past year. 

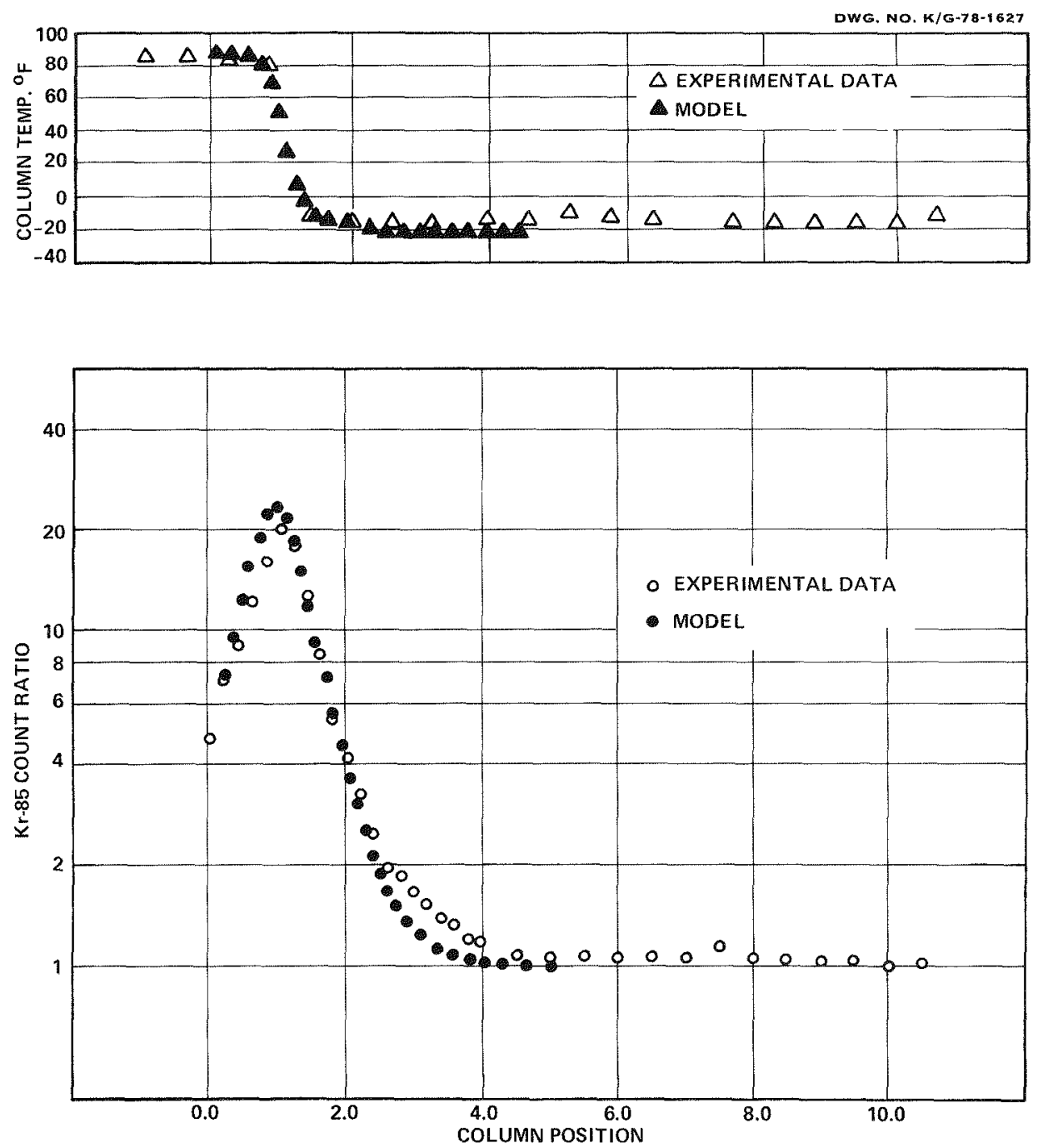

Fig. 4. 3. Comparison of fractionator model results with pilot plant data.

The stripper column operates essentially in an isothermal mode and is therefore a much simpler system to model than the fractionator. The fractionator model, however, can be used to describe the stripper operation.

\subsubsection{Chemical studies of contaminants in AFCT/TFCT off-gas processing}

I. M. Toth and D. W. Fuller (Chemistry Division, ORVI)

A study of the behavior of ammonia in Iiquid dichlorodifluoromethane (R-12 refrigerant) has been initiated to detemine the general physical and chemical properties of the solution and the ammonia liquid-vapor distribution coefficients. Ammonia has an absorption spectrum in the near-infrared range arising from vibrational overtone bands that occur mainly at 1500 , 1970, and $2250 \mathrm{~nm}$, thus permitting analytical determinations of ammonia concentrations in the liquid and vapor phases. Since these spectral bands are of the same origin as those of carbon dioxide, 4 we expect that the molar extinction coefficients will be similarly complex; in other words, they should vary with temperature, mole fraction, and liquid and vapor phase. 
Prior to a detailed examination of the ammonia distribution coefficients in $R-12$, we sought to determine the general physical chemical behavior of ammonia in $R-12$ between -40 and $+20^{\circ} \mathrm{C}$. Ammonia appears to be totally miscible in $\mathrm{R}-12$ above $0^{\circ} \mathrm{C}$, but below this temperature, a solubility limit is found which results in the formation of two liquid phases. Assuming that the molar extinction coefficients for ammonia are equivalent to those of the pure liquid phase and that there is no excess volume of mixing for the two liquids, the solubility of ammonia in $\mathrm{R}-12$ below $0^{\circ} \mathrm{C}$ is tentatively given by

$$
\log _{10}\left(\mathrm{x}_{\mathrm{NH}_{3}}\right)=2.276-743.4(1 / \mathrm{T})
$$

where $x$ is the ammonia mole fraction and $T$ is the Kelvin temperature. Although there is $a$ solubility limit for ammonia in R-12, the solubility is great enough at its minimum ( 12 mole \% at $-40^{\circ} \mathrm{C}$ ) to post few if any problems in off-gas treatment schemes. From a chemical viewpoint, however, ammonia presents compatibility problems with carbon dioxide since the two compounds react to form a white precipitate. More information on this chemical interaction will be presented in the future when interactive effects of the off-gas contaminant constituents have been investigated.

\subsubsection{Noble gas solubility studies}

J. H. Shaffer (Chemical Technology Division, ORNI)

This activity will provide a systematic evaluation of the solubility behavior of noble gases in R-12 refrigerant over a temperature range of about -30 to $+50^{\circ} \mathrm{C}\left(-25\right.$ to $\left.+122^{\circ} \mathrm{F}\right)$. Current studies have been limited to independent measurements of the distribution of krypton and xenon between the liquid and gas phases at infinitely dilute solute concentrations. The second phase of this experimental program will consist of studies on the effects of solute concentrations on solubility behavior.

As described previously, ${ }^{5}$ the experimental method is based on the direct measurement of gamma-ray intensities from ${ }^{85} \mathrm{Kr}$ (or ${ }^{13} 3_{\mathrm{Xe}}$ ) which emit from a sealed containment cylinder under equilibrium conditions. The shielded sodium iodide crystal, with a slit for collimation, can be precisely positioned along the vertical axis of the cylinder in its upright position. The crystal will yield constant count-rate data over a significant volume of either the gas or the liquid phase in the cylinder.

The experimental results reported in the previous progress report ${ }^{5}$ were biased by insufficient lead shielding around the circumference of the sodium iodide crystal. An additional 1-in. thickness of lead was required to correct this condition.

Values for krypton and xenon solubilities obtained thus far in the program are summarized in Table 4.1. Henry's Iaw was assumed for these infinitely dilute solute concentrations such that

$$
P_{i}=H_{i} X_{i}=Y_{i} P
$$

where

$P_{i}$ is the solute vapor pressure,

$X_{i}$ and $Y_{i}$ are the mole fractions of solute in the liquid and gas phases respectively,

$\mathrm{H}_{i}$ is the equilibrium coefficient for solute $i$ in the $\mathrm{R}-12$ solvent,

$P$ is the total pressure in the system. 
Table 4.1. Noble gas solubilities in Refrigerant-12

\begin{tabular}{ccccc}
\hline $\begin{array}{c}\text { Temperature } \\
\left({ }^{\circ} \mathrm{C}\right)\end{array}$ & $\begin{array}{c}\text { Pressure } \\
(\mathrm{atm})\end{array}$ & $\begin{array}{c}\text { Solvent density } \\
\text { ratio } \\
\text { (liquid/gas) }\end{array}$ & $\begin{array}{c}\text { Count-rate } \\
\text { ratio } \\
\text { (liquid/gas) }\end{array}$ & $\begin{array}{c}\text { Equilibrium } \\
\text { coefficient } \\
(\mathrm{atm})\end{array}$ \\
\hline & & Krypton & \\
10 & 4.178 & 55.798 & $0.486 \pm 0.001$ & $113.36 \pm 0.24$ \\
25 & 6.431 & 35.202 & $0.539 \pm 0.001$ & $121.94 \pm 0.25$ \\
30 & 7.352 & 30.378 & $0.556 \pm 0.002$ & $124.07 \pm 0.48$ \\
50 & 12.034 & 17.161 & $0.626 \pm 0.003$ & $129.24 \pm 0.57$ \\
& & & & \\
& & & & \\
25 & 6.431 & 35.202 & $0.224 \pm 0.001$ & $50.65 \pm 0.15$ \\
30 & 7.352 & 30.378 & $0.239 \pm 0.001$ & $53.33 \pm 0.30$ \\
50 & 9.481 & 22.769 & $0.269 \pm 0.002$ & $58.12 \pm 0.35$ \\
& 12.034 & 17.161 & $0.303 \pm 0.001$ & $62.64 \pm 0.23$ \\
\hline
\end{tabular}

Under these experimental conditions, the total pressure on the system is approximately that of the saturation vapor pressure of the R-12 solvent. Since the count-rate data are proportional to molar solute concentrations, the ratio of its mole fraction, $Y_{i} / X_{i}$, in the system can be expressed as

$$
\mathrm{Y}_{i} / \mathrm{X}_{i}=\left[\frac{(\text { count rate }) \text { gas }}{(\text { count rate }) \text { Iiquid }}\right]\left[\rho_{1 i q} / \rho_{\text {gas }}\right]_{\mathrm{R}-12} \text {, }
$$

where $p$ is the density of solvent in the designated phase. This expression assumes that the total molar concentration in either phase is essentially that of the solvent. The equilibrium coefficient, $H_{i}$, was calculated by the substitution of Eq. (4.10) into Eq. (4.9). Density values and saturation vapor pressures for R-I2 were obtained from Technical Bulletin I-12, E. I. Dupont de Nemours Company, 1956. The uncertainties assigned to the equilibrium coefficient values reflect variations in count-rate ratios from at least four independent solubility measurements at each temperature.

4.2 Tritium Retention from Voloxidizer Process off-Gas

W. S. Groenier (Chemical Technology Division, ORNI) and W. D. Holland (Tennessee Technological University)

The purpose of this activity is to determine the effect of iodine on the operation of a water vapor removal system for the treatment of voloxidizer off-gases. A 2-in.-diam by 30-in.-Iong bed of 1/16-in. -diam type 3A molecular sieve pellets is being used to remove water vapor from an air stream containing iodine. A series of experiments is being conducted at gas flow rates and iodine and water vapor concentrations designed to match the expected values of these parameters in a voloxidizer off-gas drying system.

The original bed has now been exposed to 40 loading and regeneration cycles. Total bed exposure time is $888 \mathrm{~h}$, consisting of $240 \mathrm{~h}$ during loading runs and $648 \mathrm{~h}$ during which the bed was loaded with iodine and water and awaiting regeneration.

No major changes in bed performance have been noted in the more recent runs, although there seems to be a slight decrease in performance compared with the first few runs. For instance, water loading at breakthrough has been approximately $140 \mathrm{~g}$ in the later $r$ uns as opposed to 
$4-9$

approximately $160 \mathrm{~g}$ found in earlier runs. Also, outlet dew points in the range of -40 to $-50^{\circ} \mathrm{C}$ are currently being measured. In earlier runs, dew points were found to be $-60^{\circ} \mathrm{C}$ or 3ower.

In order to verify the observed changes, a new bed, identical to the original bed, has been fabricated and will be installed and tested in the test apparatus. The original bed will be kept intact should further testing be desired.

A new hydrometer probe of different design from those originally used has been received. This probe is being used to measure outlet dew points and seems to be less susceptible to degradation caused by the iodine vapor.

\section{3 Carbon-14 Removal and Fixation}

A. D. Ryon and G. L. Haag (Chemical Technology Division, ORNL)

Processes for the removal of ${ }^{14} \mathrm{CO}_{2}$ from reprocessing plant off-gas streams and for its permanent fixation as a carbonate are under investigation and include ( 1 ) direct fixation using a $\mathrm{Ca}(\mathrm{OH})_{2}$ or $\mathrm{Ba}(\mathrm{OH})_{2}$ slurry in an agitated gas-slurry contactor; (2) direct fixation on solid $\mathrm{Ba}(\mathrm{OH})_{2} \cdot h y d r a t e ;$ and (3) carbon dioxide removal and enrichment using molecular sieves, with subsequent fixation. Variables being examined are the effects of gas flow rates, feed gas compositions, and various gas impurities on the decontamination factors (DFs).

Most of the work during the past quarter has been on the installation and calibration of a gas analyzer capable of $\mathrm{CO}_{2}$ detection to $100 \mathrm{ppb}$. Following the successful operation of the instrument, data for detecting $\mathrm{CO}_{2}$ in the parts per billion range in effluent gases were applied to three methods now under study for the removal of $\mathrm{CO}_{2}$ from off-gas streams.

\section{3.1 Analytical instrumentation}

One of the likely gas feed streams to the $\mathrm{CO}_{2}$ removal and fixation process will consist of essentially air (which normally contains about $330 \mathrm{ppm} \mathrm{CO}_{2}$ ) with various reprocessing gas impurities, including a small amount of ${ }^{14} \mathrm{CO}_{2}$. Experiments with such gas compositions require that the $\mathrm{CO}_{2}$ be analyzed in the parts per million and parts per billion range. Analytical instrumentation was brought on-line this quarter enabling $\mathrm{CO}_{2}$ analysis at a concentration as low as 100 ppb. The Baseline model 1030 gas analyzer utilizes a chromatographic column for component separation, a nickel catalyst bed for the methanization of $\mathrm{CO}_{2}$, and a flame ionization detector for hydrocarbon analysis (Fig. 4.4). Eventually, it may be possible to extend the lower detection limit to $50 \mathrm{ppb}$ or Iess.

A microprocessor can actuate many of the capabilities of the model 1030 gas analyzer at regular time intervals; thus, gas samples can be taken in-line, thereby minimizing errors. A ten-stream sampler will allow sampling of multiple streams, including various influent and effluent process streams and calibration gases. Routine sampling of calibration gases is quite important since it enables any deviation and the extent of that deviation from the instrument calibration curve to be immediately noted.

The calibration of the $\mathrm{CO}_{2}$ analyzer in the 100- to 400-ppb range has been completed with gases (analyzed to $\pm 5 \mathrm{ppo}$ ) obtained from the Bureau of Mines Helium operation in Amarillo, Texas. The calibration curve has been reproducible, but the instrument response has been nonlinear for increases in $\mathrm{CO}_{2}$ concentration. Some drift from the calibration curve has been noted during 


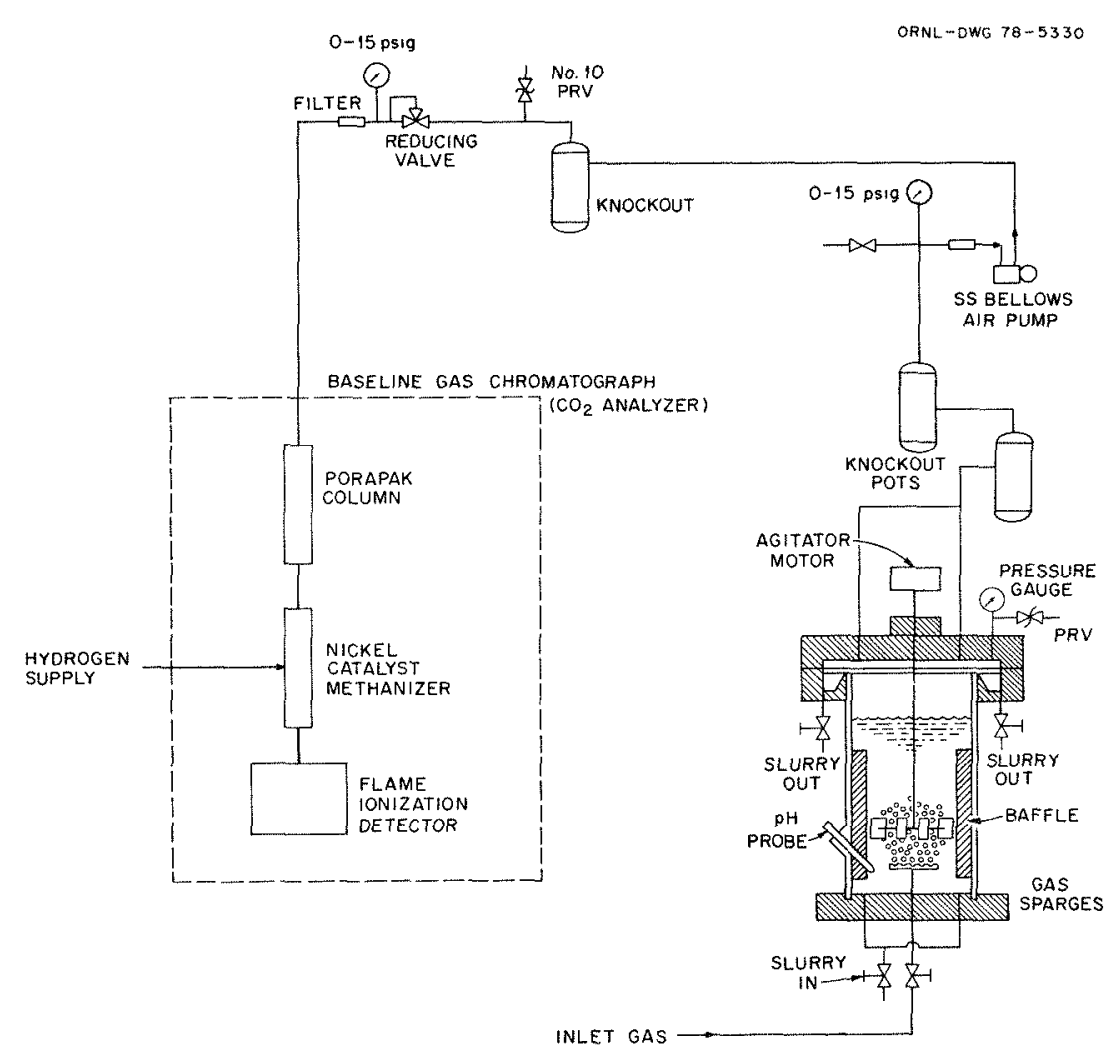

Fig. 4. 4. Schematic of the gas sampling and analysis operation.

operation over extended time periods. However, the original calibration curve can be reestablished by baking the column. The gradual drift may be due to organic compounds accumulating on the column.

\subsubsection{Gas-slurry stirred-tank reactor}

Previous work was directed toward determining the $\mathrm{CO}_{2}$ removal efficiency from a $3 \% \mathrm{CO}_{2}$ feed gas, since the analytical capability at that time did not permit determination of very low quantities of $\mathrm{CO}_{2}$ in air. The DFs for more dilute feed gases were predicted ${ }^{6}$ based on equal superficial velocities (total volumetric gas flow divided by the contactor cross-sectional area). Recently obtained data (Fig. 4.5) with a $0.033 \% \mathrm{CO}_{2}$ feed gas employing the new analytical capability gave accurate DFs between 3000 and 7500 . A preliminary comparison of this new data (0.033\% feed gas) with the previous data (3\% feed gas) indicated that predictions based on superficial velocities were inaccurate and DF's for $0.033 \%$ feed gas were higher.

Initial experimental work had indicated that temperature was not a significant variable in the $\mathrm{Ca}(\mathrm{OH})_{2}$ slurry system for $\mathrm{CO}_{2}$ removal. Recent data obtained at 15 and $60^{\circ} \mathrm{C}$ for high $\mathrm{CO}_{2}$ removal efficiencies (Fig. 4.5) showed a slight increase in the DF at the higher temperature because of a slightly faster rate of $\mathrm{CO}_{2}$ reaction with the slurry. However, the change in rate is relatively small for such a large increase in temperature, which may be rationalized by examining a rate equation developed by Danckwerts' for a pseudomirst-order reaction with negligible gas-side resistance: 
ORKL OWS 78.9647

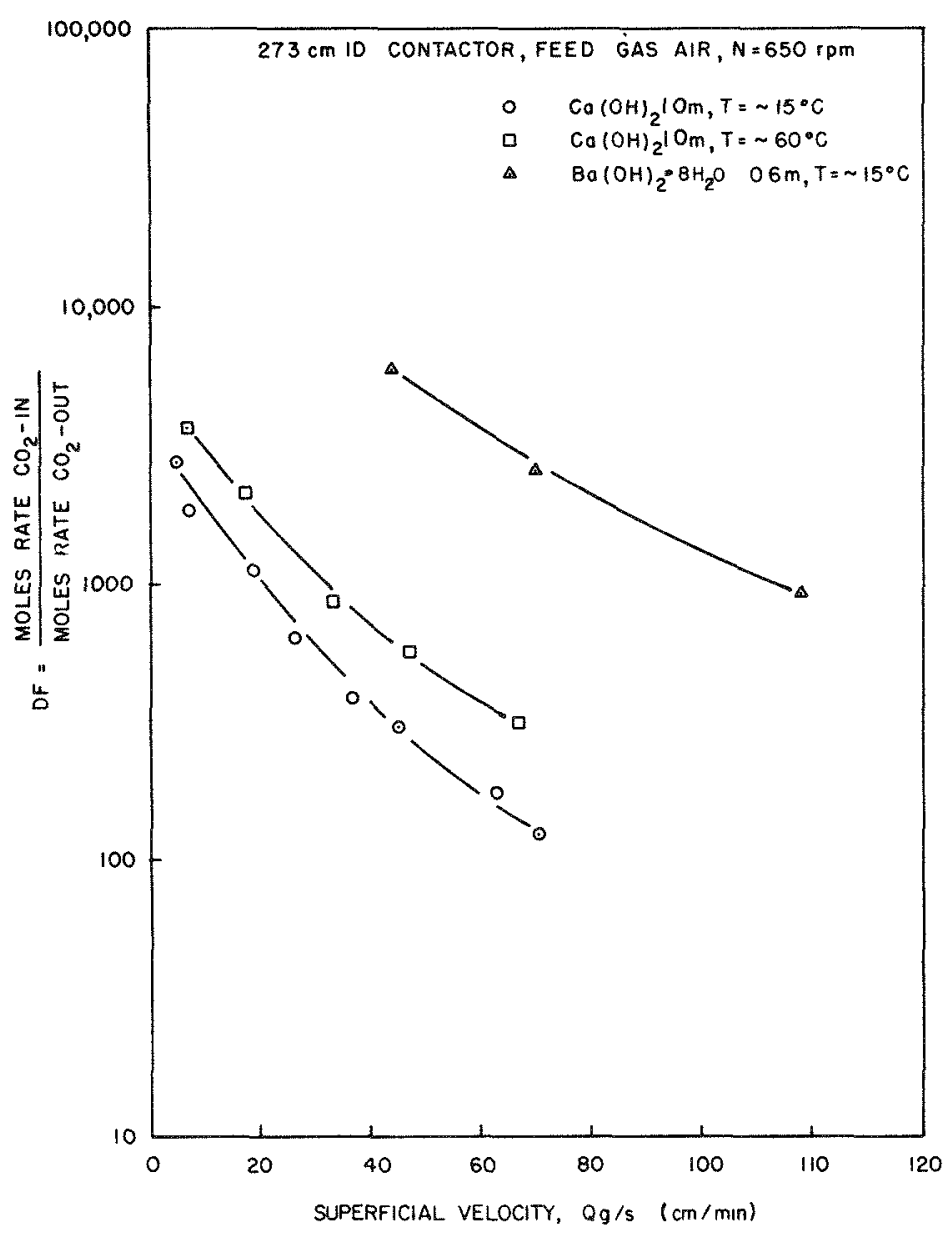

Fig. 4.5. Carbon dioxide removal from air in the gas-slurry stirred-tank reactor with $\mathrm{Ca}(\mathrm{OH})_{2}$ and $\mathrm{Ba}(\mathrm{OH})_{2}$ slurries.

$$
R=\operatorname{aHV}_{\mathrm{D}} \mathrm{P}_{\mathrm{DF}}\left(\frac{\mathrm{DK}_{\mathrm{OH}^{-}}-\left[\mathrm{OH}^{-}\right]}{\mathrm{K}_{\mathrm{L}}^{2}}+1\right)^{0.5},
$$

where

$R=$ rate of reaction, $g \cdot$ mole $/ s$;

$a=$ interfacial area, $\mathrm{cm}^{2} / \mathrm{cm}^{3}$;

$V_{D}=$ volume of dispersion, $\mathrm{cm}^{3}$;

$\mathrm{P}_{\mathrm{DF}}=$ pressure ariving force, atm;

$D=$ diffusivity of $\mathrm{CO}_{2} \mathrm{~cm}^{2} / \mathrm{s}$;

$\mathrm{k}_{\mathrm{OH}_{-}^{-}}=$reaction rate constant in the liquid phase liter $\mathrm{s}^{-1} \mathrm{~g} \cdot \mathrm{mole} \mathrm{e}^{-1}$;

$\left[\mathrm{OH}^{-}\right]=$hydroxyl ion concentration, $\mathrm{g} \cdot \mathrm{mole} / \mathrm{liter}$;

$\mathrm{K}_{\mathrm{I}}=$ liquid-side mass transfer coefficient, $\mathrm{cm} / \mathrm{s}$.

The assumption of pseudo-first order which implies that the change in hydroxyl ion concentration at the interface will be negligible has been experimentally verified in similar systems. ${ }^{7}$ As the temperature of the $\mathrm{Ca}(\mathrm{OH})_{2}$ slurry increases, values for $\mathrm{D}$ and $\mathrm{k}_{\mathrm{OH}}$ - become larger. However, this increase is offset by decreases in $\mathrm{H}$ and $\left[\mathrm{OH}^{-}\right]$. Other values will remain essentially constant. The overall effect of temperature on the reaction rate and on $\mathrm{k}_{\mathrm{OH}^{-}}{ }^{-} \mathrm{D}$, and [OH$\left.{ }^{-}\right]$is partially damped out, since the term 


$$
\frac{\mathrm{D}_{\mathrm{A}} \mathrm{K}_{\mathrm{OH}}-\left[\mathrm{OH}^{-}\right]}{\mathrm{K}_{\mathrm{L}}^{2}}
$$

is of the order of 1.0 and is added to 1.0 in the rate equation before the square root is taken. As shown in Fig. 4.5, the overall change is a small increase in the DF which results from a very small change in the reaction rate. Although data for the $\mathrm{Ba}(\mathrm{OH})_{2}$ slurry system at $60^{\circ} \mathrm{C}$ is not yet available, the effect of temperature on the overall reaction rate may be estimated. Changes in $\mathrm{H}, \mathrm{D}$, and $\mathrm{k}_{\mathrm{OH}^{-}}$with temperature should be similar to the $\mathrm{Ca}(\mathrm{OH})_{2}$ system. However, the [OH'] value will increase by a factor of 6.6 rather than decrease by 0.66 as in the $\mathrm{Ca}(\mathrm{OH})_{2}$ system, resulting in an overall change of a factor of 10 between the $\mathrm{Ca}(\mathrm{OH})_{2}$ and the $\mathrm{Ba}(\mathrm{OH})_{2}$ systems at $60^{\circ} \mathrm{C}$. A more dramatic dependence of reaction rate and $\mathrm{DF}$ upon temperature in the $\mathrm{Ba}(\mathrm{OH})_{2}$ system may be expected. The extent of the rate increase and the possibility of appreciable gas-side resistance will be detemined experimentally.

\subsection{3 $\mathrm{CO}_{2}$ removaI with $\mathrm{Ba}(\mathrm{OH})_{2}$ hydrates}

The use of $\mathrm{Ba}(\mathrm{OH})_{2}$ hydrates in a gas-solid reaction was examined in greater detail with the improved capability for $\mathrm{CO}_{2}$ analysis. Differences in the reactivity of various hydrates were examined more closely as was the feasibility of using sand as an inert material to maintain physical properties in the bed throughout a run.

Figure 4.6 shows a direct comparison of DF capability ( $4.78 \% \mathrm{CO}_{2}$ water-saturated feed gas) and final product conversions for the $\mathrm{Ba}(\mathrm{OH})_{2} \cdot \mathrm{H}_{2} \mathrm{O}, \mathrm{Ba}(\mathrm{OH})_{2} \cdot 5 \mathrm{H}_{2} \mathrm{O}$, and $\mathrm{Ba}(\mathrm{OH})_{2} \cdot 8 \mathrm{H}_{2} \mathrm{O}$ systems (vendor B). Each packed bed contained 0.2 g.mole of $-5+20$ mesh reactant. Assuming a void volume of 0.60 , the gas residence time in the reactor was approximately $3.6 \mathrm{~s}$. From this and other data,

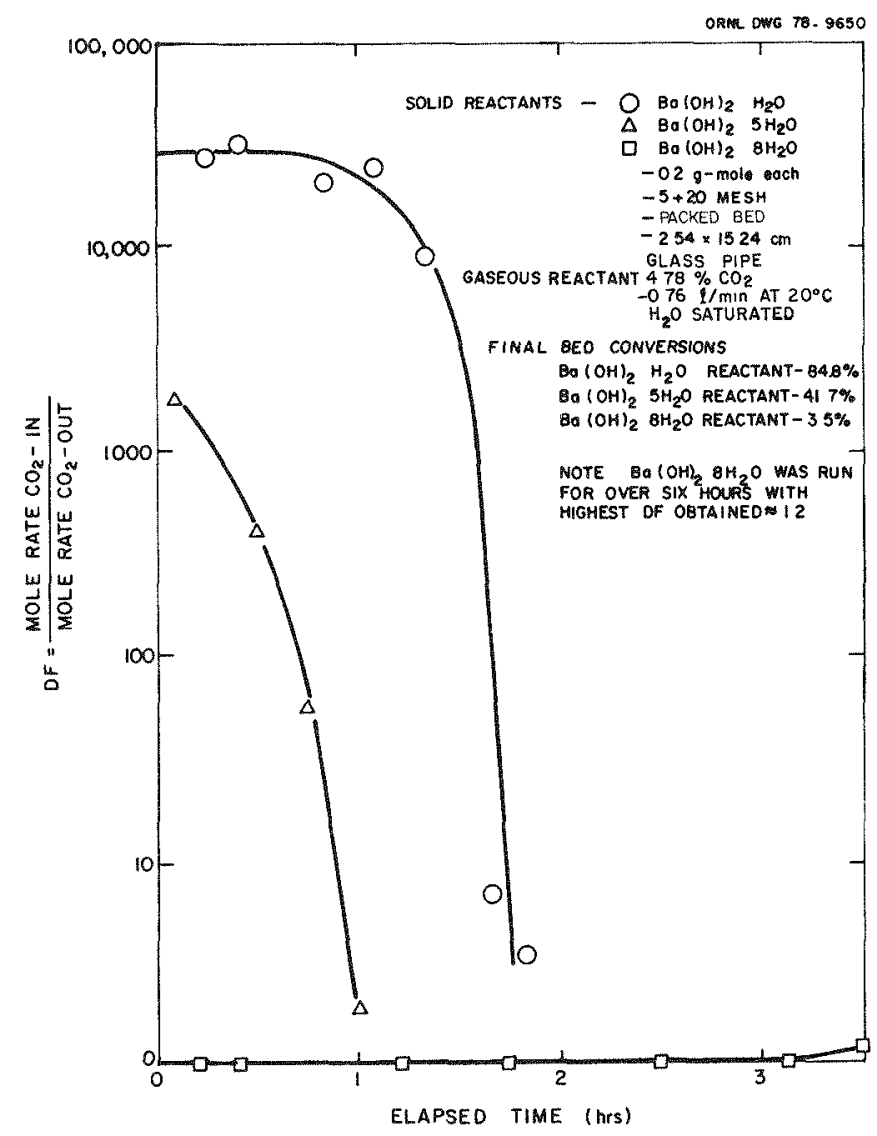

Fig. 4.6. Comparison of DFs and final product conversions for $\mathrm{CO}_{2}$ removal with $\mathrm{Ba}(\mathrm{OH})_{2} \cdot \mathrm{H}_{2} \mathrm{O}$, $\mathrm{Ba}(\mathrm{OH})_{2} \cdot 5 \mathrm{H}_{2} \mathrm{O}$, and $\mathrm{Ba}(\mathrm{OH})_{2} \cdot 8 \mathrm{H}_{2} \mathrm{O}$ (vendor $\mathrm{B}$ ). 
It may be concluded that the reactivity of the various hydrates from vendor $B$ tend to decrease as the degree of hydration increases. ${ }^{8}$ Additional data are needed for the $\mathrm{Ba}(\mathrm{OH})_{2} \cdot 8 \mathrm{H}_{2} \mathrm{O} \mathrm{system}$ from vendor A before a more general statement can be made; however, this trend did not hold for all hyarates when tested with $88 \% \mathrm{CO}_{2}$ feed gas. Future work will be directed toward a better explanation of the large differences in reactivity, with added emphasis on the determination of surface area and pore size and on the formulation of possible mechanisms.

A significant problem with the operation of the $\mathrm{Ba}(\mathrm{OH})_{2}$.hydrate-packed beds has been the flaking of the product and the subsequent bed shrinkage, which results in an increasing pressure drop across the bed as the run progresses. Two approaches to alleviate this problem are being examined. First, pressing the $\mathrm{Ba}(\mathrm{OH})_{2} \cdot$ hydrate into small pellets that might retain theix structure upon conversion is being investigated. This approach has had limited success. Smaller pellets are being examined in an effort to obtain a moxe rapid rate and higher reactant conversion. The second approach has been the use of an inert medium to maintain bed porosity. Promising results have been obtained in the treatment of low- and high-CO ${ }_{2}$ content streams with a $1:$ I volume ratio of $\mathrm{Ba}(\mathrm{OH})_{2} \cdot \mathrm{H}_{2} \mathrm{O}$ and sea sand. For $\mathrm{CO}_{2}$ removal from a highly concentrated stream, the sand performed a dual purpose. Bed porosity was maintained throughout the run, and the sand acted as a heat transfer and heat absorption medium, thereby avoiding reactant melting. The resulting product was a free-flowing solid, in contrast to previous $\mathrm{Ba}(\mathrm{OH})_{2} \cdot \mathrm{H}_{2} \mathrm{O}-88 \% \mathrm{CO}_{2}$ runs in which the product was an extremely hard porous solid. Decontamination factors and final conversion data for a typical run are presented in Fig. 4.7.

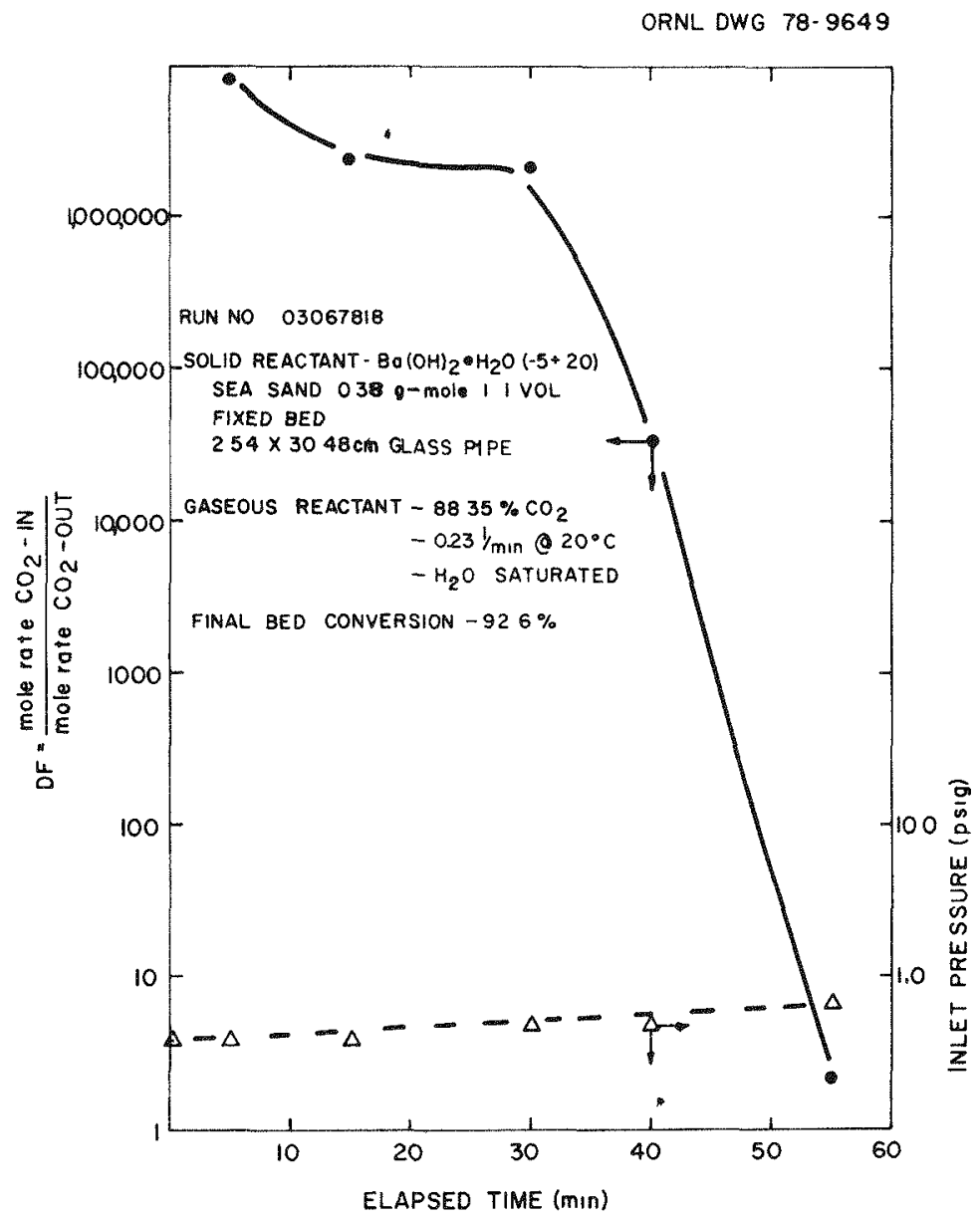

Fig. 4. 7. Carbon dioxide from an $88.35 \% \mathrm{CO}_{2}$-water-saturated feed gas with a Ba(OH)$)_{2} \cdot \mathrm{H}_{2} \mathrm{O}$ sand-packed bed in a 1:1 volume ratio. 
Data for $\mathrm{CO}_{2}$ removal from air using a $1: I$ volume ratio of $\mathrm{Ba}(\mathrm{OH})_{2} \cdot \mathrm{H}_{2} \mathrm{O}$ to sand is presented in Fig. 4. 8. Assuming a void volume of 0.6 , the gas residence time in the bed was approximately $0.7 \mathrm{~s}$. A DF beyond present analytical capabilities was obtained initially and then gradually decreased with time as the mass transfer zone shortened because of bed depletion. Decontamination factors less than 7500 may be high because of the extrapolation of the calibration curve for the gas analyzer.

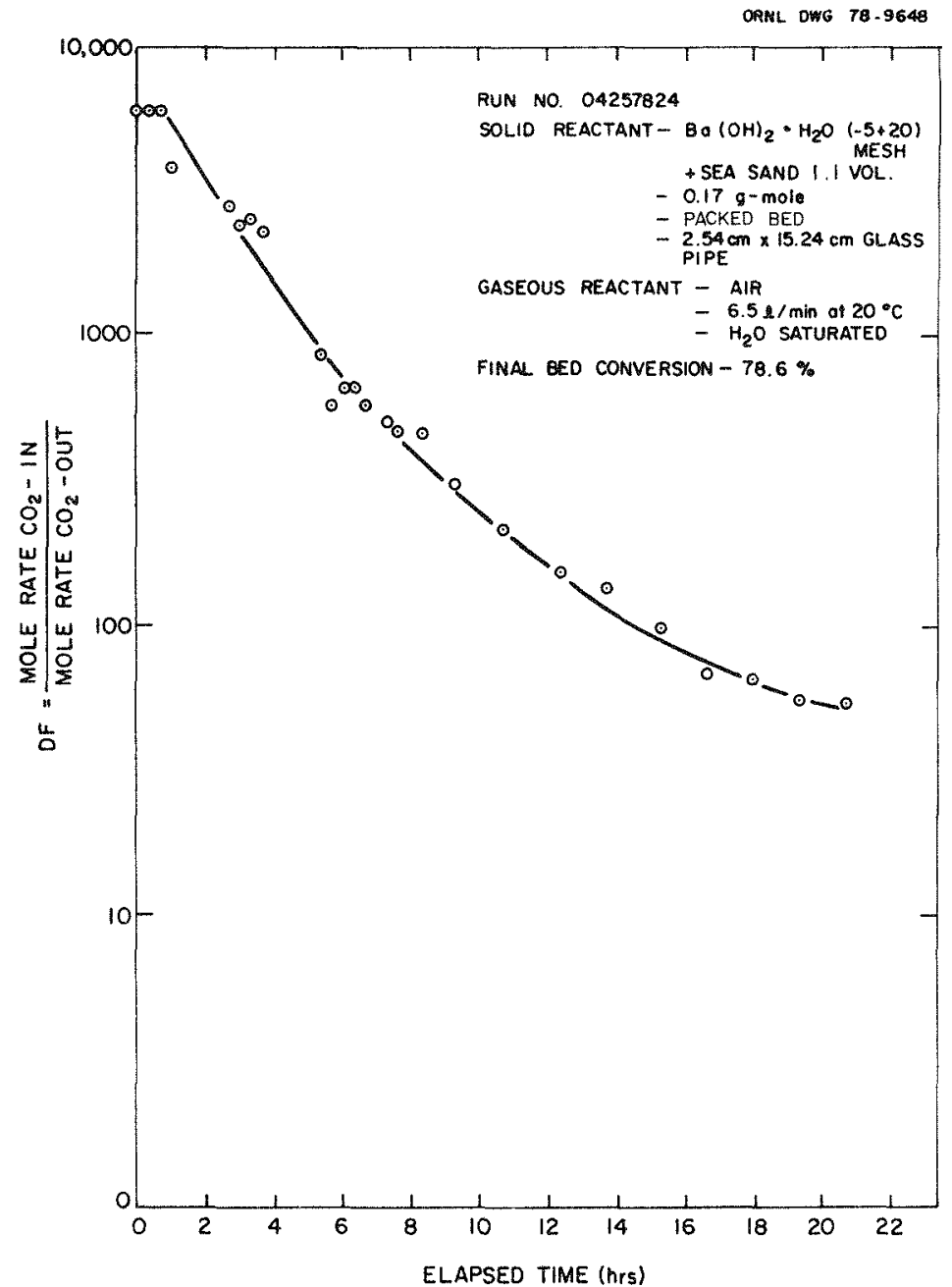

Fig. 4.8. Carbon dioxide removal from $0.033 \% \mathrm{CO}_{2}$-water-saturated feed gas with a $\mathrm{Ba}(\mathrm{OH}){ }_{2}^{\circ}$ $\mathrm{H}_{2} \mathrm{O}$-sand-packed bed in a $1: 1$ volume ratio.

A problem associated with the use of sand to maintain bed porosity has been the segregation of the sand due to differences in physical properties, primarily the density. Porous alumdum (firebrick) will be examined since it is thermally stable, chemically inert, and relatively cheap, and the porosity may be easily varied during firing.

\subsubsection{Molecular sieve (13X) for Co removal}

Frevious experimental data has indicated that the Linde $13 X$ molecular sieve is capable of providing DFs in excess of 330 (with excellent loading capacity) for $\mathrm{CO}_{2}$ removal from air. These results were obtained during a series of 11 runs under stringent regenerating conditions of $300^{\circ} \mathrm{C}$ for 4 to $6 \mathrm{~h}$ in a 20 -torr vacuum. ${ }^{6}$ The column was repacked and regenerated and a similar run was made at ambient conditions $\left(20^{\circ} \mathrm{C}\right)$ rather than at $7^{\circ} \mathrm{C}$. The effluent gas was 
analyzed with the Baseline model 1030 analyzer. No response for $\mathrm{CO}_{2}$ was obtained until $\mathrm{CO}_{2}$ breakthrough; and therefore, the effluent concentration was below 50 ppo, giving a corresponding DF in excess of 6000. Breakthrough was quite sharp, with the bed loading greater than $90 \%$ of the equilibrium loading. Gas residence time in the bed was $1.4 \mathrm{~s}$.

REFERENCES FOR SECTION 4

1. B. I. Vondra et al., IWR Fuel Reprocessing and Recycle Program QuarterIy Report for Period April I to June 30, 1977, ORNL/TM-5987 (August 1977), p. 3-5.

2. W. D. Burch et al., Advanced Fuel Recycle Program Progress Report for Period April 1 to June 30, 1977, ORNI/TM-5993 (September 1977), p. 3-11.

3. M. J. Stephenson, Analysis of a Fractional Cas Stripper, USDOE report K-1895 (in preparation).

4. B. L. Vondra et al., Alternate Fuel Cycle Technologies/Thorium Fuel Cycle Technology Programs Quarterly Report for Period January I to March 31, 1978, ORNL/TM-6307 (May 1978), p. 4-12.

5. Ref. 4, p. 4-14.

6. B. I. Vondra et al., Alternate Fuel Cycle Technologies Program Quarterly Report for Period JuIy 1 to September 30, 1977, ORNI/TM-6076 (November 1977), p. 7-1.

7. P. V. Danckwerts, Gas-Liquid Reactions, McGraw-Hill, New York, 1970, p. 244.

8. Ref. 4, p. 4-17. 


\section{SEPARATIONS PROCESSES - THORIUM SYSTEMS}

\subsection{Laboratory Studies}

\subsection{Solvent extraction kinetics ${ }^{*}$}

D. E. Horner, S. W. Thiel, and J. C. Mailen (Chemical Technology Division, ORNL)

Kinetic studies with falling- and rising-drop techniques have continued this quarter with an emphasis on thorium and zirconium. The kinetic constants for the aqueous-to-organic transfer of thorium are less precise than those reported for uranium. This results mainly from the inability to use the rising-drop technique (organic drops) for thorium because of thira-phase formation. In the falling-drop technique, the small quantity of thorium transferred yields relatively large exrors in the calculated constants.

In thorium extractions from a simulated adjusted dissolver solution $(0.5 \mathrm{M} \mathrm{Th}-0.03 \mathrm{MU}$ $0.03 \mathrm{MF}-0.065 \mathrm{M} \mathrm{Al}^{-2} \mathrm{M} \mathrm{HNO}_{3}$ ), the overall results point to first-order reaction kinetics in accordance with the assumed extraction reaction:

$$
\left.\mathrm{Th}^{4+}+4 \mathrm{NO}_{3}^{-}+2 \mathrm{TBP}=\mathrm{Th}_{(\mathrm{NO}}\right)_{4} \cdot 2 \mathrm{TBP} \text {. }
$$

The presence of fluoride appears to decrease the extraction rates of thorium; increasing the fluoride concentration over a fluoride-to-thorium mole ratio of 0.25 to 2.0 decreases the rate constant by about a factor of 2 , which is consistent with the very strong thorium fluoride complex that is known to form.

Approximate values for the forward and reverse extraction constants of thorium are $1.6 \mathrm{x}$ $10^{-3}$ and $1.0 \times 10^{-3} \mathrm{~cm} / \mathrm{s}$ respectively. The ratio, $\mathrm{k}^{\mathrm{t}} / \mathrm{k}$, of these values is 1.6 , which is close to the equilibrium distribution coefficient of 1.2. Similar approximate values for uranium in the same solution are $3.5 \times 10^{-3}$ and $8.0 \times 10^{-4} \mathrm{~cm} / \mathrm{s}$, respectively, with a ratio of 4.4 compared to the equilibrium distribution coefficient of 2.2 .

Forward extraction rate constants for thorium at room temperature (about $20^{\circ} \mathrm{C}$ ) and at $40^{\circ}$ and $60^{\circ} \mathrm{C}$ allowed calculation of the activation energy, $-6.6 \mathrm{kcal} / \mathrm{mole}$. The same calculation for the reverse extraction gives $-8.1 \mathrm{kcal} / \mathrm{mole}$, with the difference being about $1.5 \mathrm{kcal} / \mathrm{mole}$ for the heat of reaction (enthalpy). This value can be compared to a value of $3.7 \mathrm{kcal} / \mathrm{mole}$ previously obtained ${ }^{l}$ for uranium extraction.

Studies with zirconium are more complicated because of the presence of two or more chemical species, the relative amounts of each being dependent on the zirconium concentration, the acid concentration, and the method of preparation. Analyses for zirconium were made with $95 \mathrm{Zr}-\mathrm{Nb}$ tracer which requires that the active and the bulk zirconium be either exchangeable or in

\footnotetext{
*This research is supported by Basic Chemical sciences funding.
} 
equilibrium. To ensure that these conditions were obtained, we precipitated $\mathrm{Zr}(\mathrm{OH})_{4}$ from a $95 \mathrm{Zr}-\mathrm{Nb}$ spiked solution of $\mathrm{ZrO}\left(\mathrm{NO}_{3}\right)_{2}$ in nitric acid by adding $\mathrm{NH}_{4} \mathrm{OH}$. This precipitate was washed and then dissolved in nitric acid and the procedure was repeated a second time. Batch extractions of this zirconium in $3.5 \mathrm{M}$ of $\mathrm{HNO}_{3}$ solution determined that about $50 \%$ of the zirconium was extractable into $30 \%$ TBP-dodecane, with a distribution coefficient of 0.265. A kinetic detemination with this zirconium resulted in a forward reaction constant, $k^{\prime}$, of about $4.6 \times 10^{-4} \mathrm{~cm} / \mathrm{s}$, which gives a value of $9.2 \times 10^{-4} \mathrm{~cm} / \mathrm{s}$ when corrected for $50 \%$ unextractable zirconium.

Further kinetics tests are being made with this zirconium to determine the effect of TBP concentration and to determine the order of the extraction kinetics. Batch extractions, before and after each kinetic determination, are being made to allow corrections to the kinetic data for the zirconium species involved in each test.

REFERENCE FOR SECTTON 5

1. B. I. Vondra et al., IWR Fuel Reprocessing and Recycle Program Quarterly Report for Period January I to March 31, 1977, ORNL/TM-5864 (May 1977), p. 4-25. 


\section{SEPARATION PROCESSES - URANIUM AND PLUTONIUM SYSTEMS}

\subsection{Laboratory studies}

J. C. Mailen (Chemical Technology Division, ORNI)

\subsubsection{Ruthenium chemistry}

I. Maya (Chemistry Division, ORNL)

Evidence for the presence of a ruthenium species that is more tributyl phosphate (TBP)extractable than tetranitratonitrosylruthenium in equilibxium mixtures of nitrosylruthenium nitrate complexes has been found via chromatography. The proportion of this species is a function of the acid concentration and varies between $I$ and $4 \%$ between 5.5 and $15 \mathrm{M}^{\mathrm{H} N \mathrm{O}_{3}}$ respectively. This species appears to contain the nitrosylruthenium moiety since it is susceptible to photolytic oxidation.

Reversed-phase chromatography of nitrosylrutheniumitrato complexes on XAD-2 (Rohm \& Haas nonionic macroreticular resin) coated with IBP yields four different fractions by step elution using $3 \mathrm{MHNO}_{3}, 5 \mathrm{MHNO}_{3}, 1 \mathrm{H} \mathrm{MHNO}_{3}$, and hexane respectively. The last treatment also removes the TBP from the resin. Work has continued in an effort to establish whether these fractions actually correspond to distinct molecular species. The fraction removed by the hexane is of special interest since it contains highly TBP-extractable species, which Joon ${ }^{1}$ postulated as being dimeric. These species are the least understood, and it is not clear whether this fraction is indeed a distinct species.

The proportions of the different nitrosylrutheniumnitrato complexes in equilibrium mixtures have been established by a number of workers ${ }^{2-4}$ by means of solvent extraction separations, paper chromatography, and the use of ion exchange resins. It has been shown that a number of species having a generalized formula, RuNo $\left(\mathrm{NO}_{3}\right)_{x}\left(\mathrm{H}_{2} \mathrm{O}\right)_{y}^{3-x}$, where $x+y=5$ and $x \leq 4$, coexist in nitric acid solutions. At low acid concentrations, $\leq 3 \mathrm{MHNO}$, most of the ruthenium is present in the form of the low nitrato complexes, $\mathrm{x} \leq 2$; whereas at higher acid concentrations, $\geq 8 \mathrm{M} \mathrm{HNO}_{3}$, the higher nitrato complexes, $x \geq 3$, predominate. The extractability of these complexes into TBP-dodecane increases with the number of nitrato ligands bound to the nitrosylruthenium moiety.

The fact that the nitric acid concentration determines the proportions of nitrosylrutheniumnitrato complexes was used to check whether or not our reversed-phase chromatography procedure separates the mixture into different fractions that correspond to the established proportions of the different molecular species. It was found that this was the case. The fraction collected by elution with $3 \mathrm{MHNO}_{3}$ contains the total of the cationic complexes RulNo $\left(\mathrm{H}_{2} \mathrm{O}\right)_{5}{ }^{3+}$, $\mathrm{RuNO}\left(\mathrm{NrO}_{3}\right)$ $\left(\mathrm{H}_{2} \mathrm{O}\right)_{4}{ }^{2+}$, and cis- and trans-RuNo $\left(\mathrm{NO}_{3}\right)_{2}\left(\mathrm{H}_{2} \mathrm{O}\right)_{3}^{+}$. These complexes are collected as a single fraction because of their poor extractability into TBP. Separation of the individual species is possible using an ion exchange resin. Table 6.I shows some representative results. 
Table 6.1. Percentage of cationic nitrosylruthenium-nitrato complexes in various nitric acid solutions

\begin{tabular}{ccc}
\hline $\begin{array}{c}\mathrm{HNO}_{3} \\
\text { concentration } \\
(M)\end{array}$ & $\begin{array}{c}\text { Present } \\
\text { experiment }\end{array}$ & $\begin{array}{c}\text { Scargill } \\
\text { et al. }\end{array}$ \\
\hline 3 & 84 & 85 \\
$3^{b}$ & 58 & 56 \\
8 & 42 & 39 \\
12 & 21 & 16 \\
\hline
\end{tabular}

${ }^{a}$ D. Seargill et al., J. Inorg. Nucl. Chem. 27: 161 (1965).

"Aced containing an additional $2.5 \mathrm{M} \mathrm{NO}_{3}{ }^{-}$in the form of $\mathrm{UO}_{2}\left(\mathrm{NO}_{3}\right)_{2}$ or $\mathrm{LiNO}_{3}$.

The fractions collected by elution with $5 \mathrm{M}$ and $10 \mathrm{M} \mathrm{HNO}_{3}$, respectively, were found to correspond to the tri- and tetranitratonitrosylruthenium complexes, as shown by the results given in Table 6.2 .

Table 6.2. Percentage of trinitrato- and tetranitratonitrosylruthenium in nitric acid solutions

\begin{tabular}{|c|c|c|c|c|}
\hline \multirow{2}{*}{$\begin{array}{c}\mathrm{HNO}_{3} \\
\text { concentration } \\
(M) \\
\end{array}$} & \multicolumn{2}{|c|}{ Present experment } & \multicolumn{2}{|c|}{ Scargill et al. ${ }^{a}$} \\
\hline & tri & tetia- & tri - & ictra - \\
\hline 3 & 13 & 3 & 14 & 1 \\
\hline $3^{b}$ & 30 & 9 & 34 & 5 \\
\hline 8 & 41 & 17 & 50 & 12 \\
\hline 12 & 51 & 26 & 51 & 33 \\
\hline
\end{tabular}

${ }^{a}$ D. Scarglll et al., J. Inorg. Nucl. Chem. 27: 161 (1965).

${ }^{b}$ Acid containing an additional $2.5 \mathrm{M} \mathrm{NO}_{3}{ }^{-}$in the form of $\mathrm{UO}_{2}\left(\mathrm{NO}_{3}\right)_{2}$ or $\mathrm{LiNO}_{3}$.

The chromatograms obtajned using step elution showed a Gaussian peak for the first fraction; however, the peaks for the tri- and tetranitrato complexes were asymmetric, with very sharp leading edges and long tails, which is a consequence of the relatively sudden changes in the concentration of the eluant. The resolution and shapes of the peaks were improved by performing the elution with a continuous linear gradient that ranged from 3 to $12 \mathrm{M} \mathrm{HNO}_{3^{*}}$ The gradient was generated using two pumps. The use of a continuous gradient decreased the amount of tailing, a finding which is of considerable importance in trying to define whether the ruthenium retained in the column after the bulk of the sample has been eluted is just the tail. of the tetranitrato or a different species with a larger distribution coefficient (ratio of ruthenium organic/ruthenium aqueous). It was found that apparently there is another species that is even more extractable than the tetranitrato, which is in agreement with the findings of Joon. ${ }^{1}$ The proportion of this species was established by performing a material balance on the ruthenium retained in the column after completing the elution with $12 \mathrm{MNNO}_{3}$. The ruthenium content of the last fifteen I-mI fractions, corresponding to the tail of the tetranitrato peak, was found to decrease in a linear fashion when plotted as the log of the ruthenium content vs fraction number. This decrease permitted extrapolation to the amount of ruthenium still in the column coxresponding to the tail of the tetranitrato species. This amount constituted about $3 \%$ of the ruthenium as tetranitrato. The ruthenium retained in the column was eluted with hexane 
which also removed the TBP. Finally, an acetone wash of the resin displaced the hexane holdup of the colum and released an aditional small amount of ruthenium. The amount collected by this treatment was definitely larger than the estimate of the retained tail of the tetranitrato peak, indicating the possibility of an additional species. The amounts of the retained ruthenium in excess of the tetranitrato tail are given below as a fraction of the total amount of ruthenium originally present.

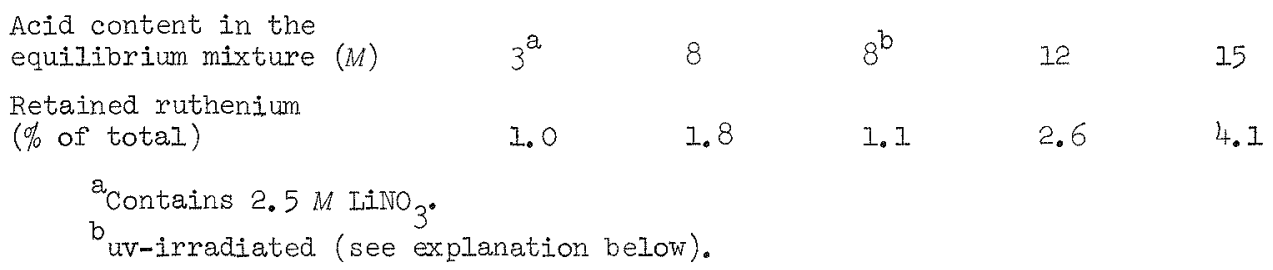

It is seen that the amount of retained ruthenium is proportional to the acid concentration of the original solution, which, in every case, is adjusted to $3 \mathrm{MHNO}_{3}$ immediately prior to injection into the column. This discounts the possibility that the retention is due to some impurity in the column. Furthermore, when the amount of extractable ruthenium is reduced by conversion to Ru(IV) by means of uv irradiation, it is seen that the amount of ruthenium retained is also reduced. This fact proves that the retention is inherent to the solution injected into the column and not to the process of separating the mixture. The reduction of retained ruthenium in a solution containing a fraction of the ruthenium in the inextractable Ru(IV) form shows that the retained species most probably is a nitrosylruthenium species of some form, since irradiation is known to cause photochemical dissociation of the nitrosylruthenium moiety.

Joon $^{2}$ concluded that the following equilibrium explained the presence of retained ruthenium:

$$
\text { 2RuNO }\left(\mathrm{NO}_{3}\right)_{4} \mathrm{H}_{2} \mathrm{O} \rightarrow\left[\mathrm{RuNO}\left(\mathrm{NO}_{3}\right)_{3} \mathrm{H}_{2} \mathrm{O}\right]_{2}+2 \mathrm{NO}_{3}^{-} \text {. }
$$

He arrived at this from a correlation between the log of [tetranitrato] ${ }^{2} /$ [dimer] vs the log of the activity of the nitrate ion. The correlation appeared as a straight line with a slope of 2. The data collected in our work does not agree with Joon's observations; a similar plot yields a slope of less than 1. Some of the discrepancy might stem from the fact that Joon did not consider the retention of part of the tail of the tetranitrato. Conversely, the fraction taken by him as tetranitrato might have contained part of the so-called dimer that had "leaked" by excessive elution with $10 \mathrm{M} \mathrm{HNO}_{3}$

Additional evidence that the retained ruthenium might constitute an additional species is derived from the fact that the ruthenium distribution coefficient of this fraction, as obtained under comparable conditions ( $3 \mathrm{M} \mathrm{HNO}_{3}$ and 30\% TBP in dodecane), is about 3.0. This coefficient is significantly greater than that of the tetranitrato species, which has a distribution coefficient of 1.6. The distribution coefficient for the trinitrato species is 0.97 , and that for the cationic mixture is 0.023 .

The nature of this retained species is unknown; as mentioned above, it appears to contain the nitrosylruthenium moiety. No quantitative correlation could be found with any of the components of the mixture. The retained species amounts to about $10 \%$ of the tetranitrato species and is inversely proportional to the water activity, which indicates that this species is formed by the dehydration of the simpler units, possibly through the formation of aqua or hydroxo bridges. Preliminary tests were done to examine the feasibility of isolating enough 
of this material for chemical characterization. It was found that the hexane fraction could be washed free of acid, with a $40 \%$ loss of activity, and then treated with sodium hydroxide to transfer most of the activity into the aqueous phase which could then be analyzed for ruthenium and nitrogen. The washing step is required to eliminate the nitric acid present in the system. Spectroscopic characterization of the species appears to be quite involved and uninformative in view of the relatively low concentration and the uncertainty as to the stability of the species once it is isolated. Future work will be directcd at establishing the stability of extracts containing this newly isolated species. Attempts will be made to determine the ruthenium to nitrogen ratio in this species.

\subsubsection{Fast-contactor studies}

J. C. Mailen, D. E. Horner, J. R. Coggins, and S. W. Thiel (Chemical Technology Division, ORIVI)

Kinetic constants for interphase transfer obtained in arop tests are being used to calculate the relative transfer of uranium and rirconium as a function of time and interfacial area per unit volume. The differential equations used to describe the transfer are identical to those developed and used in the drop tests. 5 The applicability of the calculation method and the kinetic constants are being examined in solvent extraction lests usirg cu experimental fast contactor.

Fast-contactor tests. The experimental contactor consists of a Kenics motionless mixer and a high-speed centrifuge supplied by Metallextraiktion $A B$ of sweden. Figure 6. 1 is a photograph of the unit. In operation, the aqueous and organic feeds are delivered from pressurized tanks through flexible lines $A$ and $B$ to the Kenics mixer, $C$. An advantage of this system is the ease of substitution of experimental mixers for the unit shown. After mixing and phase contact, the streams pass into the centrifugal separator, D. The separator is driven by the motor, E, and can be controlled at speeds between 5000 and 25,000 rpm. The separated streams exit the separator, pass through rotameters, and are collected at the exits of Iines $F$ and $G$. In the tests of this unit the centrifuge speed has been 12,500 rpm, the organic-tomaqueous ratio has vaxied from about 1 to 9.5, and the total flow has ranged from 250 to $630 \mathrm{mI} / \mathrm{min}$.

The data used for calculating the transfer of uranium and zirconium are listed below. Concentrations used in the contactor tests are:

Initial uranium concentration (aqueous), $0.042 \mathrm{M}$

Initial uranium concentration (organic), 0

Initial zixconium concentration (aqueous), 0.0099 M

Initial zirconium concentration (organic), 0

Aqueous-to-organic uranium rate constant, $7.2 \times 10^{-3} \mathrm{~cm} / \mathrm{s}$

Organic-tomaqueous uranium rate constant, $2 \times 10^{-4} \mathrm{~cm} / \mathrm{s}$

Fraction of zirconium transferable, $5 \%$

Aqueous-to-organic rate constant, extractable zircorium, $9.2 \times 10^{-4} \mathrm{~cm} / \mathrm{s}$

Organic-to-aqueous rate constant, extractable airconium, $3.47 \times 10^{-3} \mathrm{~cm} / \mathrm{s}$

Data from the contactor tests are analyzed as follows: First, computer calculations generate a list of uranium distributions as a function of time and interfacial area per unit volume. Then, using the experimentalyy detemined uraniun distributions and their respective known contact times, values of the interfacial area are correlated with the experimental aqueous and organic flow rates. The following equation gives the area created (square centimeters per minute) vs the aqueous $\left(F_{A}\right.$ ) and organic $\left(F_{0}\right)$ plow rates in cubic centimeters per minute. 


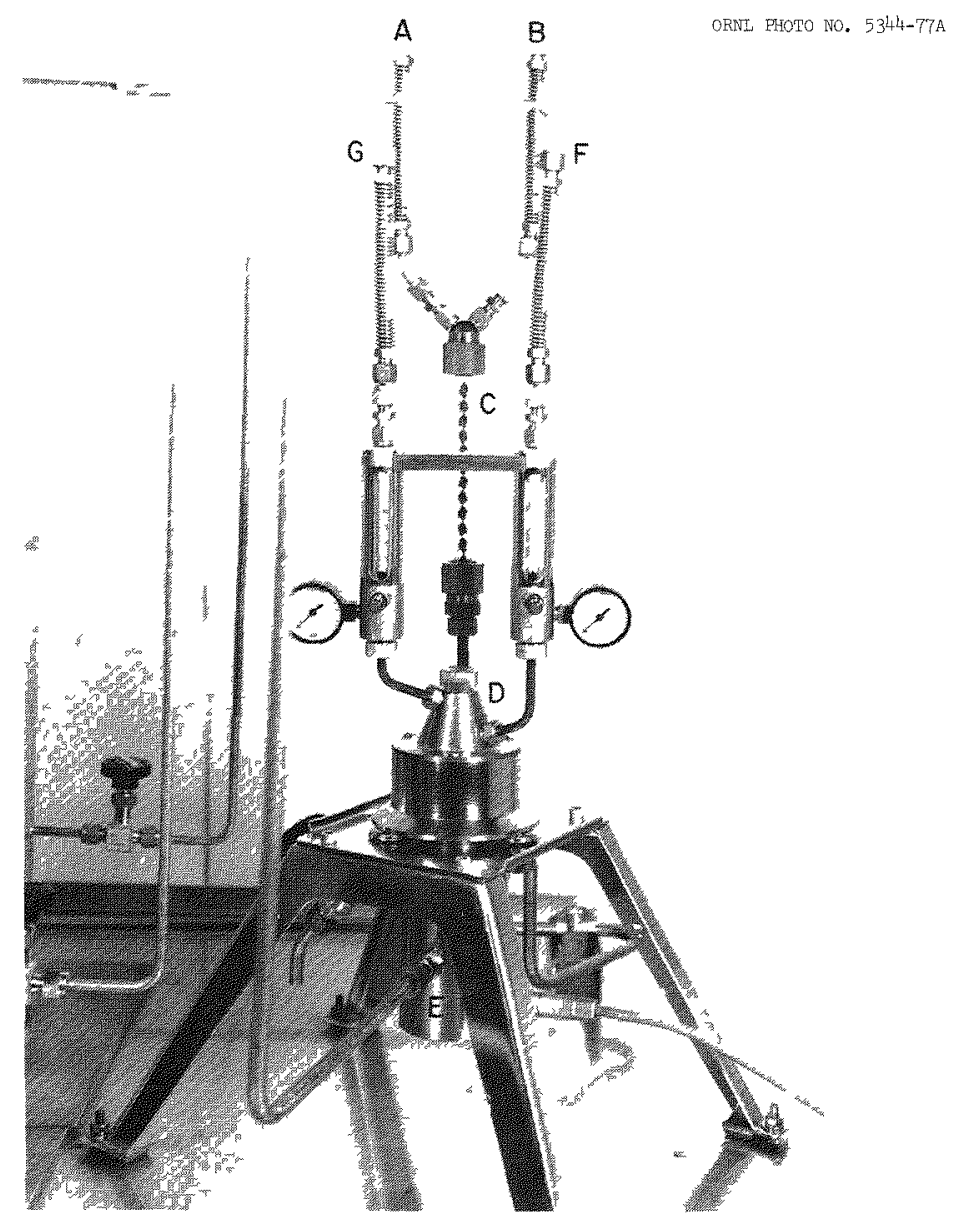

Fig. 6.1. Mixer and centrifugal separator.

$$
\begin{aligned}
& \operatorname{In} A=-4.33+1.28 \ln F_{A}+1.36 \ln F_{0}, \\
& R^{2}=0.993 \text { (for nine runs). }
\end{aligned}
$$

This equation is then used to calculate the interfacial area per unit volume to be used in calculating the expected zirconium distributions. Additionally, the computer calculations can be used to examine the predicted uranium and zirconium separations at times up to equilibrium to aetermine the predicted presence or absence of a maximum separation factor.

Figure 6.2 shows the results of calculations of the uranium distribution and the uraniumzirconium separation factor for conditions of one of several experimental runs. Whis particular calculation shows a flat maximum in the separation factor occurring where the uranium distribution is about $95 \%$ of its maximum value; however, the advantage over operating near equilibrium is not great. According to these calculations, at very short contact times the separation factor declines markedly. Also note the very small degree of transfer obtained with the present contactor. A new and, hopefully, more efficient contactor has been designed and constructed; this unit will be tested in a similar series of experiments.

The zirconium data from the contactor studies are given in Table 6.3. The reasons for the difference in zirconium distributions determined bv wet chemical methods and $x$-ray fluorescence are not known; the $x$-ray fluorescence data are thought to be more accurate due to the lesser 


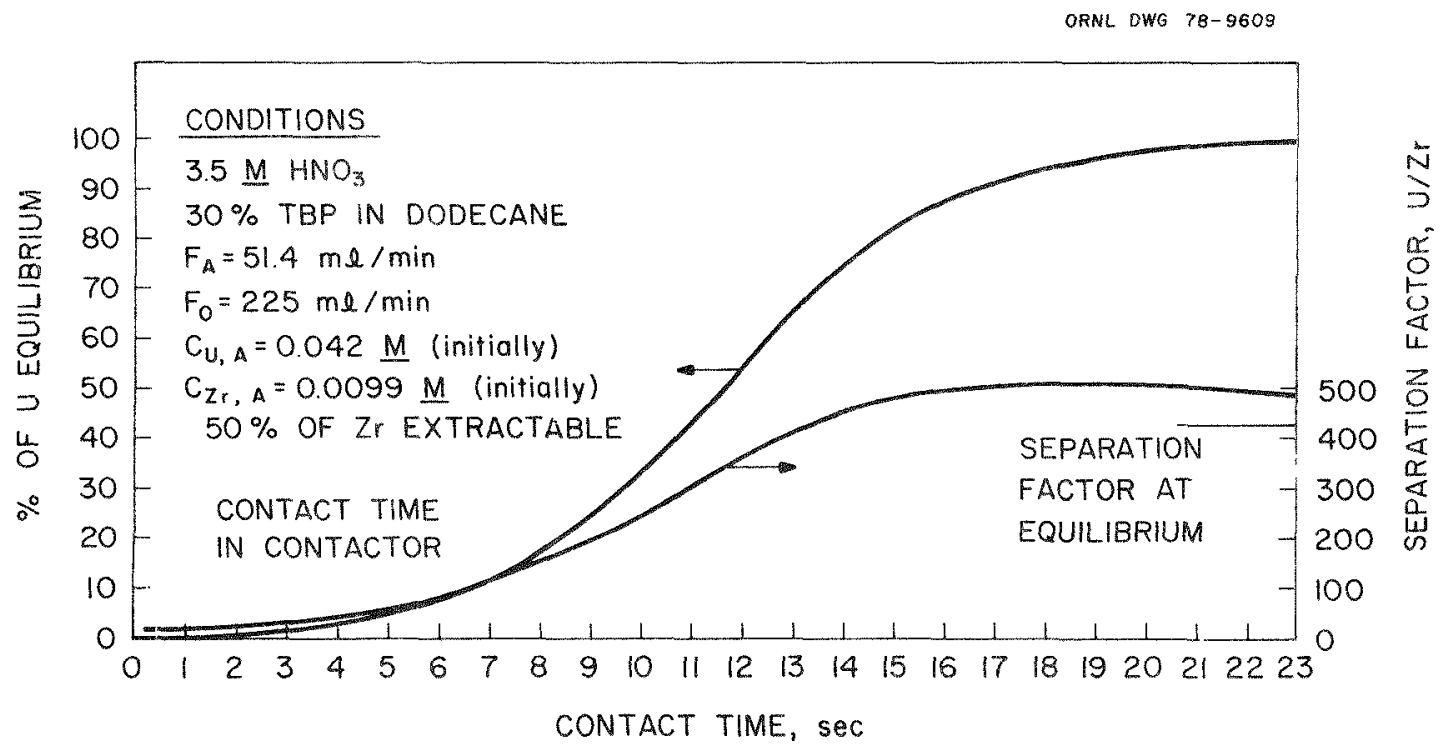

Fig. 6.2. Calculated uranium distribution and the uranium-zirconium separation for a Kenics mixer.

Table 6.3. Calculated vs experimental zirconium distributions $\left(\mathrm{D}_{\mathrm{Zr}}\right)$ from contactor tests

\begin{tabular}{cccccc}
\hline Run & $\begin{array}{c}\text { Total flow } \\
\text { rate } \\
\text { (ml/mm) }\end{array}$ & $\begin{array}{c}\text { Organic-to-aqueous } \\
\text { ratio }\end{array}$ & $\mathrm{D}_{\mathrm{Zr}}{ }^{a}$ & $\mathrm{D}_{\mathrm{Zt}}{ }^{b}$ & $\begin{array}{c}\text { Calculated } \\
\mathrm{D}_{\mathrm{Z}}\end{array}$ \\
\hline 1 & 267 & 4.4 & 0.016 & 0.025 & 0.021 \\
2 & 448 & 5.2 & 0.024 & 0.034 & 0.024 \\
3 & 629 & 5.1 & 0.034 & 0.042 & 0.029 \\
4 & 461 & 9.45 & 0.016 & & 0.013 \\
5 & 441 & 1.3 & 0.032 & 0.03 & 0.06 \\
\hline
\end{tabular}

${ }^{a}$ Experimental data, analysıs by wet chemistry.

${ }^{b}$ Experimental data, analysis by $\mathrm{x}$-ray fluorescence.

number of sample manipulations required. The calculated zirconium distributions for the first four runs are seen to be in reasonable agreement with expeximental data, but about 30\% low, which could be due to many possible sources of error, including both the uranium and zirconium kinetic constants and the fraction of extractable zirconium. The calculated and experimental values in the last run are grossly different. Obviously, much more effort is required before zirconium behavior can be adequately predicted.

one advantage of the Kenics mixer is that correlations exist which allow the calculation of approximate drop size and area per unit volume for specific flow conditions. 6 Figure 6.3 shows the recommended correlation for drop diameter vs weber number. The various quantities used in this plot are defined below.

Weber number: We $=\frac{D^{2} \rho}{\sigma_{s}}$,

where

$\rho=$ density of the continuous phase (in these tests this was the organic phase), $0.814 \mathrm{~g} / \mathrm{cm}^{3}$;

$\mathrm{V}=$ average axial velocity in the mixer;

$D=$ inside tube diameter, $0.0984 \mathrm{~cm}(0.25 \mathrm{in.})$; 
ORNL DWG $78-9611$

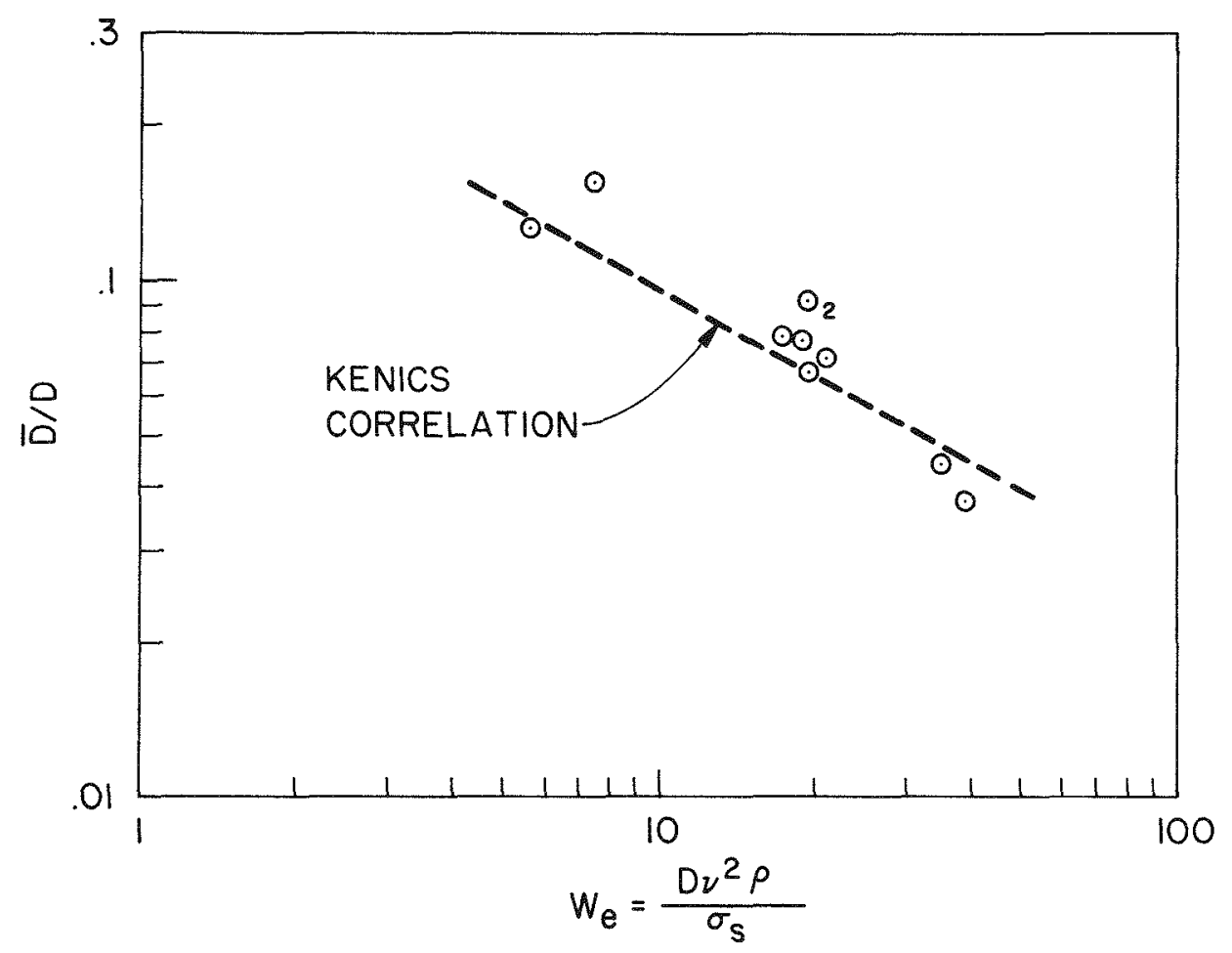

Fig. 6.3. Sauter mean drop size vi Weber number.

$\sigma_{\mathrm{S}}=$ interfacial tension, $14.5 \mathrm{dynes} / \mathrm{cm}$

Sauter mean drop diameter, $\bar{D}=\frac{6 \phi}{\sqrt{a_{V}}}$, where $\phi=$ volume fraction of dispersed phase and $a_{\mathrm{V}}=a_{\mathrm{i}}$ aa per unit volume.

The dashed line is the correlation given by Kenics Corporation. An alternative way to examine the data is shown in Fig. 6.4. Here, the area-to-volume ratio determined from the uranium transfer data is plotted vs the area-to-volume ratio given by the Kenics Corporation correlations. The agreement is seen to be good.

Several important conclusions can now be drawn:

1. The kinetic constants for uranium transfer determined in the drop tests can be used to calculate uranium transfer in a contactor of the Kenics type.

2. Since item $I$ is true, it is concluded that the mechanism for uranium transfer is such that transfer rates are not affected to any large extent by the additional mixing encountered in the Kenics mixer.

3. This conclusion (item 2) raises significant doubt about diffusion as the controlling mechanism in uranium transport; thus we believe that bulk-phase diffusion is not the controlling mechanism.

New mixer design. A new two-phase mixer has been designed for use in these studies which, it is hoped, will allow attainment of a large fraction of the equilibrium distributions. The mixer was designed with input from G. J. Bernstein of Argonne National Laboratory and W. F. Johnson and T. F. Sliski of ORNL. This mixer consists of a power-driven spindle which rotates, creating 


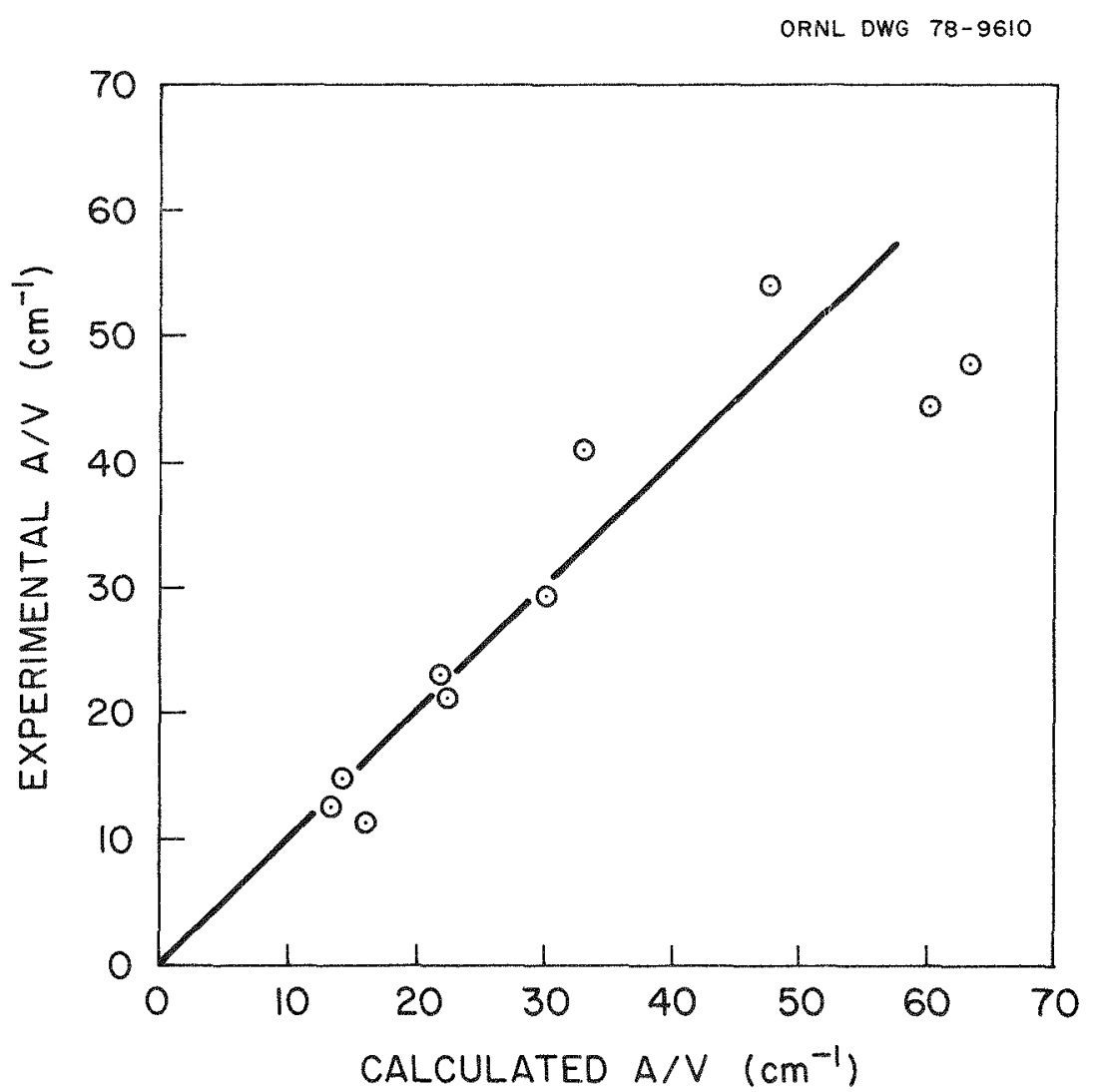

Fig. 6.4. Fxperimental area-to-volume ratio vs that calculated by the Kenics Corporation correlations.

shear between it and a stationary plate. The phases to be mixed flow to the center of the stationary plate, are mixed, and are collected at a ring at the edge of the mixing zone. If the mixer should be overloaded with solution, the excess overflows through another collecting ring at a higher level.

\subsubsection{Plutonium-uranium distribution coefficient studies}

J. H. Paehler, J. B. Knauer, and M. H. LIoyd (Chemical Technology Division, ORNI)

Experiments are being carried out to obtain plutonium and uranium distribution coefficients for the 30 vol \% MBP-normal dodecane (NDD) system as a function of the nitric acid and uranium concentrations at different plutonium concentrations: $2 \mathrm{~g} / \mathrm{litex}, 10 \mathrm{~g} / \mathrm{liter}$, and tracer level. The acid and uranium concentrations were varied from 0.1 to $4.5 \mathrm{M}$ and from 0 to $350 \mathrm{~g} / 1$ iter respectively.

The orgenic phase used in all experiments was 30 vol of TBP-NDD. Each aliquot of $30 \%$ TBP NDD was preequilibrated with an equal volume of the $\mathrm{HNO}_{3}$ concentration with which it was to be used. The aqueous feed solutions were prepared by combining the proper volumes of uranium, plutonium, and nitric acid stock solutions to obtain the desired concentrations, followed by dilution of $10 \mathrm{ml}$ with water. The plutonium stock solutions contained $8.4 \mathrm{mg} / \mathrm{ml}$ of plutonium; mass analysis showed these solutions to contain $98.5 \% 239 \mathrm{Pu}$ and to have a calculated specific activity of $7.28 \times 10^{7} \mathrm{cpm} / \mathrm{mg}$. The uranium stock solution contained $495 \mathrm{~g} /$ Iiter of ${ }^{238} \mathrm{U}$. Stock solutions of 8 and $10 \mathrm{MHrO}_{3}$ were also prepared and standardized.

The extraction technique consisted of batch contacting $5 \mathrm{ml}$ of each aqueous feed with an equal volume of the proper, preequilibrated organic phase. Phases were contacted at about 
$25^{\circ} \mathrm{C}$ for 5 min using a vortex mixer. Following the extractions and phase separation, both the organic and aqueous phases were sampled and then submitted to the analytical laboratory for gross alpha, Devies-Gray uranium, and acid analysis.

During this report period two series of experiments at 2 and $10 \mathrm{~g} / \mathrm{liter}$ of plutonium have been completed at the acid and uranium concentrations described. At $2 \mathrm{~g} /$ liter of plutonium, the distribution coefficients for plutonium increase regularly with increasing nitric acid from a value of 0.03 at $0.1 \mathrm{M} \mathrm{HNO}_{3}$ to a value of 30 at $4.5 \mathrm{MHNO}_{3}$, with no uranium present. As would be expected, increasing the uranium concentration depressed the Pu(IV) distribution coefficients significantly to a value of 0.5 at $4.5 \mathrm{MHNO}_{3}$, with $350 \mathrm{~g} /$ Iiter of uranium present in the aqueous feed solution.

Uranium distribution coefficients at $2 \mathrm{~g} /$ liter of plutonium over this acid concentration range also decrease with increasing uranium concentration. Distribution coefficient values for uranium increased regularly from 0.3 to 48 with increasing $n$ itric acid at $5 \mathrm{~g} / \mathrm{Iiter}$ of uranium. Increasing the uranium concentration in the aqueous feed solutions to $350 \mathrm{~g} /$ Iiter decreased the uranium distribution coefficient to a value of 0.55 , which remained constant over the entire acid range.

Very similar $\mathrm{Pu}(\mathrm{IV})$ distribution behavior was observed in the comparable series of experiments with $10 \mathrm{~g} /$ /iter of plutonium. Increasing the plutonium concentration, however, did. slightly depress the values of the Pu(IV) distribution coefficients obtained. For example, with no uranium present the plutonium distribution coefficients increased regularly with increasing nitric acid from 0.12 at $0.1 \mathrm{M} \mathrm{HNO}_{3}$ to 25 at $4.5 \mathrm{MHNO}_{3}$. A decrease in pIutonium distribution coefficients was again noted with increasing uranium concentrations. The uranium distribution coefficients remained virtually unchanged at the higher plutonium concentration.

In the next report period an additional series of experiments will be made over the same uranium and acid concentrations at tracer-level plutonium.

\subsection{Cold Process Development}

\subsubsection{Development of the mixer-settler system}

W. D. Bond, V. C. A. Vaughen, H. C. Savage, and F. A. Kappelmann (Chemical Technology Division, ORNL)

Two experimental solvent extraction runs, each using two I6-stage mixer-settlers, were made during this report period. In the first run, PS-2, the flowsheet was modified from previous runs ${ }^{7}$ by eliminating the scrub section in the $A$ bank and using al1. 16 stages for uranium extraction. The feed stream acidity was reduced to make the extraction less efficient, which should have produced more uniform uranium concentration profiles in all extraction and stxipping stages and also increased the uranium concentrations in the aqueous raffinate and organic waste streams so that those concentrations remained above the limits of analytical detection, $>1 \times 10^{-4} \mathrm{~g} / 1 \mathrm{iter}$. one should then be able to obtain many stages of extraction data to allow good comparison to be made between the experimental results (coneentrations of uranium and acid in all stages) and the SEPHIS predictions. The main flowsheet parameters are given in Table 6.4.

The uranium feed simulated a combined scrub and feed at low acidity (249 $\mathrm{g}$ of uranium per liter at $0.27 \mathrm{M} \mathrm{HNO}_{3}$ instead of the $300 \mathrm{~g} /$ liter at $2.50 \mathrm{M} \mathrm{HNO}_{3}$ used in previous runs). The feed stream flow rate was increased from 8.4 to $11.4 \mathrm{~cm}^{3} / \mathrm{min}$ to maintain the same aqueous-to-organic flow ratios used in previous runs. The scrub section was eliminated by ading the feed in stage 17 rather than in stage 25. This provided 16 extraction stages. The composition and flow rates of the other streams were the same as those in previous runs. 
Table 6.4. Feed stream flow rates and compositions during solvent extraction run PS-2 $2^{a}$

\begin{tabular}{llcr}
\hline Feed stream & Composition & $\begin{array}{c}\text { Flow rate } \\
\left(\mathrm{cm}^{3} / \mathrm{min}\right)\end{array}$ & Stage $^{b}$ \\
\hline Feed (AF) & $249 \mathrm{~g} \mathrm{U} /$ liter & 12.0 & 17 \\
Solvent (AX) & $30 \% \mathrm{TBP}_{\mathrm{NPH}}{ }^{c}$ & 29.4 & 32 \\
Strip (CX) & $0.10 \mathrm{MNO}_{3}$ & 33.6 & 1 \\
\hline
\end{tabular}

${ }^{a}$ Agitator speeds: $1100 \mathrm{rpm}$ with split-bladed agitators in the extraction bank; 1000 rpm with solid-bladed agitators in the strip bank.

${ }^{b}$ Strip bank: stages 1 to 16 ; extraction bank: stages 17 to 32 .

${ }^{c}$ Normal parafin hydrocarbon.

Run PS-2 was operated for $12 \mathrm{~h}$. For the first $1.5 \mathrm{~h}$, the feed stream (AF) contained only $0.27 \mathrm{M} \mathrm{HNO}_{3}$ (no uranium) to allow equilibration of the acid in the system. After $5.5 \mathrm{~h}$ operation with the uranium feed, the agitators and feed streams were stopped and samples were taken of the aqueous and organic phases in each of the 32 stages. The feed tanks were refilled. The run was restarted and continued for an aditional $5.0 \mathrm{~h}$ before it was terminated and a second set of samples was taken. Flowing stream samples of the uranium product, the aqueous raffinate, and the organic waste were taken at regular intervals (usually every 0.5 to $1 \mathrm{~h}$ ). All samples were analyzed for uranium and nitric acid. The results of this run and a comparison with SEPHIS predictions are given in sect. 6.2.2.

The second run, PS-3, was completed, but analytical results are incomplete. The purpose of run PS-3 was to duplicate the equipment and procedures to be used in the Solvent Fxtraction Test Facility (see Sect. 6.3). These included the use of solid-bladed agitators in both the extraction and strip banks, the use of recycled solvent, refilling the feed tanks during operam tion without shutdown, and control of the uranium feed stream ( $A F$ ) by controlling the feed tank pressure (instead of using an in-line control valve). The uranium product stream (CU) was continuously monitored with a Mettler flow-through density meter. Feed-stream flow rates and compositions were identical to those used in previous runs. ${ }^{8}$ Run PS-3 was operated for 14.5 h without incident except for a temporary decrease ( $15 \%)$ in the uranium feed-stream flow rate during the on-line refilling operation. The flow rate was restored without difficulty.

Flow control systems. The flow rates of all feed streams are controlled by diffexential pressure transmitters and recorder/controljers. In run PS-1, all the flow control systems were pneumatic. As previously reported., ${ }^{8}$ the flow control systems on the solvent (30\% TBP-NPH), $\operatorname{strip}\left(0.1 \mathrm{M} \mathrm{HNO}_{3}\right)$, and serub $\left(3.0 \mathrm{M} \mathrm{HNO}_{3}\right)$ streams performed well during the run, but there was poor control of the uranium feed stream $\left(300 \mathrm{~g}\right.$ of uranium per liter at $2.5 \mathrm{M} \mathrm{HNO}_{3}$ ) flow rate. An electronic differential pressure transmitter and controller (Foxboro) was installed in the uranium feed stream for $r$ un PS-2. An electronic-to-pneumatic converter (Ieeds and Northrup) was used to convert the electronic signal to pneumatic output for operation of the in-line control valve.

During run PS-2, the control of the flow rates for all input streams was excellent for the first $8.5 \mathrm{~h}$ of operation. At this time, a decrease in the feed stream flow rate (from about 12 to $11.4 \mathrm{~cm}^{3} / \mathrm{min}$ ) was observed for about $1 \mathrm{~h}$. An adjustment in the controller setting was required during the last $3.5 \mathrm{~h}$ of operation ( $1.5 \mathrm{~h}$ after recharging the feed tanks) to maintain the feed stream at the desired flow rate. During this latter period, flow rate deviations in the uranium feed stream up to a maximum of about $\pm 6 \%$ occurred. Flow rate deviations were less than $\pm 2 \%$ during the first $8.5 \mathrm{~h}$ of operation. The flow rates before and after the mid-run shutdown are summarized in Table 6.5 . 
Table 65 Summary of flow rates of the feed streams durmg solvent extraction run PS 2

\begin{tabular}{lccccc}
\hline \multirow{2}{*}{ Feed stream } & & \multicolumn{4}{c}{ Flow rate, liter/h } \\
\cline { 2 - 5 } & & Minimum & Maximum & Mean & Standard deviation \\
\hline \multirow{2}{*}{ Feed (AF) } & $a$ & 0692 & 0722 & 0707 & \pm 0008 \\
& $b$ & 0682 & 0759 & 0715 & +0020 \\
Solvent (AX) & $a$ & 173 & 181 & 177 & \pm 0023 \\
& $b$ & 175 & 185 & 180 & \pm 0036 \\
Strip (CX) & $a$ & 198 & 209 & 202 & \pm 0026 \\
& $b$ & 196 & 207 & 201 & \pm 0026 \\
\hline
\end{tabular}

${ }^{a}$ First 5.5 h of operation with uranium feed

${ }^{b}$ Last $5 \mathrm{~h}$ of operation after shutdown to refill feed tanks and sample all stages

The feed flow rate problem in run PS-2 is believed to have been caused by a malfunctioning pneumatic flow control valve. For run PS-3, the feed control system was revised to duplicate the system to be used in the SETF; in this system the flow control valve was replaced with a Lee Visco Jet (The Iee Company, Westbrook, Connecticut) orifice restrictor, and the flow rate was controlled by varying the feed tank pressure.

While flow control was generally very good during run PS-3, a flow rate decrease of about 15\% in the uranium feed stream occurred during the on-line feed tank refilling operation (after $8.0 \mathrm{~h}$ of operation). The solvent, scrub, and strip flow rates were not affected. Tentatively, it has been determined that the decrease in the feed stream flow rate was caused by improper settings in the electronic controller; therefore, there was an inadequate controller response to the momentary upset of the feed tank pressure during the refilining procedures. The system will undergo further testing in future runs.

\subsubsection{Application of the SEPHIS program to flowsheet evaluation}

V. C. A. Vaughen, A. D. Mitchell, and H. C. Savage (Chemical Technology Division, ORNI)

The SEPHIS computer model of the solvent extraction operations of the Purex process is designed to be used in flowsheet development and to predict the effects of variations in operating conditions. In developing the model, several approximations and assumptions which deal primaxily with the ideality of the fluid flow and mass transfer in the process were made to simplify the system. These approximations lead to dufferences between predicted and experimental results. It is important for the user of the program to understand where these differences will occur, and what conditions in the contractor or the program cause the differences. In comparison with recent experimental runs, several generalizations are made concerning the accuracy of the predictions made by the program. Recent changes which have been made in the SEPHIS program have improved both the transient and the steady-state predictions.

In experimental run PS-I, which was reported last quarter, 9 the transient response of the uranium and the nitric acid in the product stream was repeatediy sampled. The SEPHIS program was able to predict the time delays and the curve forms found in the experimental uranium response curve. 9 The predicted nitric acid response curve and the experimental data are shown in Fig. 6.5. The SEPHIS prediction follows the experimental data quite well up to the $5 \mathrm{~h}$ mark. Beyond that time, however, the experimental data show an abrupt but modest change that was not predicted. This difference could be due to an unmonitored upset caused by the contactor shutdown at $4 \mathrm{~h}$. The concentration of the product stream is highly dependent upon the relative flow rates; therefore, the accuracy of the transient curves is gratifying, particularly since the most closely monitored flow rate was measured only once an hour while others were measured less frequently. 


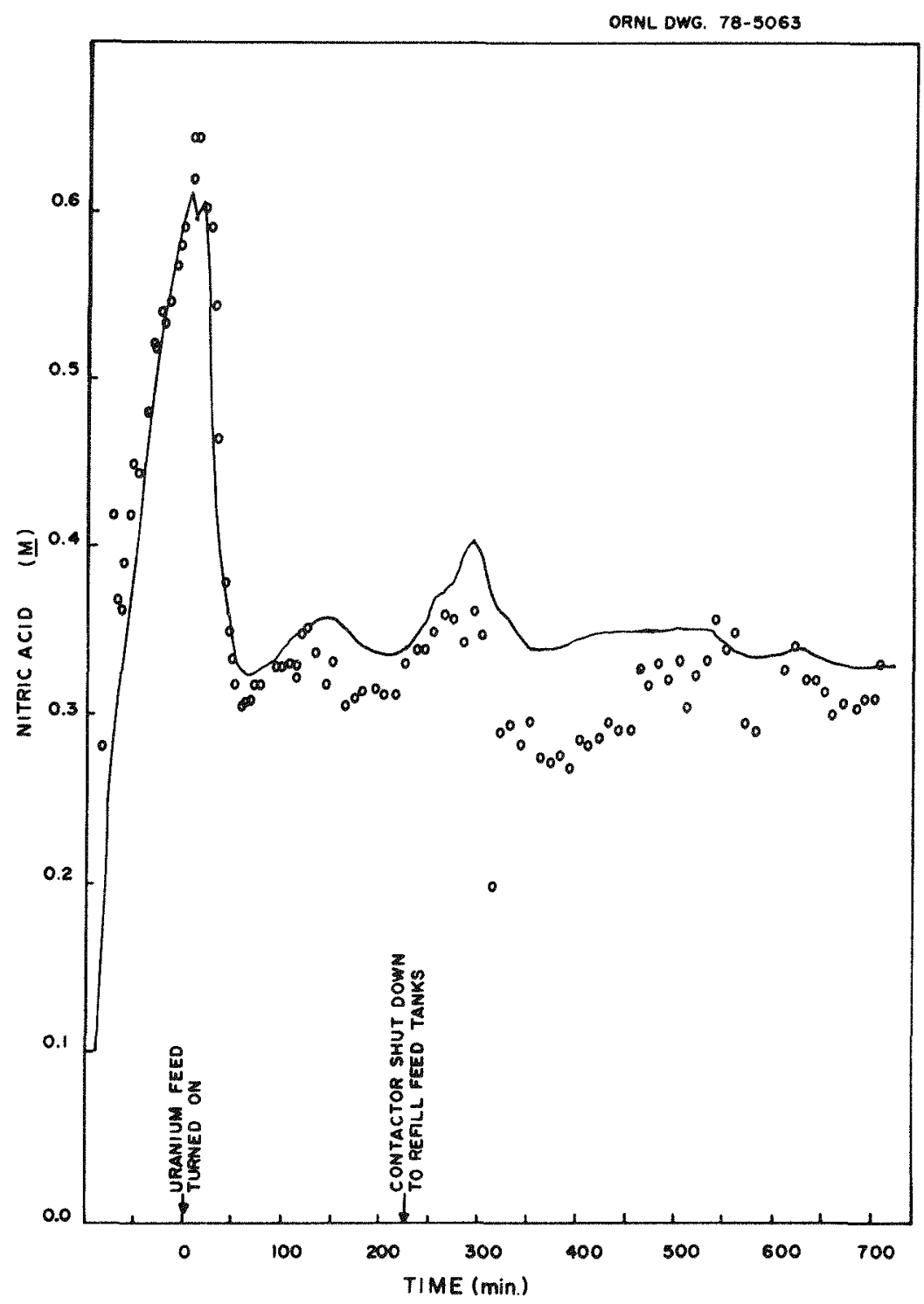

Fig. 6.5. Comparison of the product stream nitric acid concentration response data (run PS-1) with the SEPHIS prediction using the measured flow rates.

In run PS-1, sets of profile samples were taken at 10 and $12 \mathrm{~h}$ after the start of the uranium feed. Figure 6.6 shows the experimental and the calculated profile for the aqueous uranium after $10 \mathrm{~h}$. There is good agreement between the experimental and predicted values in the scrub section (stages 17 to 24 ) and in most of the strip section (stages 1 to 16). The feed stage (stage 25) has an experimental concentration much larger than the predicted value, which was probably due to incomplete mixing of the feed stream with the contents of the mixer. The extraction section (stages 25 to 32 ) was poorly predicted. Stages 25 to 27 follow the SEPHIS slope, but the final stages show no regular pattern. Figure 6.7 shows the experimental profile and the calculated profile for organic uranium after $10 \mathrm{~h}$. Again, there is good agreement in areas of high concentration; however, the agreement is poor at lower concentrations.

The next mixer-settler run (PS-2) was made to investigate the efficiencies of the mixers. Conditions were selected which gave relatively poor extraction so that the uranium concentration could be analytically detected in each of the sixteen extraction stages. Profile samples for run PS-2 were taken at 5.5 and $10.5 \mathrm{~h}$. Figures 6.8 and 6.9 show the aqueous and organic 


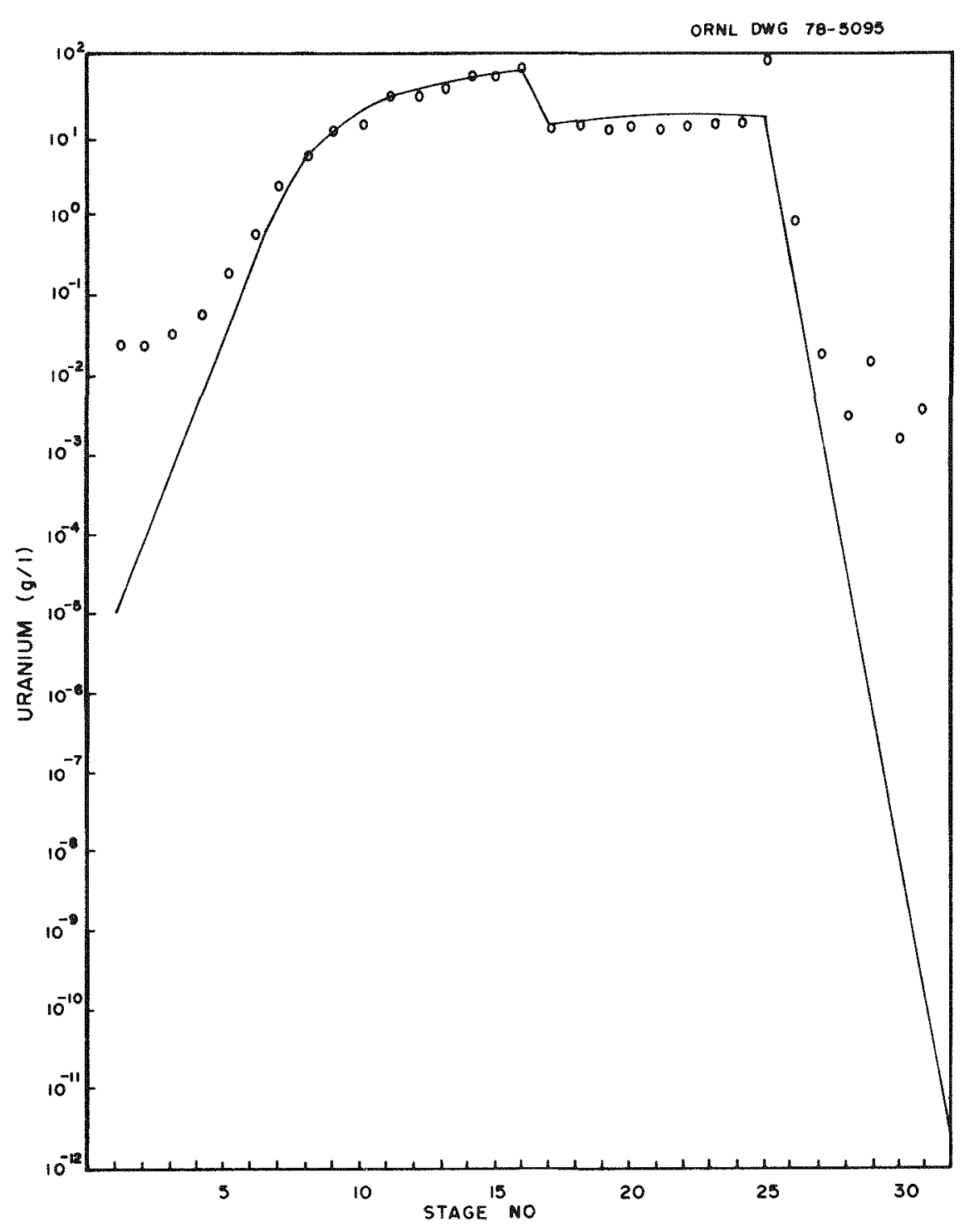

Fig. 6.6. Profile of the uranium in the aqueous phase at 10 h compared with modified SEPHIS prediction (PS-1).

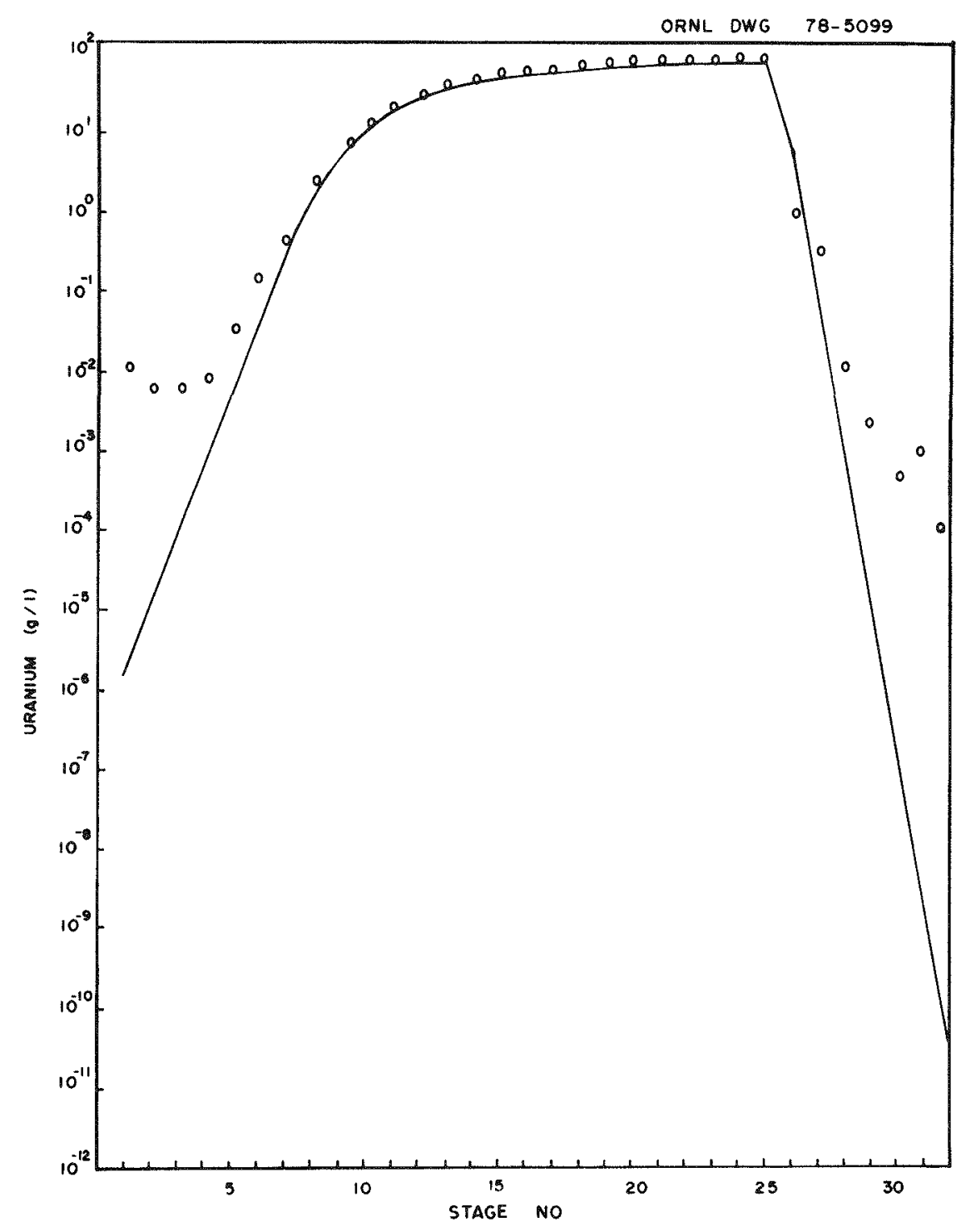

Fig. 6.7. Profile of the uranium in the organic phase at 10 h compared with modified SEPHIS prediction (PS-I). 

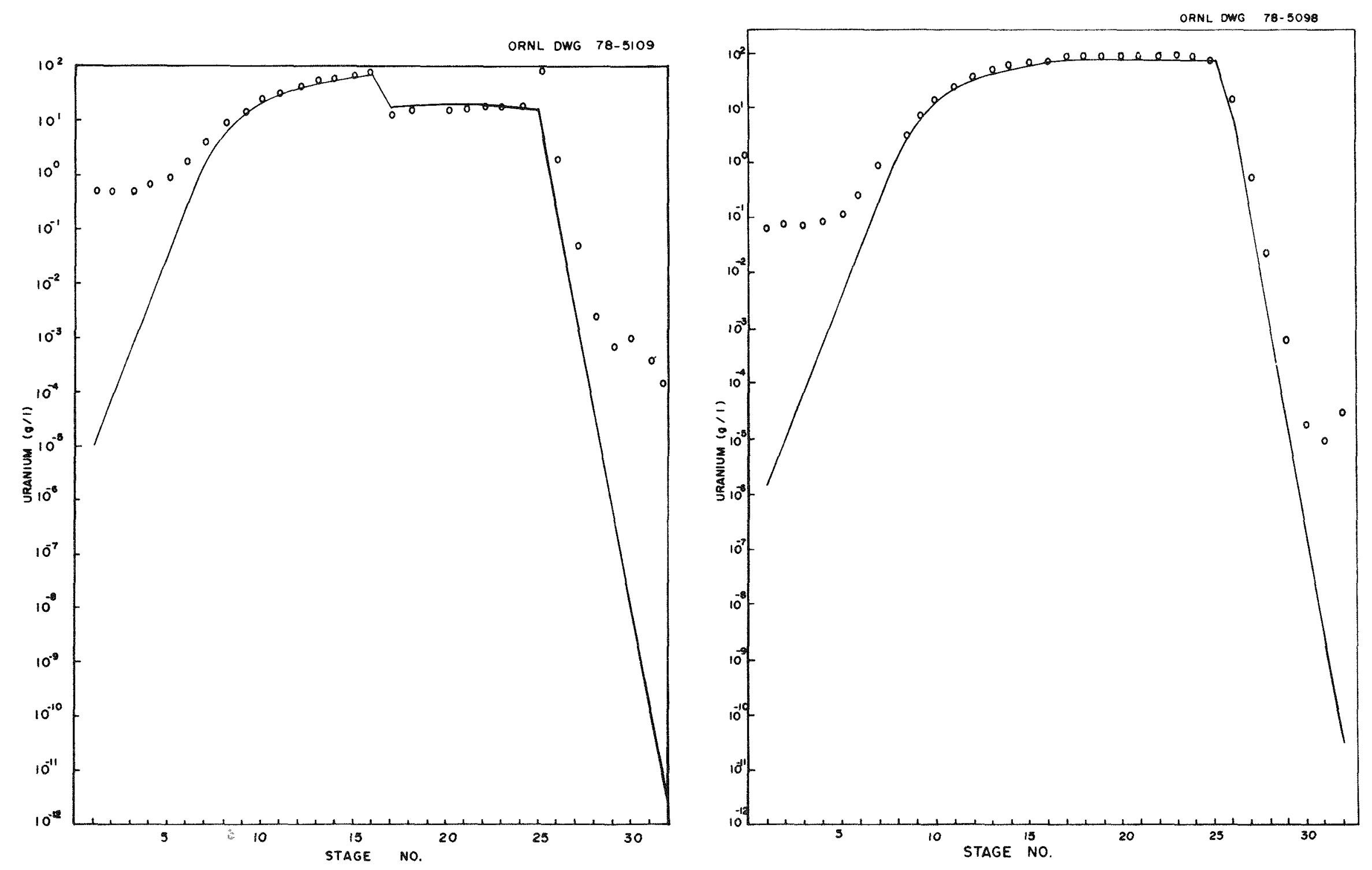

Fig. 6.8. Profile of uranium in the aqueous phase at $10.5 \mathrm{~h}$ (PS-2).

Fig. 6.9. Profile of uranium in the organic phase at $10.5 \mathrm{~h}$ (PS-2). 
uranium profiles after $10.5 \mathrm{~h}$ of uranium operation. Predictions with the present and modified SEPHIS programs are show - in this case, they differ considerably. This emphasizes the importance of the changes made in SEPHIS for the modified version. The experimental data points in the extraction section (stages 17 to 32) show the same type of straight line as seen in the predictions; however, the slope is quite different. The strip section (stages 1 to 16 ) was predicted fairly well in regions of high concentration.

It is important to determine what causes discrepancies between the experimental and SEPHIS calculated values. Sources of inconsistencies which have been identified in these tests include:

1. Stage efficiency - The SEPHIS program assumes I0o\% stage efficiency and thus cannot accommodate the lower efficiencies encountered in various types of contactors. In both runs, a significant amount of entrainment in both the organic and aqueous phases was observed in the contactors in the regions of low uranium concentration. Thus the substantial deviations between predicted and experimental values at low uranium concentrations resulted, at least in part, from the back-mixing (stage inefficiency) caused by entrainment.

2. Errors in chemical analysis of samples - In run PS-2, the analysis of feed stream acidity makes actual run conditions highly uncertain. The feed stream analysis showed $0.27 \mathrm{M}$ nitric acid, whereas the profile samples suggested that the feed contained only $0.21 M$ nitric acid. A SEPHIS prediction with the lower acidity would produce predictions much closer to the experimental results.

3. Uncertainty in the calculated distribution coefficients - The SEPHIS program usually predicts exceptionally low waste stream concentrations; however, the accuracy of the distribution coefficients calculated by SEPHIS for very low concentrations is not known. Such low concentrations result from a mathematical calculation to values nuch less than those used in the data base for SEPHIS.

4. Experimental upsets - Both transient and steady-state data indicate that the strip section was disturbed by the experimental procedure. These disturbances resulted in an increase in the uranium concentration in stages 1 to 5 by as much as a factor of 100 . Run PS-2 demonstrated that the stripping bank is very slow to recover from such disturbances. Any flow disturbance will distort the profile values, and sections with low flow rates, such as the stripping bank, will be particularly slow to return to steady-state conditions. Any one of these causes could produce the observed differences between the experimental and calculated concentrations for runs $P S-1$ and $P S-2$.

The SEPHIS program can be used to predict both transient and steady-state concentrations in solvent extraction contactors; however, due to both limitations in the mathematical model and events that occur in actual equipment, differences will always exist between the predicted and actual results. Experimental transient results have demonstrated the ability of the program to predict the timing of waves of solute passing through the contactor. Steady-state results have indicated which sections of the contactor were satisfactorily simulated by the program and showed regions wich were poorly predicted.

\subsection{Solvent Fxtraction Flowsheet Test Facility}

I. J. King and Staff of the Transuranium Processing Plant (Chemical Technology Division, ORNL)

The Solvent Extraction Test Facility (SETF) being designed and fabricated for installation in cell 5 of the Transuranium Processing Plant (TRU) will be used to evaluate and demonstrate solvent extraction flowsheets (e.g., Purex, coprocessing, spiked) and flowsheet improvements that are either developed in laboratory studies or jdentified as potential improvements. 


\section{3 .1 status}

About 100 of the estimated 150 drawings required for the SETF have been approved. The remaining drawings are undergoing final review.

The IRU equipment rack that was located in cubicle 5 has been moved to cubicle 4; all other TRU equipment that was in cubicle 5 has been moved. The cubicle has been decontaminated extensively to permit the removal of the shielding block so that service lines and penetrations in the top of the cubicle can be modified.

The oil-filled bulk shielding window was disassembled, internal surfaces were cleaned, and the window was refilled with fresh mineral oil and reinstalled. The jumper lines for interconnecting equipment in the cubicle have been fabricated and fitted on the mock-up jig.

About 90 TRU jumper lines were removed and discarded in the cell 5 tank pit. The Iine bundle connecting the cubicle and pit and one of the two existing tank-support bars in the pit were removed and discarded. One TRU tank each from pits 2 and 6 were interchanged with a tank in the cell 5 pit. New support bars were installed on the west side of pit 5; several of the tanks in the pit were fitted with tank support extensions, and the five tanks in pit 5 were positioned on the support bars. Two new service plugs were installed in the south well of the pit to provide additional service lines that will be required when the two additional tanks are installed. The two new tanks, which are annular for criticality-control purposes, have been fabricated and calibrated and are being stored at IRU awaiting installation. The two new line bundles that contain process lines for connecting the equipment in the cubicle to the tanks in the pit have been installed. All of the in-cell jumper lines that connect the tanks on the east side of the pit to the east-side line bundle, as well as the serviceentry plugs in the south wall of the pit, have been installed. All of the tank service lines (solution addition, instrumentation, and jaciet steam and water services) have been connected from the sources of service to the service-line entry plugs located in the south wall of the pit.

Nineteen new instrument transmitters have been installed on the transmitter rack located in the cold-solution makeup area. The TRU recorders, indicators, and controllers in the main control panel have been relocated to make room for SETH instrumentation. Three new sections of panel have been installed, several panel sections have been rebuilt, and installation of the SEMF instruments in the control panel is in progress. All of the bundles of pneumatic tubing and electrical wiring to the control panel, the transmitter rack, the makeup-area tank islands, the cubicle-service-entry plug, and the pit-service-entry plugs have been installed, and connections to individual instruments and junction boxes are being mede.

The glass-pipe cold-solution makeup tanks and feed burettes have been installed in the makeup-area tank $i s l a n d s$, and process and instrument connections are being installed. New piping and valve manifolds have been installed for the spargers and the jacket water services to the SETF pit tanks.

of the three racks of equipment that are to be installed in the cell 5 cubicle, the rack containing the ion exchange system and the samplers for the pit tanks has been fabricated, checked out at IRU, returned to the shop for modifications, and is now stored at TRU pending placement in the cubicle. The dissolver-feed adjustment rack is in the final stages of assembly in the fabrication shop. The mixer-settler rack frame has been fabricated, and the mixersettlers have been modified by the addition of sampler-access pots and radiation-monitor flow elements. A jig has been fabricated to ensure that the existing mixer-settlers and any replacements are interchangeable. Interconnecting piping is being installed on the rack. 
6.4 Analytical Chemistry Development

D. L. Manning (Analytical Chemistry Division, ORNI)

Using Dexil-300 as a stationary phase, a study was made on the gas chromatographic separation of several classes of high-boiling organophosphorus compounds of interest in nuclear fuel cycle technology. Dexil-300 (carborane-methyl silicone) can be used to $400+{ }^{\circ} \mathrm{C}$ and is reported to be the most thermally stable stationary phase ever developed for gas chromatography. $10-11$

A manuscript describing this work has been prepared and is being reviewed for publication as an ORIL/TM report. The abstract follows:

Several types of selected organophosphorus compounds of interest in nuclear fuel cycle technology were investigated by gas chromatography using Dexil-300 as a stationary phase and a hydrogen flame ionization detector. Dexil-300 is noted for its thermal stability at high temperatures and appears well-suited as a stationary phase for the separation of a wide variety of high-boiling organophosphorus compounds. The substances studied are representative of the trialkyl phosphate, the dialkylalkyl phosphonate, organophosphorus acid, and the trialkylphosphine oxide class of compounds.

\section{REFERENCES FOR SECTTON 6}

1. K. Joon et al., "Highly TBP Extractable Dimeric and TBP Compounds in the Nitrato and Nitro-series of Aqua-RuNO," KJeller report KR-143 (1971).

2. D. Scargill et 21., I. Inorg. Nucl. Chem. 27: 161 (1965).

3. G. Rudstam, Acta Chim. Scand. 13: 1481 (1959).

4. R. M. Wallace, J. Inorg. Nucl. Chem. 20: 283 (1961).

5. B. I. Vondra et al., IWR Fuel Reprocessing and Recycle Program Quarterly Report for Period Apri1 1 to June 30, 1977 (August 1977), p. 4-16.

6. S. J. Chen, Drop Formation of Low Viscosity Fluids in the Static Mixer Unit, KTEK-5, Kenics Corporation (JuIy 1972).

7. B. L. Vondra et al., Alternate Fuel Cycle Technologies/Thorium Fuel Cycle Technology Programs Quarterly Report for Period October 1 to December 31, 1977, ORNI/TM-6202 (February 1978), p. 6-8, Table 6.2.

8. B. I. Vondra et al., Alternate Fuel Cycle Technologies/Thorium Fuel Cycle Technology Programs Quarterly Report for Period January I to March 31, 1978, ORNL/TM-6307 (May 1978), p. $6-6$, Table 6.3 .

9. Ref. 8, pp. 6-4 to 6-13.

10. Altech Associates, Chromatogr. News, No. 31 (I978), p.6.

11. Joel A. Yancey, ed., Guide to Stationary Phases for Gas Chromatography, IIth ed., Analabs, Inc., North Haven, Conn. (1977), p. I33. 
7. URANIUM HEXAFLUORIDE CONVERSION

C. P. McGinnis (ORGDP)

The Engineering Department of DuPont has completed the preliminary design of the uranyl nitrate conversion plant, and an ORGDP review team has completed a study of the design drawings. A meeting was held at Savannah River Laboratory April 11 to review and discuss comments resulting from the study.

The fabrication of a system to conduct trapping studies on the removal of impurities from uranium hexafluoride is $80 \%$ complete. Shakedown work will be performed during the next quarter. Supports for the absorbent beds have been obtained for testing.

A flow factor analytical tool is being installed to determine the flow properties of solids. This data will be useful in designing mass flow hoppers for the conversion plant. Uranium trioxide, procured from the Paducah Gaseous Diffusion Plant, will be tested initially. 


\section{RADTOLOGICAL TECHNIQUES FOR ENVIRONMENTAI IMPACT}

ASSESSMENTS OF ALTERNATE FUEL CYCIE TECHNOLOGIES

D. C. Kocher (Health and Safety Research Division, ORNL)

\subsection{Building Shieläing Effects}

As discussed in a previous report, ${ }^{1}$ it is difficult to accurately calculate buildup factors for photon energies below $0.5 \mathrm{MeV}$ in materials such as wood and aluminum for which published. factors are not available. The building shielding effects computer code previously calculated buildup factors for energies below $0.5 \mathrm{MeV}$ in air, water, and aluminum, using the so-called linear form. It has been shown, however, that the linear form can overestimate buildup factors by as much as a factor of 5 when compared with published values and other more accurate analytical forms. ${ }^{2}$ For photons in air, published buildup factors in the energy range $15 \mathrm{keV}$ to $10 \mathrm{MeV}^{3,4}$ have now been incorporated into the code, so that uncertain extrapolation procedures are no longer required at low energies. For wood and aluminum, buildup factors below $0.5 \mathrm{MeV}$ are assumed to be the same as the values for water ${ }^{5}$ and concrete, ${ }^{6}$ respectively, because of the similarity in avexage atomic number and atomic weight between the corresponding pairs of materials. This approximation should provide more accurate buildup factors than the Iinear approximation.

Recommended values of internal and external dose reduction factors for a source term for a hypothetical fuel reprocessing plant, 7 which are applicable to population dose assessments for each of the four regional U.S. sites, were calculated and transmitted to Savannah River Laboratory. The recommended internal dose reduction factor for inhalation exposure to radionuclides occurring in particulate form is 0.7 . For ${ }^{3} \mathrm{H}$, ${ }^{14} \mathrm{C}$, and ${ }^{85} \mathrm{Kr}$, the recommended value is 1.0. As a result, no reduction exists in inhalation dose from residence inside buildings duxing a chronic release of these nuclides. 8 For external photon exposure, the recomended dose reduction factor is $0.6-0.9$, depending on the prevalent construction material for single-family dwellings in the particular region. The 0.6 value applies to regions such as the southwest where brick and stone construction predominates. The 0.9 value applies to regions such as the upper midwest where wood is used extensively. For the southeast, where both types of houses are found, an average of the two values is appropriate.

The recommended dose reduction factors for the regional assessments are probably conservative, that is, they underestimate the shielding effects of buildings on the population exposures. The reference structure for the calculation is a one-story single-family dwelling. Thus, we have ignored man's residence inside buildings that provide greater protection against radiation, such as schools and office buildings. Possible protection from the mutual shielding of buildings in urban environments has also been ignored.

A draft manuscript describing the building shielding effects models and the computer code used to perform the calculations is being prepared. 


\subsection{Resuspension}

Resuspension is the entrainment into the atmosphere of those radionuclides that were originally airborne but deposited on the ground surface. This process can be described by the resuspension factor $K$, defined as

$$
K=\frac{\text { resuspended air activity }\left(\mathrm{Ci} / \mathrm{m}^{3}\right)}{\text { deposited ground activity }\left(\mathrm{Ci} / \mathrm{m}^{2}\right)} \text {. }
$$

Thus $\mathrm{K}$ has units of $\mathrm{m}^{-1}$.

In radiological assessments during periods of chronic release of radionuclides to the atmosphere, it is usually assumed that resuspension makes a negligible contribution to the total air concentration. The validity of this assumption has been investigated for various models that have been proposed for the resuspension factor. Particular emphasis has been placed on potential resuspended air concentrations during the operating lifetime of a fuel reprocessing facility located at Savannah River Laboratory.

In this analysis, it is assumed that the chronic release results in a steady-state air concentration prior to deposition, given by $Q_{A}$ in $\mathrm{Ci} / \mathrm{m}^{3}$. The value of $Q_{A}$ is unimportant since the desired ratio of the resuspended air concentration to the air concentration from the release is independent of $Q_{A}$ and depends only on the assumed deposition velocity and resuspension factor.

The resuspension factor is often expressed as a time-dependent quantity, $\mathrm{K}(\mathrm{t})$, in order to account for the effects of downward migration of the deposited activity into the soil and other weathering effects. If at time $t_{I}$, a quantity of activity $Q_{S}\left(t_{I}\right)$ in curies per square meter is deposited on the ground, the resuspended air concentration, $R$, from the activity at some later time, $t_{2}$, is given by

$$
R\left(t_{2}\right)=Q_{S}\left(t_{1}\right) K\left(t_{2}-t_{1}\right) e^{-\lambda\left(t_{2}-t_{1}\right)}
$$

where $\lambda$ is the radioactive decay constant. Therefore, for a continuous release beginning at time 0 , the resuspended air concentration at time $t$ is given by

$$
R(t)=\int_{0}^{t} Q_{s}\left(t^{\prime}\right) K\left(t-t^{\prime}\right) e^{-\lambda\left(t-t^{\prime}\right)} d t^{\prime} \text {. }
$$

It is understood that time $t$ is within the operating lifetime of the facility. With our assumption of a steady-state air concentration prior to deposition, the deposited activity per unit of time is a constant given by

$$
Q_{S}\left(t^{\prime}\right)=Q_{S}=Q_{A} v_{d}
$$

where $v_{d}$ is the deposition velocity. Therefore, we obtain

$$
R(t)=a_{A} v_{\alpha} \int_{0}^{t} K\left(t-t^{\prime}\right) e^{-\lambda\left(t-t^{\prime}\right)} d t^{\prime} .
$$

The consequences of this result were investigated using different assumptions for the resuspension factor.

In the Reactor Safety study, 9 the resuspension factor is assumed to be

$$
\begin{aligned}
& K(t)=K_{0} e^{-\lambda t}+K_{e}, \\
& K_{0}=10^{-5} \mathrm{~m}^{-1}, K_{e}=10^{-9} \mathrm{~m}^{-1}, \lambda_{k}=0.677 \mathrm{year}^{-1}
\end{aligned}
$$


That is, the resuspension factor is assumed to be $10^{-5} \mathrm{~m}^{-1}$ immediately following deposition and to decay by a simple exponential to a value $10^{-9} \mathrm{~m}^{-1}$ after 17 years, after which time it remains constant. With this assumption for $K(t)$, it is easy to show that the resuspended air concentration is a monotonically increasing function of time and thus, has its maximum value at the time of facility shutdown. If it is assumed that the radioactive half-life is long compared with the lifetime of the facility, which tends to increase $R(t)$, we obtain

$$
R(t)=Q_{A} v_{d}\left[\frac{K_{0}}{\lambda_{k}}\left(I-e^{-\lambda_{K} t}\right)+K_{e} t\right] \text {. }
$$

Assuming a 40-year operating lifetime and a deposition velocity of $1 \mathrm{~cm} / \mathrm{s}$, the maximum resuspended air concentration becomes

$$
R(40 \text { years })=4.7 Q_{A} \text {. }
$$

Thus, in this model, after 40 years of continuous release and deposition, the resuspended aix concentration is larger than the steady-state air concentration itself. Another published parameterization of the resuspension factor ${ }^{10}$ is

$$
\begin{aligned}
& K(t)=K_{0} e^{-\lambda_{k} t^{1 / 2}}+K_{e}, \\
& K_{0}=10^{-4} \mathrm{~m}^{-1}, K_{3}=10^{-9} \mathrm{~m}^{-1}, \lambda_{k}=0.15 \mathrm{day}^{-1 / 2} .
\end{aligned}
$$

The substitution of $\mathrm{Eq} .(8.6)$ into $\mathrm{Eq} .(8.4)$ and the neglect of radioactive decay yields a maximum resuspended air concentration of

$$
R(40 \text { years })=7.7 \mathrm{Q}_{\mathrm{A}} \text {, }
$$

which is again much larger than $Q_{A}$ itself.

If we assume that the deposition velocity of $1 \mathrm{~cm} / \mathrm{s}$ is reasonable, then it is clear that the large values of resuspended air concentrations obtained from Eqs. (8.5) and. (8.6) result mainly from the assumed values of the initial resuspension factor $K_{0}$ and the time constant $\lambda_{k}$. The values used in the models are certainly open to question. The values of $K_{0}$ are based on measurements at the Nevada Test Site under desert conditions which are not encountered in other regions of the United States, particularly the southeast. The rate at which the resuspension factor decreases to its equilibrium value of $10^{-9} \mathrm{~m}^{-1}$ is also quite uncertain.

Bennett ${ }^{11}$ has suggested that measured air concentrations and surface deposits of plutonium fallout during periods of atmospheric weapons testing place an upper limit of $5 \times 10^{-6} \mathrm{~m}^{-1}$ on the initial resuspension factor, although, according to Bennett, "only a value several orders of magnitude less begins to look realistic." Since the fallout data were measured in New York State, it should be applicable to the southeast. Use of the value $\mathrm{K}_{0}=5 \times 10^{-6} \mathrm{~m}^{-1}$ in Eqs. (8.5) and $(8.6)$ gives $R(40$ years $)=2.4 Q_{A}$ and $R(40$ years $)=0.4 Q_{A}$ respectively. Thus, unless $K_{0}$ is less than the maximum value suggested by Bennett, resuspension may still be significant toward the end of the operating lifetime of the facility.

An alternative approach to resuspension ${ }^{11}$ is to define the resuspension factor as the ratio of resuspended air concentration to deposited activity in the surface soil region, which is taken to be the top I cm of soil. With this definition, the resuspension factor is constant with time, but the resuspended air concentration decreases with time as the deposited activity migrates below the top $1 \mathrm{~cm}$ of soil. The application of this idea to observed ${ }^{238_{U}}$ concentram tions in air and in the top $1 \mathrm{~cm}$ of soil suggests a resuspension factor of about $5 \times 10^{-9} \mathrm{~m}^{-1}$ 
(Ref. II), a value consistent with that obtained with the so-called mass-loading approach, assuming a mass loading of soil in the atmosphere of $100 \mathrm{\mu g} / \mathrm{m}^{3}$. Since some of the material in the atmosphere is of an industrial origin, it is likely that the value $5 \times 10^{-9} \mathrm{~m}^{-1}$ is too large.

Assuming the value $\mathrm{K}=5 \times 10^{-9} \mathrm{~m}^{-1}$ for the total activity deposited, and assuming that there is no migration below the soil surface layer, the maximum resuspended air concentration is

$$
R(40 \text { years })=Q_{A} v_{d} K t=0.063 Q_{A}
$$

Thus, the resuspended air concentration is never more than a few percent. Furthermore, if we allow downward migration from the top $1 \mathrm{~cm}$ of soil at a rate of $10 \%$ per year, a value typical of plutonium in soil, ${ }^{12}$ the resuspended air concentration becomes

$$
R(t)=Q_{A} v_{d} K \int_{0}^{t} e^{-0.1 t^{\prime}} d t^{\prime},
$$

from which we obtain

$$
R(40 \text { years })=0.015 Q_{A} \text {. }
$$

Thus, if Bennett's modeI for the resuspension factor is correct, the resuspended air concentram tion appears to be negligible during the operating lifetime of the facility.

One uncertainty about Bennett's analysis of resuspension is the possibility of resuspension factors considerably larger than $5 \times 10^{-9} \mathrm{~m}^{-1}$ for deposited activity retained on the surfaces of vegetation. Fortunately, however, the retention time for particulates deposited on vegetation is short, typically about $14 \mathrm{~d}_{0}{ }^{9}$ By assuming Bennett's maximum initial resuspension factor of $K_{0}=5 \times 10^{-6} \mathrm{~m}^{-1}$ and a decay half-life of $14 \mathrm{~d}$ in $\mathrm{Eq} .(8.5)$, one obtains a maximum resuspended air concentration of only about $10 \%$.

In conclusion, this analysis has shown that the application of time-dependent resuspension factor models with large initial values to the case of long-term continuous releases can result in resuspended air concentrations that axe much larger than the oxiginal aix concentration prior to deposition. There are experimental data to suggest that the calculated values of resuspended air concentrations are unreasonably large, but significant contributions cannot be ruled out. Negligible resuspended air concentrations are obtained by using a time-independent resuspension factor applied to the total amount of activity deposited. In order to resolve the discrepancies between the two types of models, careful measurements of initial resuspension factors and the time-dependence of the resuspended air concentration for different climate, ground vegetation, and soil conditions would seem desirable.

\subsection{Iong-Term Dose Commitments}

A process of potential importance for man's long-term exposure to long-Iived radionuclides deposited on the ground surface is the erosion of particulates from the soil into surface waters. This process would tend to decrease the amount of activity available for resuspension, external exposure, and ingestion of terrestrial foodstuffs. A literature review pertinent to the probability that deposited radionuclides will be transported into surface waters and oceans is in progress.

one very useful result has been obtained. A study ${ }^{13}$ has suggested that a global-scale relationship can be established between annual precipitation and sediment yield in rivers and 
reservoirs which accounts for the opposing influences of the amount of rainfall and vegetation cover. Such a relationship is of obvious importance for a regional study of radionuclide transport. For the southeast, the study suggests a sediment yield in rivers of about 100 tonnes $\mathrm{km}^{-2}$ year ${ }^{-1}$, which corresponds to $0.01 \mathrm{~g} \mathrm{~cm}^{-2} \mathrm{year}^{-1}$. Assuming an average soil density of $1.4 \mathrm{~g} / \mathrm{cm}^{3}$, the erosion rate is thus $7 \times 10^{-3} \mathrm{~cm} /$ year. If, for example, we assumed that deposited activity was unifomly spread throughout the root zone to a depth $20 \mathrm{~cm}$, the probability per year that activity would be removed from the root zone by erosion is thus about $4 \times 10^{-4}$. This number can then be interpreted as the time constant for the removal of activity from the root zone by erosion. REFEREINES FOR SECTION 8

1. B. I. Vondra et al., Alternate Fuel Cycle Technologies/Thorium Fuel Cycle Technology Programs Quarterly Report for Period January 1 to March 31, 1978, ORNI/TM-6307 (May 1978), p. 8-1.

2. D. K. Trubey, A Survey of Empirical Functions Used to Fit Gamma-Ray Buildup Factors, ORNL/RSIC-10 (February 1966).

3. A. B. Chilton, Engineering Compendium on Radiation Shielding, vol. 1, ed. by R. G. Jaeger, Springer-Verlag, New York (1968), p. 202.

4. F. H. Clark, "Gamma-Ray Buildup Factors for Sand, Air, and Wood (CelIulose)," Nucl. App1. 6: 588 (1969).

5. M. J. Berger, "Energy Deposition in Water by Photons from Point Isotropic Sources," I. INucI. Med., Supp1. No. 1, 15 (1968).

6. C. M. Eisenhauer and G. I. Simmons, "Point Isotropic Gamma-Ray Buildup Factors in Concrete," Nucl. Sci. Eng. 56: 263 (1975).

7. R. E. Cooper, Population Dose Estimates Resulting From Radioactive Materials Discharging from a Nuclear Reprocessing Facility, DPST-78-217 (January 1978).

8. B. L. Vondra et al., LWR Fuel Reprocessing and Recycle Program Quarterly Report for Period october I to December 31, 1976, ORNL/TM-5760 (February 1977).

9. Reactor Safety Study: An Assessment of Accident Risks in U.S. Commercial Nuclear Power Plants, Appendix VI. Calculation of Reactor Accident Consequences, WASH-I400 (October 1975 ).

10. I. R. Anspaugh, J. H. Shinn, R. I. Phelps, and N. C. Kennedy, "Resuspension and Redistribution of Plutonium in Soils, "Health Phys. 29: 571 (1975).

I1. B. G. Bennett, "Transuranic Element Pathways to Man," Transuranic Nuclides in the Environment, IAEA-SM-199/3 (1976), p. 367.

12. A. T. Jakubick, "Migration of Plutonium in Natural Soilds," Transuranic Nuclides in the Environment, IAEA-SM-199/3 (1976), p. 47.

13. W. B. Langbein and. S. A. Schum, "Yield of Sediment in Relation to Mean Annual Precipitation," Irans. Am. Geophys. Union 39: 1076 (1958). 


\section{ENVTRONMENTAL EFFECTS SUPPORT - STANDARD DATA INTERCHANGE FORMATS}

F. D. Hammerling (Computer Sciences Division, ORNL)

This project, which is concerned with planning, developing, and implementing software, is a joint effort shared by the Oak Ridge National Laboratory (ORNL), Battelle Northwest Laboratory (BNWL), Los Alamos Scientific Iaboratory (IASI), Lawrence Livermore Iaboratory (LII), and the Pacific Northwest Laboratory (PNL).

Although there have been labeling and compatibility problems with some systems, all sites have a fairly complete working version of levelmone software, Oak Ridge, cooroinator of the project, is developing the IBM PL/I version and BNI and. IASI are both developing the CDC version. However, to accommodate its system, the Lawrence Laboratory had to rewrite portions of the CDC version.

Pacific Northwest Laboratory has developed and distributed a level-one PDP-11 version of the software written in standard FORTRAN IV. However, since the PDP-II is a small computer, this software has some restrictions (e.g., logical record size). Documentation of this version is under way.

While the CDC sites are waiting on level-two implementation (which is to be supplied by BNL and IASL), funds are being spent to interface the level-one software to user data files that are to be exchanged. Several data exchanges using the different versions of software have been made this quarter. A meeting was held at BNI May 31-June 2, 1978, to discuss past problems with data exchanges as well as future plans for level-two implementations.

A PI/I implementation of the American National Standard Institute (ANSI) format-scanning algorithm and a FORTRAN implementation of the ANSI hiexarchy to Corresponding Binary Tree representation algorithms have been incorporated into the PI/I software to form the core of the leveltwo routines. The completed version of the PI/I level-one implementation and the final draft documentation have been distributed to all sites. The PL/I version has also been installed at the DOE headquarters.

Level-two calling sequences have been defined for both the CDC and IBM versions of the software, and development is under way. 
INTERNAL DISTRIBUTION

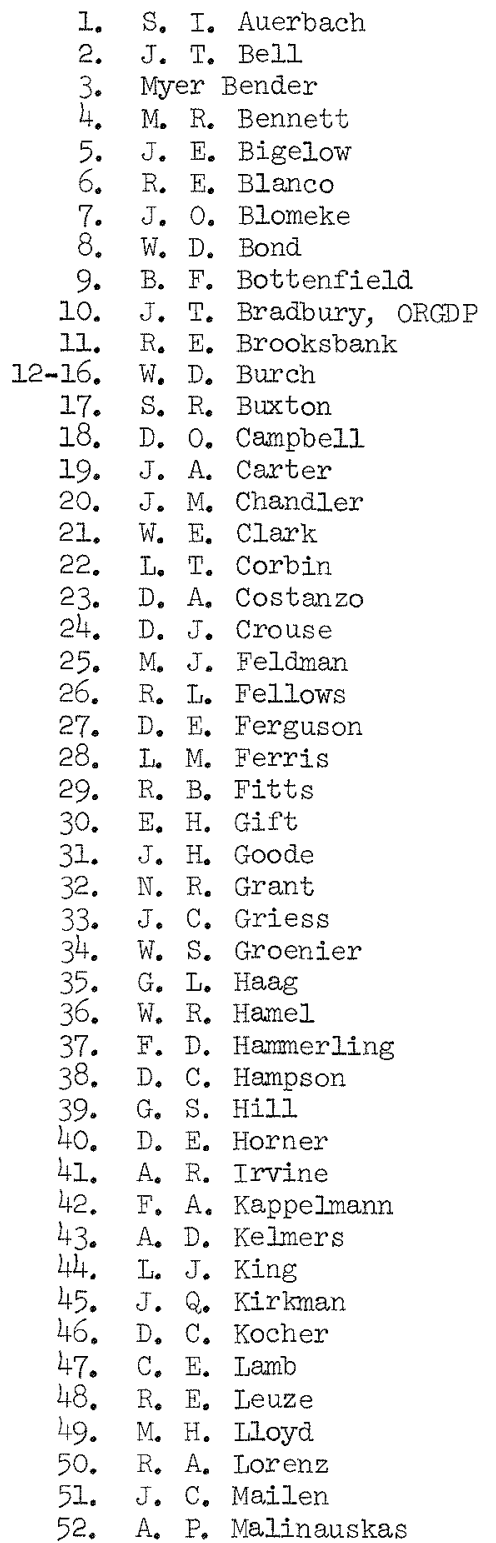

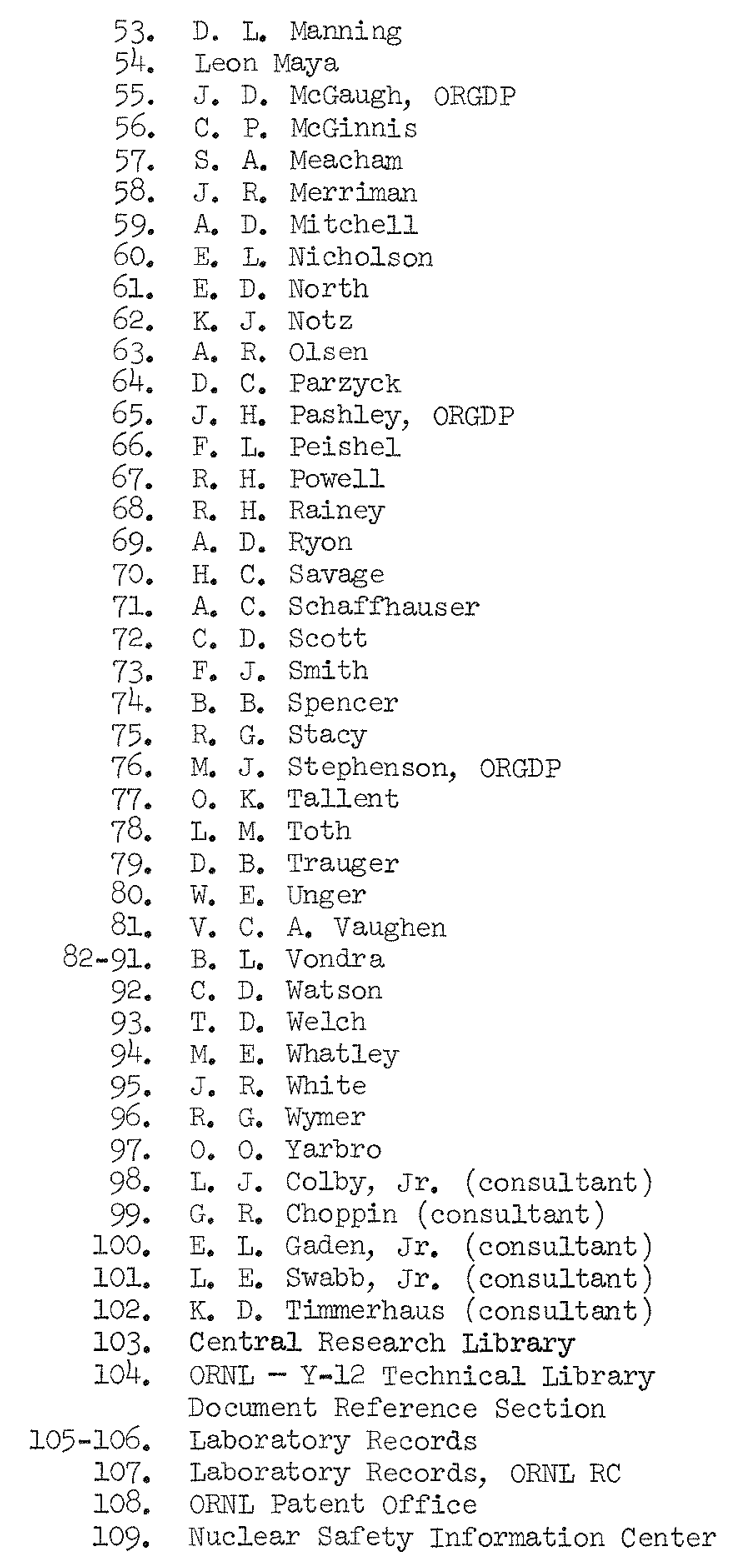


110-111. I. B. Hindman, Jr., Director, Fuel Cycle Project office, Department of Energy, Savannah River Operations office, P. O. Box A, Aiken, SC 29801

112-121. M. I. Hyder, Separations Chemistry \& Engineering Section, E. I. du Pont de Nemours \&. Company, Savannah River Laboratory, Aiken, SC 29801

122. S. W. O'Rear, TIS, Savannah River Laboratory, E. I. du Pont de Nemours \& Company, Aiken, SC 29801.

123-247. Technical Information Center, P. 0. Box 62, oak Ridge, TN 37830 (Distribution Category UC-83).

248. Director, Research and Technical Support Division, DOE-ORO

249. Director, Reactor Division, DOE-ORO 